Portland State University

PDXScholar

1981

\title{
Henna, Uses of it in the Middle East and North Africa
}

Diane M. Humphrey-Newell

Portland State University

Follow this and additional works at: https://pdxscholar.library.pdx.edu/open_access_etds

Part of the Social and Cultural Anthropology Commons Let us know how access to this document benefits you.

Recommended Citation

Humphrey-Newell, Diane M., "Henna, Uses of it in the Middle East and North Africa" (1981). Dissertations and Theses. Paper 3555.

https://doi.org/10.15760/etd.5450

This Thesis is brought to you for free and open access. It has been accepted for inclusion in Dissertations and Theses by an authorized administrator of PDXScholar. Please contact us if we can make this document more accessible: pdxscholar@pdx.edu. 
HENNA: USES OF IT IN THE MIDDLE EAST AND NORTH AFRICA

by

DIANE M. HUMPHREY -NEWELL

A thesis submitted in partial fulfillment of the requirements for the degree of

\author{
MASTER OF ARTS \\ in \\ ANTHROPOLOGY
}

Portland State University

(C) DIANE M. HUMPHREY-NEWELL 1981 
TO THE OFFICE OF GRADUATE STUDIES AND RESEARCH:

The menbers of the Committee approve the dissertation of Diane M. Humphrey-Newe11 presented 11 May 1981.

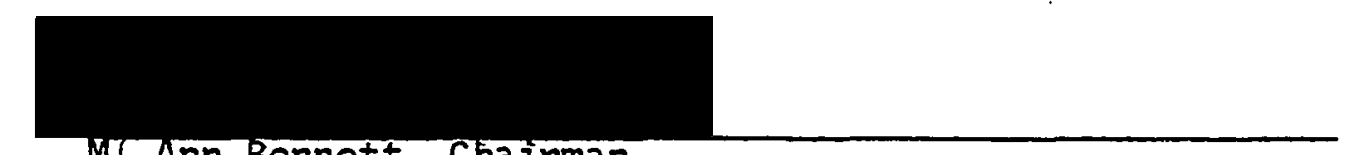

M! Ann Bennett, Chairman

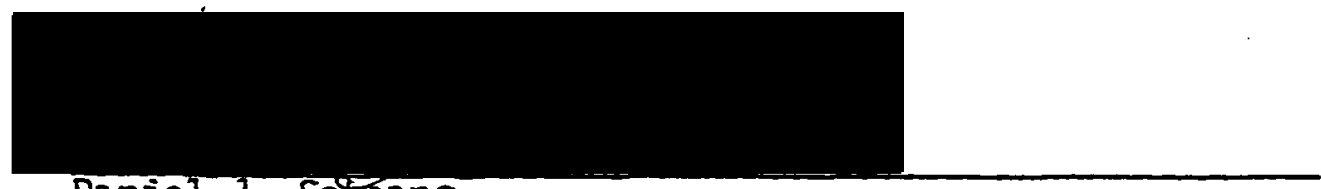

Daniel J. Scheans

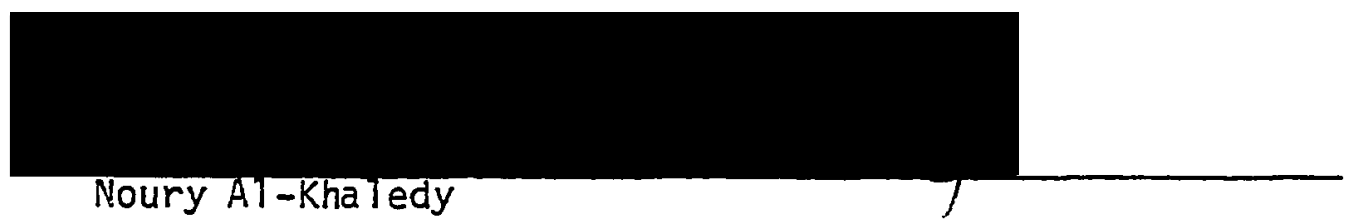

APPROVED:

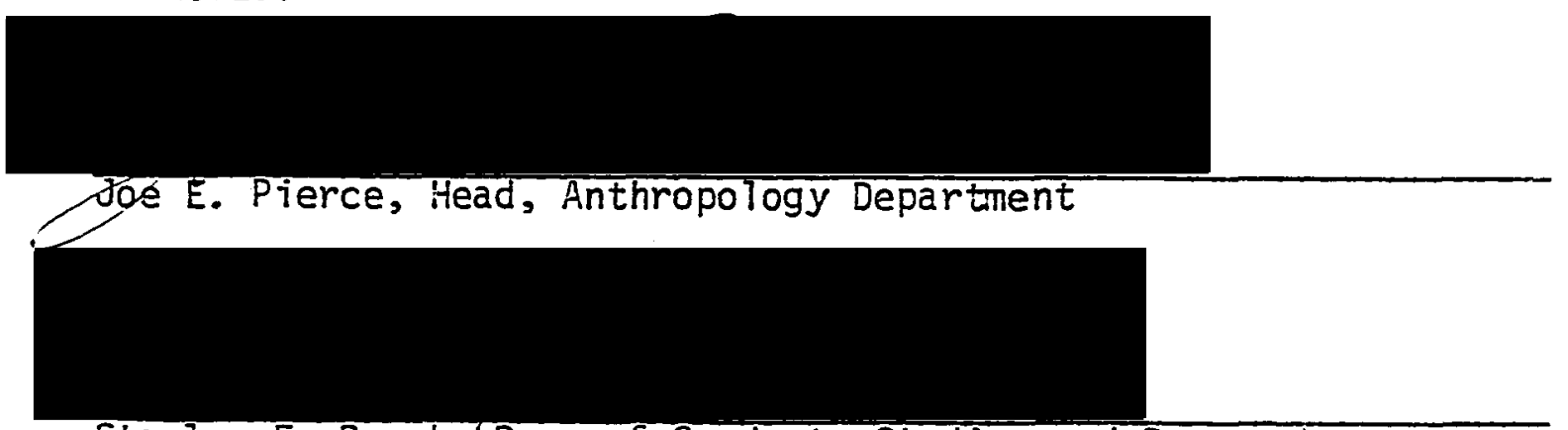

Stantey E. Rauch,(Dean of Graduate Studies and Research 
AN ABSTRACT OF THE THESIS OF Diane M. Humphrey-Newe! 1 for the Master of Arts in Anthropology presented 11 May 1981.

Title: Henna: Uses of it in the MiddTe East and North Africa APPROVED BY MEMBERS OF THE THESIS COMMITTEE:

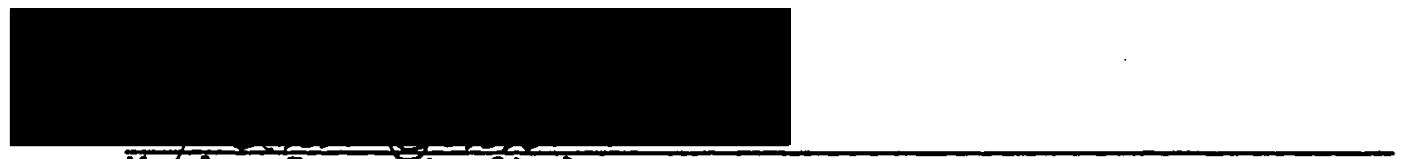

M. Ann Bennett, Cha irman

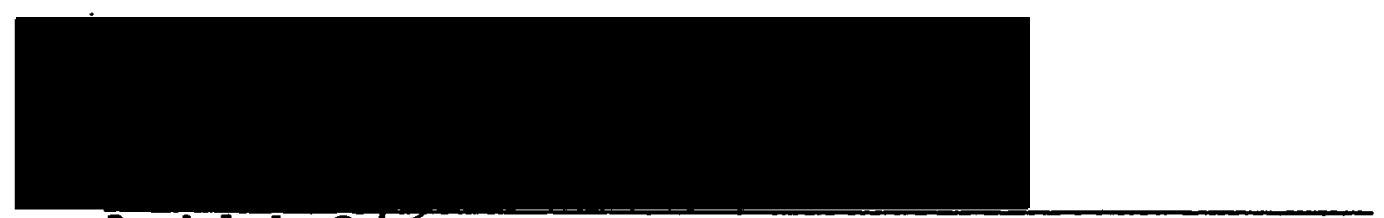

Daniel J. Scheans

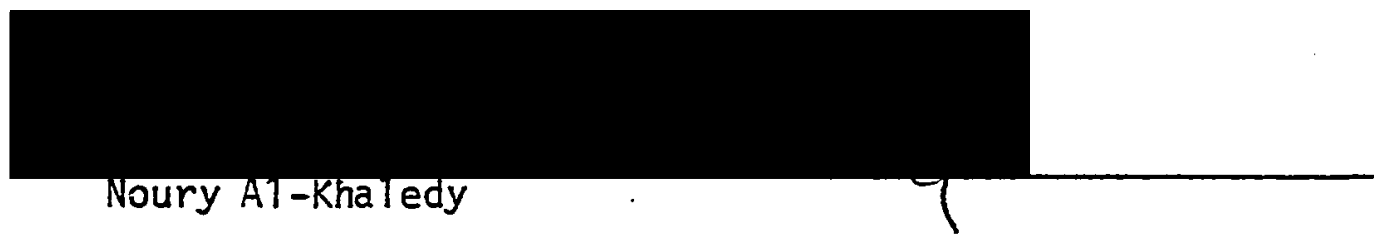

Since gradually replacing red ochre as a dye in ancient Egypt, henna has been cultivated throughout the Middle East and North Africa. Traditional uses dealing with body art and medicine were associated with traits commonly connected with the color red, the dichotomies of life and death, good and evil. Today, these traits have all but disappeared while henna's use as a cosmetic dye, an embellishment, has remained prevalent in some regions. There can be no doubt that many uses and symbolisms attached to uses have gone unrecorded, been forgotten, and are irretrievable. The purpose of this research was to preserve 
that knowledge which still exists concerning previous uses and current practices in the Middle East and North Africa.

Data gathered from publications indicates that the once traditionai belief that the ability to purify and protect from evil was emanate in henna was acknowl edged as recently as twenty years ago. Personal interviews conducted with fifty informants revealed that, with the exception of the Zar Cult in Egypt, present day users of henna make no association between henna and purification or protection from evil.

During the Middle Ages, henna was a common ingredient in medicines believed to be beneficial in the curing of various skin diseases and internal discomforts. Knowledge of medicinal uses today is confined to a few regions where external application is still practiced, but interna? use is rare.

Henna's association with the rites of passage and other occasions was once common. Staining the hands and feet of participants in ceremonies with henna was a tradition. Today the Night of Henna, a ritual dyeing of the bride-to-be's hands and feet, is the only widely recognized traditional use of henna.

Henna as a cosmetic dye for hair may be gaining in popularity in the Middle East and North Africa due to its use in modern products. Women in Morocco, Pakistan and the Arabian Peninsula continue to use henna as a cosmetic stain on feet, hands and nails. This continued use may be attributed to pride in tradition and modern methods of application. 


\section{ACKNOWLEDGEMENTS}

I am indebted to numerous persons who advised, assisted and offered their support to this research. I fee] a special thanks is due to the Director of the Middle East Studies Center at Portland State University and my advisor, $M$. Ann Bennett, who sparked my interest in this project and encouraged me during my graduate work at Portland State University. I also wish to thank Daniel Scheans and Noury Al-Khaledy for their assistance as committee members.

The assistance received from AT ice Rodgers, Carol Trotter, Suaad Al-Noman, Robin Church, Karen Nordgren, Mary Dozark, Hussein Ahmed Hussein Mohammed, Khatid AT-Ghefaili, and Aziz SuTtan is gratefulty acknowledged. For their special interest and continued enthusiasm I am indebted to the families of Suleiman AT-Ethimeen and SuTeiman ATSuleiman. A personal thanks is owed to the families of Saleh Batroukh and Elias Subeh of Bethlehem for their gracious hospitality.

To Haifa AT-Suleiman and Hannan AT-Ethimeen who will learn the traditional uses of henna from their mothers, I dedicate this work. 
TABLE OF CONTENTS

PAGE

ACKNOWLEDGEMENTS................................... ii

LIST OF FIGURES.................................... vi

CHAPTER

I INTRODUCTION................................ I

II BOTANICAL AND AGRICULTURAL ASPECTS................ 3

III EVIDENCE OF HENNA: PALEOLITHIC TO THE

RISE OF ISLAM............................. 7

IV THE MORE RECENT HISTORY OF HENNA $\ldots \ldots \ldots \ldots \ldots \ldots \ldots \ldots, 10$

$\checkmark$ RITES OF PASSAGE AND OTHER OCCASIONS.............. 15

Birth................................. 15

Circumcision............................ 17

Marriage................................ 19

Death.................................. 25

Other Occasions.......................... 26

Pilgrimage

Gifts and Guests

Cowardl iness

Revenge

Exorcism

After a Long Absence from a Friend

After Fasting

Swearing

Traveling

Lunar Calendar Events

Festival of the Kiswa

Birth of Mohammed 
CHAPTER

PAGE

Solar Calendar Events

Abstention

Animals Associated with Events

VI MEDICINAL USES OF HENNA.................... 30

VII $\quad$ COSMETIC USES............................ 37

VIII ATTITUDES EXHIBITED IN RESPONSE TO

ETHNOGRAPHIC INQUIRY........................ 39

IX CONCLUSION............................ 41

REFERENCES................................... 43

APPENDIX

A INTERVIEWS. ........................... 49

B METHODS OF APPLICATION ...................... 80

C FIGURES ............................. 87

D. LINGUISTIC DATA......................... 127 


\section{LIST OF FIGURES}

FIGURE

PAGE

I Henna (Lawsonia inermis I., or Lawsonia alba L.)......... 6

2 Woman from the United Arab Emirates straining

henna...................................... 83

3 Application of strained henna by using metal hairpin..... 83

4 Henna drying after pattern has been completed........... 84

5 i Henna moistened by water, sugar and lemon mixture........ 84

6 Scraping off henna with the aid of vegetable oit........ 85

7. 0 il coated palms after the removal of henna........... 85

8 Drawings by Pakistani male..................... 88

$9 \quad$ Drawing by Pakistani male....................... 89

10 Drawing by Pakistani male....................... 90

11 Drawing from notebook of Saudi Arabian female........... 91

12 Drawing from notebook of Saudi Arabian female........... 92

13 Drawing from notebook of Saudi Arabian female.......... 93

14 Drawing from notebook of Saudi Arabian female........... 94

15 Drawing from notebook of Saudi Arabian female.......... 95

16 Drawing from notebook of Saudi Arabian fema le.......... 96

17 Drawing from notebook of Saudi Arabian female.......... 97

18 Drawing from notebook of Saudi Arabian female.......... 98

19 Drawing from notebook of Saudi Arabian female.......... 99

20 Drawing from notebook of Saudi Arabian female.......... 100 
21 Drawing from notebook of Saudi Arabian female........... 101

22 Drawing from notebook of Saudi Arabian female.......... 102

23 Drawing from notebook of Saudi Arabian female........... 103

24 Drawing from notebook of Saudi Arabian female........... 104

25 Drawing from notebook of Saudi Arabian female.......... 105

26 Drawing from notebook of Saudi Arabian female.......... 106

27 Drawing from notebook of Saudi Arabian female.......... 107

28 Drawing from notebook of Saudi Arabian female.......... 108

29 Drawing from notebook of Saudi Arabian female........... 109

30 Drawing from notebook of Saudi Arabian female.......... 110

31 Drawing from notebook of Saudi Arabian female.......... 111

32 Drawing from notebook of Saudi Arabian female.......... 112

33 Drawing from notebook of Saudi Arabian female.......... 113

34 Drawing from notebook of Saudi Arabian female........... 114

35 Drawing from notebook of Saudi Arabian female.......... 115

36 Drawing from notebook of Saudi Arabian female.......... 116

37 Drawing from notebook of Saudi Arabian female.......... 117

38 Drawing from notebook of Saudi Arabian female.......... 118

39 Drawing from notebook of Saudi Arabian female......... 119

40 Drawing from notebook of Saudi Arabian female.......... 120

41 Drawing from notebook of Saudi Arabian female.......... 121

42 Drawing from notebook of Saudi Arabian female.......... 122

43 Wedding pattern drawn by Saudi Arabian female......... 123

44 Wedding pattern drawn by Saudi Arabian female.......... 124 
45 Bahr ini folk-dancer's foot.................... 125

46 Kuw iti foot pattern (Dickson 1949:159)............. 125

47 Packaging from Sudan.......................... 126

$48 \quad$ Packaging from Egypt........................ 126 


\section{CHAPTER I}

\section{INTRODUCTION}

An acceleration of the process of westernization within the Middle East and North Africa has brought to people from Morocco to Pakistan much of what western civitization has to offer. The benefits have, at times, been gained at the expense of tradition.

The custom of staining various parts of the body with henna and using henna powder for medicinal purposes may go back as far as ancient Mesopotamia. Travelers to the Middle East and North Africa, as little as fifty years ago, reported seeing men and women using henna to stain their hair, hands, feet and nails. Yet today the traditional staining done for various celebrations is being eschewed by the western-educated new generation. The medicinal uses are practiced by few.

Data for the present study were collected from three sources: published, personal interviews with informants and participant observations. Published sources included medical texts, travel journals, historic accounts, literary works, and ethnographies. The majority of informants were students from the Middle East or North Africa enrolled at Portland State University or Lewis and Clark College in Portland, Oregon. Family members of some of these students were also questioned. Other persons permanently residing in the United States, but originally from the Middle East, current residents of Bethlehem, West Bank, arid individuals familiar with the Middle East and North African cultures 
a1so served as informants. Observations occurred while attending a wedding in Bethiehem, at six weekly meetings attended by 18 to 26 Moslem women in Portland, during three applications of henna to my. hair and while having henna applied to my hands and feet.

Customs involving traditional body art and folk medicine are slowly being replaced by western cosmetics and pharmaceuticals. Both body art and folk medicine, whether or not it is comprehended by the individual, impart information concerning a culture's attitude toward the body. They are a means of strengthening relationships both between individuals and the individual's natural and supernatural worlds.

A task of anthropology is to endeavor to understand a culture. Cultures in North Africa and the Middle East have a traditional base which is disappearing. The purpose of this study is to salvage a portion of that base. 


\section{CHAPTER II}

\section{BOTANICAL AND AGRICULTURAL ASPECTS}

Henna is known to botanists as Lawsonia inermis of Linnaeus or Lawsonia alba of Lamerck; the mature form may be referred to as Lawsonia spinosa. Is is in the family of Eythrariceas. This shrub may reach tree-like proportions of nine to tweive feet in height.

There are four varieties of henna in the Middle East which are grown as an export. These henna plants vary slightly. The Egyptian henna, which is also found in Sudan, has medium-sized leaves and a greenish flower. Syrian henna has a white flower which is the least fragrant of the four. Henna of Baghdad has large dark green Teaves. The fourth variety has thorns, sma 11 leaves and the most fragrant flowers.

The most suitable soil for growing henna is a mixture of mud and sand that contains a minimum of alkali and salt. Henna can be grown in rotation with wheat or cotton. The herb lupine may be planted among the henna plants.

The Department of Agriculture of Egypt has published a pamphlet concerning the planting, harvesting, and marketing of henna (Al-Ra'uf 1960). Experiments with various soils, planting methods, watering schedules, and fertilizers are dealt with in this publication.

Planting can be done by seed; however, the most commonly employed method is the use of cuttings. While seeds may be stored two to five 
years before planting, cuttings may be planted immediately after stripping their leaves, or can be stored in moist hay for up to one week. Cuttings are made by trimming the shrub in the same place each year so that only the new growth is used. Each cutting is a maximum length of $20 \mathrm{~cm}$, and $1 / 2$ to $3 / 4 \mathrm{~cm}$ in diameter. A sickle is used to make the cutting and care is taken so that it is not cracked or peeled.

The soil best suited for the planting of cuttings is extremely muddy. Abd A7-Ra 'uf (1960) reported that specially trained children walked backwards in the fields, planting the cuttings 25 to $30 \mathrm{~cm}$ apart in rows. He also reported that the fields benefitted from the flooding of the Nile; the Aswan Dam has now put an end to these floods. Watering is done from March through Novemeber as needed, every six to ten days. No watering is done from December to March.

Maintenance of the plants includes hoeing, weeding, thinning, fertilizing and pruning which are done with a special blade that makes a shallow break in the ground. Weeding is done by hand; thinning is done in November and the plants which are removed are processed for use in basket weaving. Organic fertilizer is preferred but it is sometimes mixed with potassium sulfate. Pruning occurs at three times. The first is in early September and the trimmings are used for basket weaving or brooms. The second pruning is in late October; these trimmings serve as kindling. The third pruning occurs in March and involves the removal of growth which has occurred during the period when the plant has not been watered. It consists of spike-like growths which are rich in color for dyes. Flowers are collected during the early autumn mornings and are immediately processed to obtain their oil. Leaves are 
removed from all the trimmings and are processed for marketing.

Leaves and smal1 branches are prepared for marketing as henna powder. Bundles of the leaves and small branches are set out in the - sun for four to six days. They are rotated to prevent rotting or yellowing. The bundles are then taken apart and the material is beaten by workers with light sticks "curing in the heat from noon until sunset" (AT-Ra'uf 1960:13). Sifting is done frequently to remove that portion which is fine enough to be sent for grinding. Grinding may be done by oxen-turned grinding stones or by modern machinery.

There are three recognized classes of henna powder. The first is the purest and most expensive; the second, which has been affected by rain, is less red when dyeing and is less expensive. The third is roughly ground and is used as a filler for the first and second class (A1-Ra 'uf 1960:14-15).

Henna is of economic importance to various areas in the Middle East because it can be grown in soils that can no longer support wheat or cotton. Maintenance is not difficult. All parts of the shrub are useful and therefore profitable. The flower produces oil used in perfumes, the leaves and stems are ground to a powder used for dyeing, and the trimmings are used for weaving, as kindling, or for brooms. 


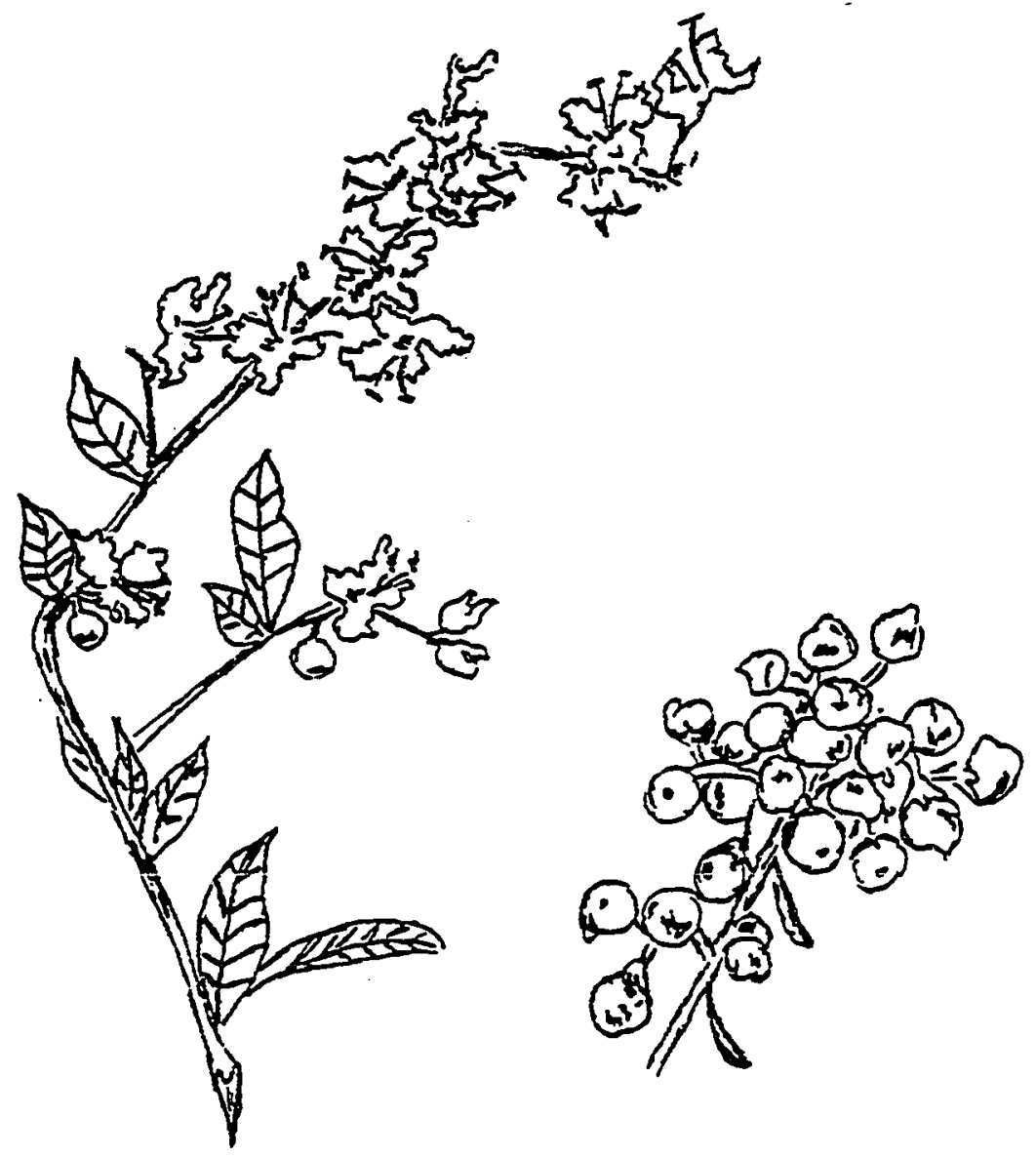

Figure 1. Henna (Lawsonia inermis L., or Lawsonia aLba L.). 


\section{EVIDENCE OF HENNA: PALEOLITHIC TO THE RISE OF ISLAM}

Evidence of the use of red mineral colorants, which will be referred to as ochre, in the Levantine and North Africa exists at sites dated to as early as the Paleolithic and Epipaleolithic. It has been argued that archeological evidence for other colorants could be less prevalent due to reasons such as different levels of biodegradability (Masset 1980:639). This should not detract from the fact that the red colorants have been found to have had a close relationship with mortuary rites since the Paleolithic. The fact that ochre was collected and prepared for use implies a social and cultural relationship.

While we have no way of knowing if the same peoples who sprinkled ochre on bodies in the graves, dyed bones, drew symbolic figures on cave walls and coated symbolic objects, had specific beliefs concerning the color red, recent tests involving color terms and symbolism have shown red is symbolic of the dichotomy of life and death. This reflects the fact that red is representative of blood. The importance of the color red was shown in the study by Berlin and Kay (1969) which concluded that cultures have a minimum of two color terms, black and white, and that if there is a third color term, it is almost always red. Whether or not the conclusion of these recent tests for color preference and symbolism can be applied to prehistoric populations is a subject of debate. 
There are eighteen Paleolithic sites and Epipaleolithic sites in the Levantine and North Africa which contain traces of ochre, six of these being burial-related. Cave sites in the coastal range of Palestine and some open sites in the Judean desert are referred to as the Kebaran Culture. These Epipaleolithic sites date from 18,000 B.C. to 9500 B.C. Human remains are rare at these sites and onty six conta in red ochre. Evidence of ochre-related burials has been found at the Natufian sites of Ain Mollaha, Yonim Cave and Nachal Oren (Wreschner 1980:631). The Zarzian Culture in the Zagros is contemporary with the Kebaran. A burial from Shanidar Cave contained a Tump of red ochre. Both red ochre and haematite were used for ornamental purposes (Mellaart 1975:72-73).

The Beldiki Culture of Anatolia was contemporary with the Natufian. Rock engravings credited to the Beldiki are painted red and black (Mellaart 1975:92).

Thirteen Neolithic sites in the Middle East have ochre finds and five of these are burial-related. Symbolic figurines (Eye Goddess, rain giver, pebble figurines from Byblos, Munhatta, and Sha'ar-ha Golon) were painted or coated with red ochre (Wreschner 1980:633).

The Tassili caves in the Sahara have yielded much information on the life of the peoples who have exploited the area since 8500 B.C. The over 10,000 paintings and engravings have been divided into five periods. The earliast period is represented by stick-like human figures which are painted with a violet ochre. The second period has been referred to as the "Round-headed" period due to the presence of painted figures with large round heads outlined in red. The middle period 
tinues the use of red to outl ine round-headed figures of yellow or green. Light and dark red paint was made from ochre. The fourth period is known for its large figures outlined in yellow and red but filled in with white. The final period was the most versatile. This period is called the Bovidian, and it is characterized by polychrome painting with red, brown or white outlines (Colombel 1975:69-75). Along with the social-cultural relationship created by the collection and processing of ochre, there may have also existed a magic-related aspect concerning ochres. This same magic-related aspect could have also applied to henna which changes from green to red. 


\section{CHAPTER IV \\ THE MORE RECENT HISTORY OF HENNA}

The western worid has been unaware of much of the literature of the Middle East and North Africa. The oral traditions of storytelling and poetry allowed portions of history and culture to survive centuries. Although there is much literature from the early Islamic period on, translations of Arabic and Farsi writings are relatively few.

Sadi, a Persian author who died in A.D. 1292, wrote stories and poetry concerned with human behavior. One of his poems begins, "Is that a full moon veiled, or does the houri have her hand in dye?" (Kritzeck 1964:249).

Scientific and medical information was continuously sought by the various Islamic empires. Translations from other languages to Arabic were numerous. Few of the Arabic medical texts were transiated into western languages. Levey (1966) and Levey and A1-Khaledy (1967) translated the medical formularies of AT-Kindi and AT-Samaraandi. These texts gave samples of the uses of henna in medicine during the Middle Ages.

The 1600 's brought travelers to the Middle East and North Africa from Europe. Journals of travels mention customs which were different from those of the Europeans. Among those cited in the Oxford English Dictionary (1933:223) are Leo's Africa (translated by J. Pory, 1600) which told of gold oil called Hena. Pilgrimage (Purchas 1613) 
cribed women "with a certaine colour in their hands called Hanna, which will staine." Travenier's Travels (translated by J. Phillips, 1684) mentions a water with dye that was used to make hands and fingernails red called Hina.

Browne's (1799) Travels in Africa, Egypt and Syria from the Year 1792 to 1798 is an account which includes plants of the region. He describes "El Henne" as a plant growing into use, but neglects to say what is the use. His descriptions of women, weddings, medicines and treatments of diseases do not mention henna.

Lane's (1871) An Account of the Manners and Customs of the Modern Egyptians covers the years he visited Egypt, 1825-28 and 1833-35. This two-volume work is frequently referred to by later Orientialists. He gives a description of henna paste and an illustration of nails, hands and feet stained. He comments on colors and which tints are "agreeable to our taste" (Lane 1871:49).

There are numerous travel journals from the 19th century on that describe uses of henna. While none appear to be as detailed as Lane, they do mention uses in occasional descriptions of clothing, personal ornaments or weddings.

Sir Richard F. Burton (1898) noted that any man returning from Al-Madinah to the women of his family would be poorly welcomed if he neglected to bring henna. In his translation of The Book of the 1000 Nights and a Night, henna as a stain for the body is mentioned several times.

Westermarck's (1914, 1926) publications concerning the peoples of Morocco are excellent ethnographies. His picturesque descriptions of 
customs and rituals are extremely detailed. Granquist's (1931, 1947) studies on birth, childhood and marriage in Palestine are also of excellent quality. They include basic ethnographic information and data such as songs associated with various ceremonies. Ethnographic studies of the Middle East and North Africa done during the past thirty years however, are generally lacking in description and analysis of the uses of henna. Its role in ritual and custom is often mentioned in a brief paragraph. This lack of information may be partially due to the fact that the customs involving henna were being practiced less, but the gradual decline that should be made obvious in literature is lacking, due to poor ethnographic records for the area.

The origin of the henna plant is believed to be in the region ranging from present day Iran to western India. Although no early records of its uses in this area are known, some stone pots have been fourd in Mesopotamia which contained henna (Singer 1954:246). It was introduced to the Levant and Egypt as a dye. There are three opinions as to how the plants spread in popularity.

An 11th Dynasty, 2133-1991 B.C., murmy was said to have had a red appearance which some credit to henna. This is not a widely-held opinion because such practice is not documented until the 18th Dynasty, 1567-1320 B.C.

The Hyksos, Asian, and possibly partly Semetic, infiltrators of Palestine and Egypt established rule in Lower Egypt between 1786-1567 B.C. It is believed that the Hyksos worshipped the henna shrub and used the dye in their religious practices. Their introduction of the plant to the Delta region is supported by finds from the beginning of 
the New Kingdom, 1567-1085 B.C. Mummies have been described as being bright red. Munmies from the 20th Dynasty, 1200-1085 B.C. through the 25th Dynasty, 751-668 B.C., have been found to have fingernails dyed with henna (Al-Ra'uf 1960:2-3). The wigs of several mumies were found to have been dyed with henna (Corson 1965:25).

The third opinion may be supported by the grave goods from the 20th Dynasty. Samples of henna plants were found in graves. These samples are in the Museum of Agriculture in Egypt. Henna powder was spread under dead bodies in the grave during this period. There are records of an expedition of naturalists sent to Asia by Ramses I at the beginning of the 19th Dynasty, 1320 B.C. This expedition returned with many specimens of plants. Upon their return, they are said to have planted a henna shrub in the garden of the Temple of Amun at Karnak (A1-Ra'uf 1960:3).

The god Osiris has been linked with the henna plant which is said to shade his grave (AT-Ra'uf 1960:3). Osiris is a god of earth and vegetation. His rebirth was symbolic of the seasonal flooding by the Nile and subsequent growth of vegetation.

Ancient Egyptians are believed to have used henna for a cosmetic dye to hands, feet, nails and hair. The henna flower's oil may have been used as a base for perfume. The Assyrians are known to have dyed their hair and beards (Corson 1965:27). Cleopatra (30 B.C.) is said to have used henna to dye her hair (Winter 1974:119).

In Historia NaturaZis the Roman naturalist, Pliny the Elder, mentions henna. Dioscorides, in his De Materia Medica, praises the henna from Judea (Singer 1954:246). The Talmua gives medical informa- 
tion concerning henna (Encylopedia Judaic 1971). The Holy Bible states, "..my beloved is to me a cluster of henna blossoms in the vineyards of Enge'di"' (Solomon 1:14).'

The seventh century brought Islam out of the Arabian Peninsula and began the spread throughout the Middle East. Muhammed, the Prophet, is said to have considered henna his favorite flower and is believed to have used henna to dye his beard (Winter 1974:119). The Prophet is credited with having said that henna is "...the chief of the sweetscented flowers of this world and of the next" (Lane 1971:165). In several regions of the Middle East, henna is referred to as the "light of the Prophet" (Westermarck 1914:113). Among the Prophet's advice to the Muslims was to "bind henna" and he is believed to have said that one dirham spent on henna was "...greater than that of a thousand spent for charity" (Donaldson 1938:188).

${ }^{3}$ It should be noted that while the Revised Standard Version of the Bible states "...cluster of henna blossoms" the King James Version uses "..cluster of camphire." 


\section{CHAPTER V}

\section{RITES OF PASSAGE AND OTHER OCCASIONS}

Rites of passage consist of religious or magical acts which have been established by tradition. They are believed to purify, strengthen and protect from evil. The ceremonies are associated with fundamental events: birth, circumcision, marriage and death.

\section{Birth}

At the beginning of this century, Moroccan women were known to have painted with henna the hands and feet of an expectant mother just prior to her giving birth. In addition, her lips were colored with walnut root and her eyes were out 7 ined with antimony. This appearance was that of a bride and prepared her for Paradise should she have died in childbirth (Westermarck 1926:383). This procedure was repeated for seven days in some regions of Morocco, to ensure a boy infant would like his future wife (Westermarck 1926:396). The birth of a child was greeted with songs and dance. Two songs mention henna. The first occurs in the villages where the birth took place, the second welcomed the announcement's arrival at a different location.

1. It is our duty, it is our duty,

To sing and dance is our duty

At the coming of (name of mother) a duty

Out friend, she filled our hands, a duty

She colored our hands with henna.

2. When the letter arrives with the news

I will color it with henna!

I will walk unto her mother and color her with henna, 
Give to the messenger his tools and knives!

(Westermarck 1926:86).

After birth, henna was placed on various parts of the infant's body. This practice varied by village and tribe. Medicinal reasons for the application of henna on the newborn are discussed in the following chapter. Protection from evil and acquisition of strength appear to be motives for the application of henna to the navel and head. In some regions, a mixture of henna and oil was rubbed on a three-day-old infant to strengthen his skin (Westermarck 1926:383).

The navel-string was disposed of in various ways. It was either thrown in a river or buried. If buried under a tent pole, it was placed in the hola with seven grains of barley, rock salt and henna. If buried at a saint's shrine, it was coated with ashes and henna and a silk thread was tied around it before placing it in a hole (Westermarck 1926:372-373).

The Ait Yusi of Morocco painted the new mother's hands and feet with henna on the third day after delivery. Seven dots of henna were then placed on a white cloth which was wrapped around her head. After four months, the cloth was removed and the mother tied it above the knee on the right foreleg of a camel. This procedure was to give her child strength (Westermarck 1926:384).

During the nineteenth century, women and young girls in Egypt visited the new mother and infant on the seventh day after birth. They would hold candles which were stuck in lumps of henna while the mother scattered salt and fennel seeds on the floor in order to protect the child from evil (Lane 1871:243). 
The seventh day of life was considered important in Morocco during the first half of this century. That was the day the child received its name. The mother's hands and feet were hennaed prior to the ceremony; then women and small boys would visit and give small gifts of money and henna. The boys would then hold candles while the midwife held a bowl of henna, water and a boiled egg above the child. In addition to having its navel and head covered with henna, the infant was often painted on its hands, feet, neck, armpits and legs. These applications of henna and ceremonies were to protect the infant from $j$ inns and the evil eye (Westermarck 1926:389).

During the 1960's Nubian women in Egypt, in an effort to please the Nile's spirits, placed henna on their hands and feet before giving birth. This cutoms was especially important if it was to be her first child (Kennedy 1977:35). Women today in Upper Egypt, and some of those from Upper Egypt who have moved to Lower Egypt, will henna their hands and feet upon giving birth or if a member of their family gives birth. In Libya, some women will henna their hands and feet immediately after giving birth, while others will wait one week. In Oman, a new mother will henna her hands and feet only if she gives birth to a girl. No explanation other than tradition was offered by informants from Egypt, Libya and Oman. Informants from other regions were unaware of henna being used in association with birth.

\section{Circumcision}

There appear to be few observations recorded of henna's being used in the Middle East in association with circumcision. However, it was and is commoniy used throughout North Africa as a part of the rite. 
Its purpose during this rite was both medicinal and to keep evil away from the child.

A male child in Palestine during the 1930's and 1940's was circumcised at any time between the ages of eight months to five years. For one week the women of the village were given henna and it was freely applied to hands and feet. While the application of henna was not mandatory, only those women with hennaed hands and feet were allowed to sing at the ceremony (Granquist 1947:184).

In Egypt of the 1920's, two days prior to the circumcision, the hands and feet of the boy were hennaed at sunset. Afterwards the circumcision would was washed and henna paste was applied daily until it healed (Blackman 1968:87). During the 1960's, the Nubian community in Upper Egypt would place a dish of henna in front of the mother and a bowl of water in front of the boy. The mother would mix the two into a paste and apply it to the boy's forehead. The father would press a gold coin into the paste and then it would be washed off. An excision ceremony was also required for girls. On the eve of the ceremony, the child would have her hands and feet hennaed. The wound was washed with raw egg and henna (Kennedy 1977:37).

Sudanese boys have henna applied to their hands and feet during the afternoon after circumcision. This is usualiy done by an older women, preferably the grandmother or an aunt. Women and children sing and friends give gifts of money during the hennaing (Barclay 1832:247).

Customs concerning circumicision varied slightly throughout Morocco during the early part of this century. The hands and feet of the boy were hennaed either on the night before or immediately after the 
mony. The henna was painted on by the mother or the barber who performed the circumcision. The wound was dressed with henna and oil or butter. The Berber women applied henna to their hands and feet if a relative was being circumcised (Westermarck 1926:427). Informants told of henna still being used in association with circumcision during the later 1960's. The evening before the ceremony, the child would have it applied to his hands ard feet. The women would apply a pattern which was solid coloring from the tip of finger to the second joint, and pattern the palm with dots and wavy lines to the wrist.

Informants from Libya stated that boys are circumcised in age groups. They all have their hands and feet hennaed overnight for the ceremony. An informant observed circumcisions in Egypt and stated that boys age five and six have, hennaed hands and feet for the ceremony.

Marriage

Brides and grooms were considered to be vuinerabie to the same evils as the newborn infant or boy undergoing circumcision. One protection from these evils was obtained by the hennaing. Besides being a guard against evil and magic, henna helped to purify the bride and groom.

The aspects of protection and purification are not known by the majority of brides who are hennaed today.

In a lmost every country in North Africa and the Middle East, there is a feast day prior to the marriage that is specifically for the purpose of ritually dyeing the bride's hands and feet, and is referred to as the Night of Henna. A paraliel ceremony probably once occurred for 
the grocm, but the only writing of such practice comes from Westermarck (1914) and Fakhouri (1972).

For centuries the hands and feet of the bride have been dyed after a ritual bath. The application of the henna to the bride stems from a sunneh ordinance which states that the bride must wash and then henna hands and feet and make her best possible appearance (Lane 1971:234). Because it is a sunneh ordinance it is assumed that the tradition has existed since, at the very latest, the time of Mohammed. A marriage contract, dating from 1554, stated the following:

M. Joseph, the esteemed young man...engaged and contracted a marriage with Negekah, the bride.. and undertook to pay her 10 dinars as her first instal7ment plus the cost of the henna...

(Goitein 1978:71).

Travelers in North Africa and the Middle East during the nineteenth century described ceremonies involving the application of henna to the bride, her family and friends. This ceremony continues today in much of the Moslem world as a prelude to marriage.

According to an informant, henna is used today by the majority of the brides in Morocco. It is the first gift a man gives to his bride-to-be. The henna is applied to the hands and feet in patterns of stars, crescents, and geometric designs (Dolinger 1960:170). Earlier this century, it was also applied to the hair, face, arms and lower portion of the legs. The application may be in public or private, but usually oniy women and children are allowed to observe. The person applying the henna patterns must have certain qualifications which vary by tribe. These qualifications once included any of the following: a maiden, mother, aunt, sister, bridegroom's sister, married woman who 
is the first wife of her husband, girl first-born only child of her family and named Fatima, or a female professional (Westermarck 1914:9798). Women present may also appiy henna to their own hands and feet. The occasion includes lighting candles, loud music, dancing (sometimes with a bowl of henna above the hoad), singing, and a feast. In some regions there were two evenings set aside for the dyeing. When this occurred, the first was called "the little evening" and the second "the great evening." The difference between the two was the size of the audience and feast. The only exception to having the Night of Henna was when the bride had to travel a great distance; she would be hennaed upon her arrival at the home of the groom. However, modern transportation has largely remedied this situation.

The use of henna by the groom is not widely practiced today, but in 1914, Westemarck described the following ceremony:
Guns went off in the village for a half hour, then the groom came out and welcomed people. After a few hours of going through the village with musicians and friends, they returned to the father's house... the groom sat with his head covered with a long white woolen cloth... his mother came out of the house with a bowl of henna, an egg, four candles and a bottle of water. She sayd, 'May God be gracious to you'.... best-man breaks the egg into the bowl and a bachelor pours in the water...best-man mixes it with his little finger of his right hand...applies to the palm of the bridgroom's right hand and then left palm, then his own other little finger and smears it on his hands while he sings.

The other bachelors dance with the bowl of henna which has the burning candles placed in it. Each takes a turn dancing while the best-man sings the fo! Towing: 
In the name of God the merciful and compassionate, 0 God. I take refuge with God from the devil, the stoned one, 0 God. We have made our lord Bular our leader and 0 God. We have made our Tord Utman our leader and 0 God. We have made our Tord Esa cur leader and $O$ God. We have made our Tord ATi our leader and $O$ God. His face is like the moon and 0 God. Stretch out your hand and we shall pa int you with henna, 0 my lord....

At the ending of the song and dance, the bowl of henna is allowed to drop and break (Westermarck 1914:97-98).

The application of henna on the groom varied from covering only the little finger on the right hand to staining the hands and feet. The person painting the groom was selected by the tradition of the tribe. Traditional requirements varied from having a female relative or the best-man be the person applying the henna to having it done by a firstborn son who was an only child named Mohammed. The ceremony usually occurred before the arrival of the bride and was most often public (Westermarck 1914:119-121).

Today grooms in Egyptian villages may rub henna on their hands and feet. According to informants, their friends may also apply henna before dancing and singing on the night before the wedding. Grooms in other regions usualiy have a dinner with friends during the bride's henna night.

Informants from Palestine were not all aware of henna's being used in association with weddings, yet Granquist (1931) gave accounts of its importance there during the 1920's. During that time, two or three of the groom's female relatives would visit the bride's home for the purpose of applying henna to her. While this was being done, henna was given to members of the groom's village. The bride was said to have 
cried during the application, while the groom's family sang, prayed and danced. When the bride's hennaing was completed, henna was distributed to guests. When the marriage plans were successfully concluded the groom would hear the following song:

Oh (groom's name)! Receive the good tidings!

There did not remain nor is there left over time.

Gone is the night of the henna

As well as that of the meeting

There remains for the bachelorhood only a few nights.

(Granquist 1931:51).

Marriage plans were known to have had their problems due to quarreling between families. One bride was said to have been left sitting with henna paste on her hands and feet for three days while the families debated the terms of the marriage (Granquist 1931:46-53).

Today, according to informants, the Night of Henna is still practiced in North Africa, the Arabian Peninsula and Pakistan. It may be practiced elsewhere throughout the Middle East, but recent ethnographic materials offer little or nothing in the way of description or analysis of the tradition. Women in city environments are slowly abandoning the custom. Those who have continued the Night of Henna in the Arabian Peninsula and Gulf make patterns of crescents, tear drops, sickles, stars, hearis, flowers, vines, and geometrics on their palms and soles of the feet for weddings. The fingertips, nails and toenails are usually dyed a solid orange. There are professional women whose services cost the bride's family much money. The professionals from Sudan and India are considered the most artistic. If a professional cannot be afforded, then an older women, preferably a relative, is asked to serve the bride. Brides usually draw their idea of the pattern they desire and the person applying the henna will elaborate on this pattern. 
Patterns may also be applied to guests and relatives, or the sol id orange effect received from binding the hands and feet overnight may be preferred. The henna is provided by the bride's family. The groom's family may or may not be present, dependent upon the families' relationship.

Villagers in southern Iraq may still henna the hands, nails and feet of the bride as was reported fifteen years ago (Fernea 1965:138). It is interesting to note that while the use of henna by brides in Baghdad has declined, and grooms have not been observed using henna during recent studies, a mourning lament for a deceased son stili includes the line, "I thought I would put henna on his hand and stand by his wedding bed and sing" (Masiiyah 1980:26).

Iranians in the villages during the late 1960's used henna in the traditional ways mentioned for the bride (Kendal1 1970:100). Informants from Iran were not aware of any connection between henna and marriage ceremonies.

A Pakistani informant stated that brides have elaborate patterns on both sides of their hands and feet. Women will make small floral patterns among 7 ines and dots. These patterns resemble those which can be found in India.

Prior to the introduction of cars, brides were taken to their new home on the back of a mule, horse or camel. The animal often had its tail dyed with henna; it may have been sprinkled with henna and water or milk. In Fez, Morocco, the woman who applied the henna to the bride was obligated to walk behind the animal holding its tail uniil reaching the groom's home. 
The women of the groom's village once cleaned wheat while waiting for the new bride to arrive. They sang a song with the Tine, "..the daughters of your father's brother rejoice for your sake, they plaited the hair of their head with henna" (Westermarck 1914:188).

When the wediding was over and the marriage consummated, the bride was given gifts by the groom. While this tradition still exists, the gifts of henna, dates, cloth and household staples have been replaced by gold.

$\underline{\text { Death }}$

The nails and hands of an Egyptian mummy were dyed with henna 3000 years ago. During this century, it was observed that unmarried persons in Morocco were buried with henna-dyed palms (either the right pa $7 \mathrm{~m}$ or both pa $7 \mathrm{~ms}$ ) and referred to as the bride or groom of the other world (Westermarck 1926:448). Twenty years ago in a Nubian community in Egypt, the body of the deceased was washed and rubbed with henna and perfumed by a relative of the same sex (Kennedy 1977:35). Saudi Arabian and Omani informants stated that today in the Arabian Peninsula, a woman is buried with henna bound in her hands, on her feet and in her hair. These customs may be preparations to enable the deceased to be protected against evil and to appear beautiful upon reaching the next world and judgment.

In ancient Egypt those who were left to mourn scattered henna powder on the grave to keep away animals (Westermarck 1926:530). During the 1920's and $1930^{\prime} \mathrm{s}$, headstones from North Africa to Iran were sometimes smeared with henna and water (Donaldson 1938:189). Sprigs of 
henna were laid beside graves and ground roses were added to the henna and water paste before smearing headstones in Morocco (Westermarck 1926: 480-481). These red headstones protected the deceased from being questioned by the evil spirits (Donaldson 1938:189).

In Morocco in the $1920^{\prime} \mathrm{s}$, an entire village would mourn the death of a member. For one week no one would use henna, antimony, walnut root or soap. This practice was common in many areas with a variation in the length of time. If the death required revenge, the avenger would coat his hands with henna to announce he had completed his duty successfully, thus ending the mourning period. The end of mourning meant women would paint their palms and tops of their feet with henna (Westermarck 1926: 471-472). Today women still refrain from using henna during mourning according to informants.

There vere several brief mentions in reference materials and by informants, of henna's uses in association with other occasions. These have been arranged into the categories below 1 isted.

\section{Other Occasions}

Pilgrimage. Members of a family would not use henna while a relative was on a pilgrimage. Meccan henna was brought home to friends and family by piigrims (Westermarck 1926:251).

Gifts and guests. A host would throw a little henna into the fire. The guest would tell the host if he was carrying henna (to avoid evil) and would throw a small amount into the fire before departing (Westermarck 1926:539). 
Cowardliness. If a man failed to go to war or made trouble, the women would dye his clothing with henna and hang it on the tent (Vinogradov 1974:65). Women would rip the shirt off the back of a coward and smear him with henna (Hamard African Studies 1931:88).

Revenge. If revenge was required, women and young boys would not use henna unti1 it was completed (Westermarck 1926:515-516).

Exorcism. The Zar cult of Egypt is a women's cult which exorcises evil from women. According to informants, henna is smeared on the hands and feet of the possessed woman before the ceremony.

After a long absence from a friend. Informants stated that women in Arabian Gulf countries will apply henna patterns to each other when seeing each other after being apart for several months or longer.

After fasting. Informants noted that women in the Arabian Peninsula may fast for three days each month beginning with the appearance of the full moon. On the fourth day, they will apply henna to their hands and feet. This may be in the form of patterns or a solid stain.

Swearing. Both men and women would hold a lump of henna in the right hand and say "By this 1ight of the Prophet" (Westermarck 1926: 504).

Traveling. An informant from Saudi Arabia stated that she hennaed her hands and feet before coming to the United States. Her feet and those of her husband were placed together and a pot of rose water was poured over them. When the pot was empty, friends and her husband placed money in it for her. 
Lunar calendar events. The last seven days of the month of Ramadan was a time to henna tent poles, domestic animals and the hands and feet of women and children. The exception was the 27th night when it was bel ieved by some that the jinns were released and dangerous (Westermarck 1926:98). Various feasts occur during the eighth month and tenth month. Women rubbed henna on their hair during the first and second days of the feasts (and possibiy later, if the feasts were lengthy) (Westermarck 1926:108).

Festiva! of the Kiswa. Some women hennaed their hands and feet on this day when the Kabba is given a new covering. This practice according to informants is practiced in Upper Egypt and the Arabian Peninsula.

Birth of Mohammed. Informants stated that this occasion is ceiebrated in various ways. Women may henna their hands, feet and hair or they may do their hair the following day.

Solar calendar events. New Year's Eve was a time when women and children hennaed their hands and feet; men smeared their paims (Westermarck 1926:171).

Abstention. Informants stated that women refra in from using henna while in mourning, while a member of the family is on a pilgrimage, and during menstruation.

Animals associated with events. Animals were frequently smeared with henna during feasts. Horses, sheep and dogs would have a dye mark between their eyes, on their chests, and on their ankles. If a horse had white spots, they were often dyed. Informants stated that in some regions, the animals which will be sacrificed is marked with a henna 
stain on its back or head.

One informant had been told by a grandparent that at the end Ramadan in Mecca approximately fifty ago, donkeys were shaved and patterns were painted on them with henna. They were then raced in the streets.

Camels used during the 1830's Procession of the Kiswa were stained (Lane 1871:215).

Henna according to one informant from Saudi Arabia, is used to mark sheep much like a brand or to point out those to be sheared or siaughtered. 


\section{CHAPTER VI}

\section{MEDICINAL USES OF HENNA}

Sumerian and Akkadian medical texts conta in numerous prescriptions which include unidentified plants, herbs, trees and roots. According to Levey (1966) henna was probabiy used for medicinal purposes in Mesopotamia, but this use has not yet been verified.

Dioscorides wrote in his Materia Medica that henna powder had a good effect on uicers in the mouth. It was also used on the skin of victims of Teprosy. The Talmud mentions that henna was used as a cure for urinary organs which were diseased.

The Abbasid philosopher, Al-Kindi (Levey 1966) included six medical formulas containing Meccan henna in his Aqrabadizin. The following was prescribed for a child with head uicers:

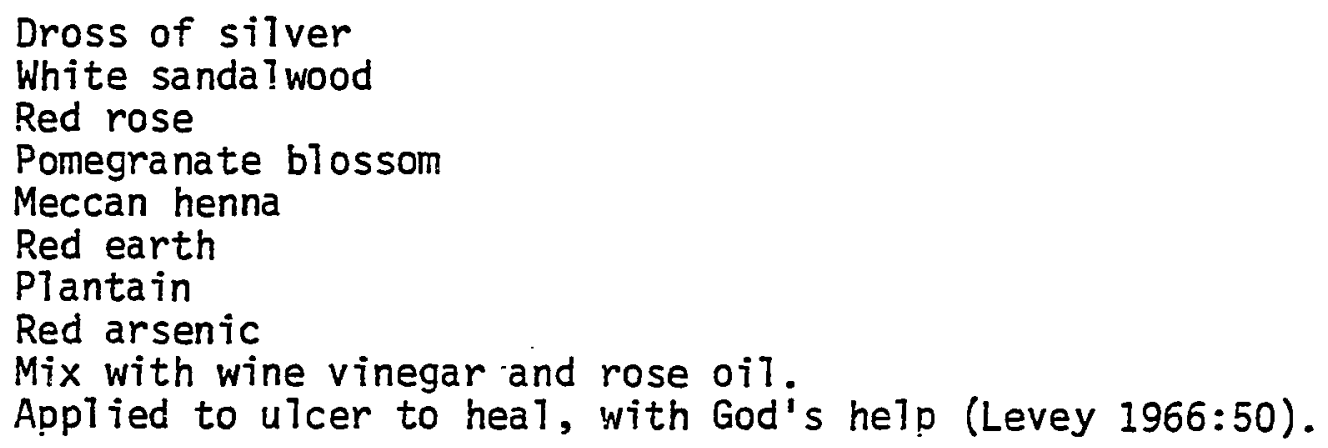

Long Aristolochia

Kama la

Meccan henna

Wild pomegranate flower

Burnt green cress 
Rose oil

Rubbed together with vinegar and pine resin (Levey 1966:62).

The following salve is made to ease itching caused by "what remains under the skin":

Indian saffron

Liccrice root

Pyrethrum

Pulp of the colocynth

Yellow sulfur

Mint

Mel iot

Rose of the camomite

Meccan henna

Natron

Fennel flower

Mustard

Mushrooms

Rinds of sweet pomegranate

Pulverize and moisten with the best penetrative Judas tree tar until saturated. Mix with 7 ime and daub on in bath or warm place free from odors. When the lime removes the blemish, wash off the saive with warm water. It is useful, God will ing (Levey 1966:70).

The gums are strengthened and teeth sweetened by applying the following to the teeth:

Barley flour is kneaded with tar. It is placed in the oven until it is dry. The red color changes to black and it is not burned strongly. Ash of false bdellium is kept in the furnace until heated to hardness. Ten parts of each are used. They are mixed well with one part Meccan henna, one part yellow alum, and one part of Darani salt after staining with a silk cloth. It is applied and it is useful, with God's he1p (Levey 1966:118).

Al-Kindi recommended for drinking, placing on one's chest or for binding, to one's head with his own decoction. This decoction is given in a unit of measurement referred to as a dirham which is approximately 3.3 grams. 
Yellow myrobalan

Chebul ic myrobalan

Fumitory

EmbT ic myrobalan

Koshmahan seeded raisins

Plums of Qamas (Iraq)

Seed of the tamarind

Common polybody

Meccan henna

Agaric rubbed between the fingers

BTue bdellium
10 dirhams

5 dirhams

4 dirhams

4 dirhams

4 dirhams

21

4 dirhams

1 dirham

4 dirhams

1 dirham

1 dirham

Cook with one ratl (approximately 60 dirhams) of water until it loses eight awquyas (approximately 20 dirhams). Add five dirhams of the best Cretan bindweed. It is kept on the fire for an hour until it is changed. Then it is clarified into a glass flask. At night, throw into it:

$\begin{array}{lc}\text { Turpeth } & 1 \text { dirham } \\ \text { Black iyarij (an electuary) } & 1 / 2 \text { dirham } \\ \text { Andarani sait } & 1 / 3 \text { dirham } \\ \text { Mastic } & 1 \text { carat (approximately } \\ \text { Borage } & 1 / 2 \text { dirham }\end{array}$

Stir and apply or drink. It is useful with God's leave. (Levey 1966:208)

AT-Kindi mentions a drug that is to be taken after mealtime. The weight is measured in a methqa 7 , which is 1 and $3 / 7$ dirhams. He states that the dose is five dirhams. The weight was after the items were sieved through a silk cloth. The following are then ground and mixed with honey.

$\begin{array}{lr}\text { Good fresh colchicum } & 12 \text { mithqals } \\ \text { Leaf of Meccan henna } & 1 \text { mithqal } \\ \text { Caper leaf } & 1 \text { mithqal } \\ \text { Pepper } & 1 \text { mithqal } \\ \text { Long pepper } & 1 \text { mithqal } \\ \text { Cinnamon } & 1 \text { mithqal } \\ \text { Indian cumin } & 1 \text { mithqal } \\ \text { Ginger } & 1 \text { mithqal } \\ \text { Dry storax } & 1 / 4 \text { mithqa } \\ \text { Cuttle fish bone, cleaned } & 1 / 4 \text { mithqal } \\ \text { Sal ammoniac, pure, crystal-1ike } & 1 / 4 \text { mithqal } \\ \text { Naphtha salt } & 1 / 4 \text { mithqal }\end{array}$


This drug is the last of AT-Kindi's to mention henna and is said to be good for the spirits (Levey 1966:210).

The medical formulas recorded by A1-Samarqandi date from the thirteenth century. He describes a balm including henna which penetrates the pores (Levey and A1-Khaledy 1967:113). Henna was used on moist uicers which had dirt and pus to dry them (Levey and AT-Khaledy 1967:148). Henna was also considered a hair conditioner (Levey and Al-Khal edy 1967:168).

At tine beginning of the twentieth century, henna was recorded as being used in Iran and Iraq for external treatment of skin diseases, boils and leprosy. It was applied as paint to the pubic region as a remedy for gal1 bladder problems (Levey 1966:232).

Westermarck (1926) discussed several medicinal uses of henna in Morocco. It was credited with two ways of curing a headache mixed with the blood of a sacrificial animal and applied to the hair (Westermarck 1926:123) or mixed with a woman's saliva and applied to the head (Westermarck 1926:157). Fleas, Tice and ringworm (Westermarck 1926: 443) were expelled from the body by a henna and water paste. This same paste was applied to the forehead for a fever (Westermarck 1926:113). Open sores were cured with a mixture of henna, earth, tar and the saliva of the sufferer. The navel of a newborn baby was rubbed with henna mixed with ashes or butter. If the child was born in the sumer, a mixture of henna and butter or oil was placed in the armpits, between the legs, and on the navel to prevent perspiration which cause a chill. This same formula was used to prevent colds by burning a green candle while the infant was painted with the mixture (what remains of the 
candle upon completion of the procedure is given to the midwife). In Fez on the day after birth and for three consecutive days, a lotion of henna, water and oit was rubbed on the infant to strengthen the skin (Hestermarck 1926:383).

The Ulad Bel'aziz made cuts in an infant so that he would be "prevented from (the evil of) his own blood." These cuts were dressed with henna and soapstone (Hestermarck 1925:395).

The circumcision would be dressed with henna and butter through most areas of Morocco.

If a nursing woman had a sore breast, she would swing the right forepaw of a porcupine over the breast seven times and then dip the forepaw into henna and water. The forepaw, once red, would then be swung over the breast seven more times and worn over the breast for seven days. A forepaw could be loaned but the borrower was obligated to dip it in henna and water before returning it to the owner; this dipping was to prevent the spread of disease (Westermarck 1926:401).

It was reported in the $1920^{\prime} s$ that a male child in Upper Egypt would have his head shaved just above the forehead and the area then coated with henna paste. This practice was believed to benefit the child's eyesight (B1ackman 1927:57).

The Moroccans of the $1920^{\prime}$ 's bel ieved that henna and the curative powers of the moon could prevent hair from falling out. Three days after a new moon, giris would sit on house rooftops at night and comb henna and oil into their hair while repeating, "I gave you this hair of mine, Oh moon, give me yours" (Westemarck 1926:126). This custom might be repeated every three days for a Tunar month. In other 
accounts, the ashes from a burned toad were mixed with henna to prevent 1oss of hair (Westermarck 1926:345). The skin and bristles of a hedgehog were burned and mixed with henna to make a hair strengthener (Westermarck 1926:324).

Donaldson (1938) reported that henna was used in Iran to aid eyesight, keep nose membranes soft, sweeten breath, strengthen teeth roots, remove body odor and rid the body of swelling or shifting pain (Donaldson 1938:188). Iranian and Iragi medical uses of henna during the thirties also included treatment of skin diseases and leprosy (Levey $1967: 219$ ).

Henna was used in all regions of the Middle East on cuts and sores located on hands and feet. It was used to bind wounds and to dry sores as well as to toughen skin. Pearl fishermen in Kuwait used henna on their palms to prevent blisters from rowing or hauling (Dickson 1949: 159).

It is believed that women can make a tea from the buds of the henna plant. This tea will cause them to abort (Ammen 1956:182-183). The application of henna and water paste on cuts and skin infections is still practiced in the majority of Middle East and North African countries. An informant from a village in southwestern Saudi Arabia stated that it is good for people who do not wear shoes to have henna on the soles of their feet, and for people who work with their hands to have henna on their palms. An informant from Morocco noted that laborers have put henna on the entire palms of their hands, but non-laborers make patterns on their palms. Two Libyans and several Saudi Arabian informants had used henna to ease pain from sunburn. 
According to one Libyan, his grandfather is his village's expert on folk medicine. He recommends milk from a nursing mother mixed with henna for relieving pain from burns. A third Libyan informant from a southern village, stated that only men use henna for the purpose of healing cuts. An American informant who had been to Egypt, said she had seen people drink henna with water for dysentery.

Al1 informants from the Middle East and North Africa, with the exception of one male from Oman, thought that henna was beneficial to hair. Henna was reported to be used on the beards of some old men in Saudi Arabia, Morocco and Iran, but not on their head hair. No one reported henna on the hair of a male over the age of ten. The benefit to the hair and scalp was not considered medicinal by some.

The use of henna for medicinal purposes was more well known by informants from villages or small farm environments, or those who had one or both parents from such an environment. 


\section{CHAPTER VII}

\section{COSMETIC USES}

Henna has been used as a cosmetic dye for centuries. Literature previously mentioned reflects the attitude toward henna which still prevails in North Africa and the Middle East. It is considered an attractive colorant for skin and hair.

Persian women 150 years ago dyed their hair and eyebrows and stained their bodies with figures of trees, birds, animals, stars, suns and moons. Patterns were placed from the chest to the navel and $V$-neck clothing displayed the art. Men dyed their beards, nails, hands and feet (Atkinson 1932:14-16).

Women in Egypt during this same time, stained their soles, palms and nails. Stripes appear to have been the fashion. Some added ash or other ingredients to make the henna darker. This practice was believed to be done for the sake of appearance (Lane 1871:47-48).

Informants stated that throughout North Africa and the Middle East, henna is used by many women to stain the fingernails and dye hair. Many Moslem women prefer henna to nail polish due to religious rulings forbidding the wearing of nail polish while praying. The red tint given to hair is believed to be beautiful and the effect of henna on greying hair is thought to be one of giving a youthful appearance. This ability to hide age by dyeing white hair was practiced by men also. Mubarak, a ruler of Kuwait in 1914, hennaed his beard and eyebrows so 
as to not show his seventy-seven years (Hewins 1963:162).

Commercial hair dyes were introduced to the Middle East in the 1930's. While they have gained popularity, henna is still a commonly used hair coloring and is considered more healthfut than commercial products.

Many lotions and perfumes manufactured in Europe contain henna oil. These products are combinations of the oil of several flowers besides the henna plant, such as jasmine and rarcissus (AT-Ra'uf 1960:21). The odor of henna is considered by some to be spermatic and is a possibie aphrodisiac.

Informants mentioned that gloves and plastic stencils to aid women in applying henna patterns are now in the markets in the Middle East. These new products surely are a sign that the cosmetic aspect of hennaed hands and feet is prevalent in that region. 


\section{ATTITUDES EXHIBITED IN RESPONSE TO \\ ETHNOGRAPHIC INQUIRY}

The ethnographic inquiry for the present study began as a formal questionnaire, but it soon became obvious that this format would not be as productive as a loosely conducted interview. Key questions were still asked, but in the context of a conversation.

Fifty interviews were attempted. Forty-nine persons responded favorably. Once these persons understood the purpose of the inquiry, they appeared to be genuinely interested in adding to the information which had been gathered from written materials.

Interviews conducted in Bethlehem, West Bank, took place after the writer had attended a wedding with one of the informants and her family. The fact that no henna was used by the bride or anyone at the wedding was unexpected in view of research done previously. The responses from informants showed that the custom had not been practiced for several years, as the majority were aware only of the cosmetic aspects of henna. Informants from areas other than Israel, Lebanon, Iraq, Iran and the West Bank had much information concerning various aspects of uses of henna. The majority had personal experiences to relate.

Several informants became enthusiastically involved with the research. A Pakistani male went home after the interview and drew pictures of patterns he remembered. One Saudi woman willingly drew her wedding pattern. Another Saudi woman loaned her book of patterns 
(Appendix C) which she had recorded but had previously refused to let other women borrow. A Bahrani girl allowed a picture to be taken of her foot which had been decorated for a folk dancing presentation.

One Libyan and two Saudi males called their homes to ask their mothers questions. Two informants called from Saudi Arabia with additional information after returning home from the United States.

Four informants gave this writer henna they had brought from home, had their families send samples or sent henna themselves upon their arrival back in the Middle East.

A female informant from the United Arab Emirates had offered to henna her hands and feet so that the process could be recorded and photographed. Due to a death in the fami7y, however, she was in mourning when the time arrived, so she applied the henna to the writer instead of to herself.

There appeared to be no variation in responses between males and females familiar with uses of henna. There was an attitude of pride exhibited by the majority of both sexes about the custom. The most negative response was from an Egyptian male. It is interesting to note, however, that upon seeing the writer's hands and feet patterned with henna, he asked if a pattern could be made on his wife's hands. 


\section{CHAPTER IX}

\section{CONCLUSION}

Red colorants have played a role in the cuitures or populations throughout North Africa and the Middle East since the Upper Paleolithic. Although the time of its introduction to the area is debated, henna seems to have slowly replaced the mineral colorant ochre in ceremonial and cosmetic uses. It is most probable that henna was brought to the region by the Bronze Age peoples collectively referred to as the Hyksos. These peoples are believed to have come from areas where plant-worshipping was common.

Recent studies of color terms and their symbolic significance led researchers to associate the color red with the dichotomy of life and death or good and evil. This dichotomy is reflected in the uses of henna as a purific and protector from evil. The best example exists in the Night of Henna, which is a remnant of old customs which still exists among the rites of passage practiced today. It was believed that the bride, while being vuinerable to evil, was herself a potential source of evil to the groom's family. The Night of Henna purified and protected the bride and other participants.

Medicinal uses of herna appear to be as ancient as the belief in its magical qualities. The medicinal uses have been replaced by modern drugs in most cases. 
The majority of informants were aware of the fact that uses of henna pre-date Islam. There was a definite line drawn between religious practices and the customs surrounding the uses of henna. The bride-tobe's use of henna appears to be the most widely recognized use, second only to its cosmetic application.

The process of westernization has brought with it the mass-produced cosmetics which dictate what is fashion. Body art, which was once symbolic, is looked upon by the western world as primitive. However, pride in tradition may allow henna body art to survive as a cosmetic associated with some occasions. The fact that plastic stencils are sold in the markets of Pakistan to help women pattern their hands reflects the fact that this custom is still widely practiced and is itself becoming "westernized."

While the symbolic role of henna in the North African and Middle Eastern regions is not widely known by its modern day users, the plant is respected and considered virtuous. This attitude is, in part, due to its use by the Prophet Mohammed. Its importance prior to Islam has recently been recognized by the Egyptian government which planted a henna bush in the garden at Karnak, thus repeating what had been done centuries ago by Ramses I. 


\section{REFERENCES}

Abercrombie, Thomas J.

1979 Bahrain: Hub of the Persian Gulf. National Geographic 156:301-29.

A7-Ra' 'uf, Abd

1960 AZ-Einna. Cäiro: Commercial and Agricultural Productions.

Ammen, Ahmed

1956 Egyptian Customs and Traditions and Expressions. Cairo: Publishing, Translating and Authoring Comittee Printing.

Atkinson, James

Customs and Manners of Women of Persia and Their Domestic Superstitions. Trans. 1832. London: J. L. Cox and Son.

Barclay, Harold

1964 Burpi al Lamaab: A Suburban Village in the Sudan. New York: Cornell University Press.

Berlin, Brent and Paul Kay

1969 Basic Color Terms: Their Universality ana Evolution. Los Angeles: University of California Press.

The Bible Sons.

Revised Standard Version. New York: Thomas Melson and

Billard, Jules B. (ed.)

1978 Ancient Egypt: Discovering its Splendors. Washington, D.C.: The National Geographic Society.

BTackman, Winifred

1927 The EalZahina of Upper Egypt. London: Frank Cass and Company Limited.

Brain, Robert

1979 The Decorated Body. San Francisco: Harper and Row Publishers.

Browne, H. G.

1799 Traveis in Africa, Egypt and Syria from the Year 1792 to 1798. London n.p. 
Budge, Sir E. A. Walli is

1972 The Dwellers on the Wile: Chapters on the Life, History, Religion and Literature of the Ancient Egyptians. New York:

Benjamin Blom, Inc.

1974 The Mromy. New York: Causeway Books.

Burton, Sir Richard F.

1898 Personal Narrative of a Pilgrimage to AZ-Madinah and Meceah. Edited by Isabel Burton. London: George Bel1 and Sons.

1978 The Book of the Thousand Nights and a Night. Translated by Sir Richard E. Burton. New York: Avene?.

Chasman, Major R. E.

1926 In Unknown Arabia. London: MacMillan and Company, Limited.

Cole, Donald Powell

1975 Nomads of the Nomads: The AI Murrah Bedoin of the Empty Quarter. Illinois: AHM Publishing Corporation.

Colombel, Pierre

1975 Old Frescoes Show Sahara Once had Pleasanter Climate. Smithsorian 6:69-75.

Cooper, Elizabeth

1975 The Earim and the Purdah: Studies of Oriental Nomen. Detroit: Gale Research Company.

Corson, Richard

1965 Fashion in Hair: The First Five Thousand Years. New York: Hastings House.

Dickson, H. R. P.

1949 The Arab of the Desert: A Glimpse into Badowin Life in Kuwait and Sau'di Arabia. London: George Allen and Unwin, Ltd.

Dol inger, $J$.

1960 Behind Harem walls. London: Alvin Redman.

Donaldson, Bess Allen

1938 The Wild Rue: A Study of Muhomadan Magic and Folklore in

Iran. London: Luzac and Company.

Ebers, G.

1878 Egypt: Descriptive, Eistorical and Picturesque, II. New York: Cassel, Petter, Golpin and Company. 
Fakhouri, Hani

1972 Kafr EZ-EZow: An Eguptian VizZage Transition. San

Francisco: Holt, Rinehart and Winston, Inc.

Faris, James $C$.

1972 Nuba Personal Art. Great Britain: Jarroid and Sons, Ltd.

Fernea, El izabeth Warnock

1965 Guests of the Sheik: An Ethnology of an Iraqi Vilzage.

New York: Doubleday and Company, Inc.

1976 Some Women of Marpakesh. University of Texas at Austin, dir.

Goitein, S. D.

1978 A Mediterranean Society: The Jewish Community of the Arab

World as Portrayed in the Documents of the Cairo Geniza. Vol.

III. Los Angeles: University of California Press.

Granquist, HiTma

1931 Marriage Conditions in a Palestinian Vizlage. Helsingsfors:

Centraltryckeri Och Bokkinder AB.

1947 Birth and Chizdhood Among the Arabs: Studies in a Muhammadan Viliage in Palestine. Hel singsfors: Soderstrom and Co. Forlagsaktiekolog.

Hansen, Henny $H$.

1960 Doughters of AZZah: Among Mosiem Women in Kurdistan. London: George Alten and Unwin, Ltd.

1961 The Kurdish Woman's Life: Field Research in a Muslim Society. Colpenhagen: Nationalmuseet.

"Henna"

1971 In Encyclopedia Judaic. Jerusalem: Keter Publishing House, Ltd. Pgs. 326-27.

"Henna"

1933 In The oford English Dictionary. Oxford: Clarendon Press, p. 223.

Hewins, Ralph

1963 A Golden Dream: The Miracle of Kuwait, London: W. H. Alien.

Hunt, Ignatius

1967 The World of the Patriarchs. New Jersey: Prentice-Hall, Inc. 
"In the Name of Allah"

1969 Television Broadcast, Bloomington: Indiana University.

Kay, Shirley

1978 The Bedouin. New York: Crane, Russan and Company, Inc.

Kendall, K. W.

1970 Personality Development in an Iranian Vizlage: An Analysis of Socialization. England: University Microfilms.

Kennedy, John $G$.

1977 Struggle for Change in an Nubian Community: An Individual in Society and Eistory. Palo Alto: Mayfield.

Kramer, Samuel Noah

1963 The Sumerians: Their History, Culture and Character. Chicago: The University of Chicago Press.

Kritzeck, James

1964 Anthology of Islomic Literature: From the Rise of Islam to Moderm Times. New York: The American Library, Inc.

Lane, Edward William

1871 An Account of the Monners and Customs of the Modem Egyptians: Written in Egupt during the Years 1833, -34, and -35, Partiy from Notes made During a Former Visit to that Country in the Years 1825, -26, -27, and -28. London: John Murray, 2 vols.

1971 Arabian Society in the Midale Ages: Studies from the Thousand and One Nights. New York: Barnes and Noble, Inc.

Leach, Edmund

1976 Culture and Communication: The Logic by Which Symbols are Connected. Cambridge: Cambridge University Press.

Levey, Martin

1966 The Medical Formulary or Aqrabadhin of AZ-Kindi. Trans. 1966. Madison: The University of Wisconsin Press.

Levey, Martin and Noury AT-KhaTedy

1967 The Medical Formulary of AZ-Scmarqandi and the Relation of Early Arabic Simples to those Found in the Indigenous Medicine of the Nlear East and India. Trans. 1967. Philadelphia: University of Pennsylvania.

Locker, A.

1890 With Star and Crescent. Philadelphia: Aetna. 
Masliyah, S.

1980 Mourning Customs and Laments Among the Mus7 ims of Baghdad. Is Zamic Cuiture: An Engiish Quarteriy 1:19-29.

Masset, $\mathrm{Cl}$ aude

1980 Comment to Red Ocher and Human Evolution: A Case for Discussion. Ernest E. Wreschner. Current Anthropology 21:639.

Mellaart, James

1975 The Neolithic of the Near East. New York: Charles Scribner's Sons.

Mez-Mangold, Lydia

1971 A Eistory of Drugs, Basle: F. Hoffman La Roche.

Redman, Charles L.

1978 The Rise of Civilization: From Early Farmers to Urban Society in the Ancient Near East. San Francisco: W. H.

Freeman and Company.

Ronart, Stephen and Nancy Ronart

1959 Concise Encyclopedia of Arabic Civilization. Amsterdam: Djambatan.

Roper, Joyce

1974 The Women of Nar. London: Farber and Farber.

Singer, Charles, E. J. Holmyard and A. R. Hall

1954 A History of Technology. New Yor:s: Oxford University Press, Vol. I.

Smith, Wh. Robertson

1927 Lectures on the Religion of the Semitics. New York:

The MacMilian Company.

Tremearne, A. J. N.

1970 Hausa Superstitions and Cusoms: An Introduction to the Folk-Lore and the Folk. London: Frank Cass and Company, Ltd.

Van Ess, Dorothy

1961 Fatima and her Sisters. New York: The John Day Company.

Vinogradov, Amal Rassam

1974 The Ait Ndhir of Morocco: A Study of the Social Transformation of a Berber Tribe. Ann Arbor: The University of Michigan.

Warner, Charles Dudiey

1876 My Winter on the MiZe, Among the Mumies and Mostems. Hartford: American Publishing Company. 
Westermarck, Edward

1914 Marriage Customs in Moroceo. New Jersey: Rowman and Littlefield.

1926 Ritual and Belief in Morocco. London: MacMillan, Vols. $I$ and II.

White, Jon Manchip

1967 Everyday Life in Ancient Egypt. New York: G. P. Putnam's Sons.

Winter, Ruth

1974 A Consumer's Dictionary of Cosmetic Ingredients. New York: Crown Publishing.

Wreschner, Ernest E.

1980 Red Ocher and Human Evolution: A Case for Discussion. Curpent Anthropology 21:631-644. 


\section{APPENDIX A}

\section{INTERV IEWS}

The majority of interviews were conducted in Portland, Oregon between A.pri1, 1980 and March, 1981. Those interviews from Bethlehem in the West Bank were conducted in August and September, 1980.

\section{Informant: 01}

Country: Morocco

Age: Approximately 20

Sex: Male

Background: This informant lived in France and the United States for several years. His father is a Persian and his mother is a Moroccan Jew. The informant is Bahai. He was raised in Rabat.

Responses: Henna is used by old women mostly, especially to color their white hair. They wrap it for any amount of time from two hours to overnight. The time depends on the color they want.

Women use it for weddings on the night before. The designs are different by economic class. The rich have sophisticated designs, the others have modest dots. At the party they put it on the bride and carry her around on a big metal tray. Possibly the men use it for the wedding but I never saw it.

Women put patterns on their hands and feet. Men workers will have it solid on their hands. I don't know, maybe it is good for the skin. 
It is something I saw every day and never thought much about it. We are going to be doing it less with westernization.

Informant: 02

Country: Libya

Age: $\quad 24$

Sex: Male

Background: This informant was raised in a city. His father is from the city and his mother is from a village.

Responses: Boys and girls as young as two years old can use it. Something on boys is that the first time is when 211 the boys in a group have [described circumcision].

A woman has it on her hands when she has a baby, at the time when the baby is born.

A71 day before the wedding, there is a party. The bride mixes it with oil and water. All the women sing songs. It looks pretty and it is on the hair, feet, and usualiy a star is in the center of the hand [he pointed to his palm]. It is around the feet. It lasts three months.

You can use it on burns.

It is better than a tattoo but it is not religious.

The plant is a nice plant to have in your garden.

It is used less now because modern products like hair dyes are in our markets. 
Informant: 03

Country: Libya

Age: $\quad 22$

Sex: $\quad$ Male

Background: This informant is from a village where both of his parents were raised.

Responses: My sisters and mother use it on their hair and fingernails. old women use it on their grey hair to make it blonde. 'Some still do their hands and feet; they put a 1 ine around the edge of their feet. There is no pattern on the top of the hand but they put 1 ines on the inside of the hand [pointed to his palm]. They try to make dark color in the Tines on the hand.

I don't know about weddings; my sisters are not married. Men don't use it except for medicine on cuts.

Informant: 04

Country: Libya

Age: $\quad$ Approximately 25

Sex: Male

Background: The family lives in a small town in the west, Bani Walid. Both parents are from the town.

Responses: When a woman has a baby, she puts it on her hands and feet one week after the birth.

Kids use it because women think it is cute. It is hard to keep the hands wrapped overnight because of the way the kids sleep. 
For weddings, women do it unless they are going to Europe or here [United States] for their honeymoon.

It is done for special occasions like Moharmad's birthday. They will put it on their hands and feet. They put dots and flowers and their feet look like shoes are on. It goes up to the wrist on the hand. On the feet, they put dots on the heels. Tattoos are against Islam but henna is okay.

Women put it on their white hair and on their nails. My grandmother is 76 and she uses it.

It is mixed with oil to help the color stay on.

For medicine, it is used to hold cuts together and dry them. It is put on sunburns and on burns from fire. Ashes are added to it sometimes or the milk from a woman with a baby. I know this because my grandfather is well-known in my village for his knowledge of this type of medicine.

\section{Informant: 05}

Country: Egypt

Age: $\quad 24$

Sex: Male

Background: This informant is from the "heart of Cairo." His father is from Luxor and his mother is from Aswan.

Responses: The first time a child uses henna is for a family occasion. They may be 4 or 5 years old. The child will not like it because the hands have to be wrapped in cloth for two days. Then you can't scratch or eat; it drives you crazy. I will never forget it. 
I saw my mother put it on the heads of my five sisters and wrap their heads in cloth. They have to leave it on overnight.

You mix this henna with water and leave it on until it will rub off; then you wash it off. Women do feet also but men don't use it.

It is a good cure for some skin diseases but I don't know which ones.

The colors can vary.

It is not religious but women always use it for a wedding. The women and children gather in the house of the bride and put the henna on everyone. They have a party and sing and eat. This is not a tradition in Cairo except for the people from the south.

There is a Zar ceremony where the hands and feet of the person with the evil in them is covered with the henna. This gets rid of the evil spirits and is part of the ceremony.

Informant: 06

Country: Egypt

Age: $\quad 25$

Sex: Male

Background: This informant is from Cairo. Both his parents were raised in Cairo.

Responses: Men don't use that [expletive deleted].

Women do it to please men because they think that men think that it looks good.

Upper Egyptians use it more than Lower ones and the Sudanese use it more than anyone. They make patterns with dots and fiowers. 
Informant: 07

Country: Saudi Arabia

Age: $\quad 23$

Sex: Male

Background: The family has lived in Jedda for generations.

Responses: My sisters do not use it but my mother and her mother use it still. It is good for women to do their hands. Some still do it for their weddings but not many anymore. The older women are the oniy ones today. Men and animais do not use henna.

Informant: 08

Country: Saudi Arabia

Age: Approximately 20

Sex: $\quad$ Female

Background: The family is from Riyadh.

Responses: My mother used it maybe twenty years ago but not anymore. Children won't use it. Men never use it. Women who use it only use it on their hair and fingernails. My mother told me it is good for my hair but I cannot find it in the United States. It is mixed with water for the hair.

It is not religious and it is not medicine. We use it now to mark the sheep before the hair is cut off them.

Informant: 09

Country: Saudi Arabia

Age: Approximately 20

Sex: $\quad$ Female 
Background: This informant is from Dhahran.

Responses: The night before I was married, I put on a red dress and mixed the flour and water and then in a second dish, the henna and water. Then I drew the picture I wanted with a pen on my hands and feet and the lady that puts the henna on came and put it on me. She is my aunt, my father's sister. But this woman does it for lots of people. You must have an old lady do it and its better if she is related but she doesn't have to be. She puts the henna on the pattern and first, she puts the flour and water on the places I wanted to be skin color. The henna goes everywhere else. The henna was some I bought myse7f. When I was done, it was wrapped with a bathroom paper and then anyone else who wanted to do it, used what was left. The children as little as 2 years old want it. Then there is eating, music and dancing. All the people are girls. First you go to the bath in a green dress, then you get the henna in a red dress. Five days after the wedding, you get to see your parents again and then you wear the black abba agains.

Now I put henna on my fingernails under the paint. It is good for the nail.

Two days before I came to America with my husband, I put henna on my feet and then my husband I put our feet together and his mother poured rose water over our feet and when there was no water left in the pot, people put money in the pot. My husband put money in the pot and gave it to me. 
Informant: 10

Country: Saudi Arabia

Age: $\quad 24$

Sex: Male

Background: This informant was raised in Riyadh. His father is from Riyadh and his mother is from the Asir region.

Responses: My mother uses it on the palm of her hand but when she visits me in the United States and England, she gets funny looks.

There is no special occasion. She just mixes it with water and puts

a piece in her hand and wraps it in material for the night.

Men to not use it.

It is not because of Islam that it is used but I think most people that are in Islamic countries know about this.

You can use it to make a sunburn feel better or to help a cut.

I guess maybe men could use it for those reasons.

01d people use it more than anyone else.

I don't know about before weddings, but I would not marry a girl who would not put it on for the wedding.

\section{Informant: 11}

Country: Saudi Arabia

Age: $\quad 26$

Sex: Male

Background: This informant's family is from Mecca.

Responses: Don't tell anyone that I talked to you about this. My grandmother told that during Ramadan, they use to shave the donkeys and 
then dye patterns on them with henna. Then they would race the donkeys through the streets. I never saw it but she told it was from when she was little.

You mix it only with water. It is good to use in warm weather but not cold weather because it will make you colder.

It is good to hold cuts together like a bandaid. You put it on sunburn because it is cold.

My grandmother says that henna is a gift from heaven.

\section{Informant: 12}

Country: Saudi Arabia

Age: $\quad$ Approximately 24

Sex: Male

Background: This informant is from Abha. His mother and father are both from the same region.

Responses: If a woman is not married, she should not put henna on the tops of her hands. There is a party the night before the wedding and then she can put henna on her entire hand. (NOTE: This informant was sitting with the informant 11 isted immediately above and would only add this information.)

\section{Informant: 13}

Country: Saudi Arabia

Age: $\quad 28$

Sex:- Male

Background: This informant is from Abha and his entire famity comes from that region. The following information was given while he showed 
me a picture of his little sister with her left hand hennaed, and his brother's wedding picture.

Responses: Henna was first put on my little sister's hand when she was seven. There was no special occasion. See how she is smiling. My brother was married in the Fal1 (1980) in Cairo where he is a medical student. The fingers of his mother were orange from the henna (she is not my mother but we have the same father). She dips her fingers in the henna to the first joint. The bride also did this.

The people who still use henna have people in their family from the Asir region because this is where it came from. 01der men and women in Abha use henna on their hands and feet in some hill areas. Some of those people do not wear shoes so this makes their skin tough so it won't break. Some people who work a lot with their hands use it on their hands.

Girls sometimes think it looks pretty and want to try it. People our age are more educated and they don't use it.

People in Sudan make dots on their palsm too, for a pattern and on their feet, the bottoms are solid but the edges have patterns, sometimes even up to the ankles about six inches.

If you want it darker, then you put ashes with it or smear ashes over the henna when it is on your skin. It looks best if it is dark on men; it should be yellow on women and dark on men.

Informant: 14

Country: Saudi Arabia

Age: 28 
Sex: $\quad$ Male

Background: This informant is from Riyadh. His father is from the area just north of Riyadh and his mother is from Abha.

Responses: When I was a smal1 boy, my grandmother put that henna on my hair because I have crazy hair. She did it two times. I was very mad at her because it is a girl's thing and I could not play with the boys because they laughed at me. But I think that it helped my hair.

Henna is used by women to make them beautiful. It is on their hair, feet and hands. It is good for the skin. During Ramadan and the Hajj, women can use it but men can't so you can tell the men from the women.

Women use it when they get married. A lot of women at the wedding use it.

\section{Informant: 15}

Country: Saudi Arabia

Age: $\quad 24$

Sex: Male

Background: This informant is from "central Saudi Arabia."

Responses: We have a joke about this stuff. What is green in the store and red on your mother?

It is good when it is hot. My sisters sit in the sun and put olive oil on their hair and then henna. They leave it on for two days and maybe a little longer. Sometimes they put six braids in their hair and then put on the henna. Little girls want to have colored string and henna on their hair. 
For the wedding they put henna on the radies and the bride. Sometimes they put 1 ines and flowers.

The night before a feast, they put henna on the animals that the men will kill.

01d men mix henna with gasoline and put it on their beards.

Informant: 16

Country: Saudi Arabia

Age: $\quad 18$

Sex: Female

Background: This informant is from the Asir region.

Responses: Henna is used by women on their hands, feet and hair. It is good for the skin and the color is beautiful. It makes your hands beautiful because it shows the lines in your skin. I mix it with sour cream and gasoline and put some on my hands. Then tie the hands and leave overnight. This is really a good thing to do.

older women make designs on the backs of their hands. They mix it with ashes to make it darker; this is done in the south region the most.

I have only done my hair and feet and hands with no patterns.

Informant: 17

Country: Saudi Arabia

Age: $\quad$ Approximately 45

Sex: $\quad$ Female

Background: This informant is from Riyadh and was visiting her son in Portland, Oregon. The interview was done through her son. 
Responses: She still puts henna on her hands because it looks pretty and it is from a holy tree. She must have it on her hands, nails, feet and hair to feel comfortable.

She gave instructions on its use and gave her son a bag of henna to give to me. The instructions are as follows: mix it with water, put it in the middle of your hand, urap cloth around your hand while you sleep. If you put it on your hair, wrap cloth around your head for 24 hours.

At death, a Mosiem woman has henna placed in her hands and her hands are bound. It is also put in her hair and wrapped. This is done so that she will be beautiful and smell good when she is judged by Allah. It is done after the entire body is washed; it is done to women only.

(NOTE: Her son was not aware of the customs surrounding the death of

a woman and found it very interesting.)

Informant: 18

Country: Saudi Arabia

Age: $\quad 22$

Sex: $\quad$ Femate

Background: This informant is from Jedda.

Responses: We use henna for our fingernails because it is good. You cannot pray if you have paint on then but henna is good. We put henna on our hair for stronger hair and it gets longer.

I did not use henna when I was married because my husband had to come to Portiand. It is not used by every girl today for her wedding but some mothers want their daughters to use it. 
I don't think that it is a medicine except that it is good for your hair. Children and men don't use it.

\section{Informant: 19}

Country: United Arab Emirates

Age: $\quad 25$

Sex: $\quad$ Female

Background: This informant has spent several years in India. She has relatives in Oman and Qatar and has spent much time with them.

Responses: Henna is used for ceremonies, expecially the wedding. The hands are painted with a special type of henna because it is mixed with tea and lemon. Then it is strained through a cloth. If you want it on your hair, then you mix it with lemon if your hair is oily, or yogurt if your hair is dry.

You never use it during the winter on your hair because it makes your head cold. It is best in summer. You never use it during your period. This is because the Prophet used it so it has some connection with our religion so you must be clean. Men use it on their beards, especialiy the religious men.

When you put it on your feet, you must hold your feet above the fire for several hours. It is a time for having many friends together because you all laugh and have fun. One poor girl must not do it because she has to be the one who carries the other girls to the toilet. This is the most difficult part because she can tickle you and make you laugh. It is good for the skin so people who work with their hands use it. They just make a solid color without a pretty pattern. 


\section{Informant: 20}

Country: Oman

Age: $\quad 25$

Sex: Male

Background: This informant is from Salalah on the coast.

Responses: Men don't use it. Women use it for all celebrations because it is used with happy things.

When people return from Mecca, there is a feast and 211 the women, even the little babies have henna on their hands and feet. They just leave it on about three to four hours for the color.

Sometimes when girl friends have not seen each other for a long time, they will put henna on together when they visit. Women will put it on the day after the baby is born if it is a baby girl. A woman's body has henna on it before she is buried.

A11 the girls use it when they get married. Two days before the wedding, there is a dinner and all the relatives come. The women of both families use the henna. The woman's relatives take her to the man's house after she has the henna on and then the man's girl relatives put on henna.

It is not popular to use on the hair. It is not used for medicine. It is only popular for celebrations. It will continue to be done because the young are doing it more than the old.

Informant: 21

Country: Kuwait

Age: 
Sex: $\quad$ Mate

Background: This informant is from Kuwa it City and his family has lived in the city "for a long time."

Responses: Both men and women use henna for fever. They put it on the head. It is a secret that old women put it on their white hair. Some women put it on their hands but not just for weddings. Not too many girls are using it for weddings anymore. They just make the color on the hand; they do not make a pattern.

\section{Informant: 22}

Country: Kuwait

Age: $\quad$ Approximately 23

Sex: $\quad$ Female

Background: This informant is a Palestinian who was born in Kuwait. Her family went from Lod, Palestine in 1948 to Kuwait. She has spent much time in Egypt and married an Egyptian.

Responses: Henna is not used by many Palestinians in Kuwait. My mother does not like it but I have a sister who does like it. My sister makes flowers on her hands and feet because she likes it, but I think it is ugly.

I use it on my hair by mixing it with a little water in a stocking and rubbing the stocking over my hair. It is good for the hair.

Everyone hates to use it for the wedding because it stays for up to three months. The products are from Kuwa it or Sudan.

There was a film made about a wedding and there was a 10t shown about henna. It played in the movie house for three months and everyone hated it. It was made by people in Kuwait and Sudan. It was 
called "The Wedding of Zair."

It is not religious but it is old customs.

Informant: 23

Country: Iran

Age: $\quad 2 i$

Sex: Male

Background: This informant is from Baghdad.

Responses: My city is where the best henna comes from. We export it all over the world.

When women put it on their hands, they wrap the hands in material all night. This is so that it does not get all over the bed.

Some girls use it when they get married. They put it on their hands and around the feet but not on the top of the feet.

I think they use it more in the villages than in the cities.

You can mix it with water and put it on where the skin has problems.

Informant: 24

Country: Iran

Age: $\quad 21$

Sex: $\quad$ Female

Background: This informant is from Tehran.

Responses: Henna is used for sunburn, coloring naits and hair, and that is all. It is not used in any ceremonies. I don't think it was used for ceremonies in the past. 
Informant: 25

Country: Iran

Age: Approximatley 30

Sex: Male

Background: This informant is from the area by the Caspian Sea.

Responses: Henna is found in the markets just like any other cosmetic product. My father drives a truck that delivers henna to the stores.

It is used for drying the hair. I am not sure what they mix with it. That is up to the individual. You can mix water or whatever you like.

This is a very old thing to use. It is a natural product so it is better for you.

Informant: 26

Country: Bethlehem, Hest Bank

Age: $\quad 54$

Sex: Female

Background: This informant is a Palestinian woman who has lived in Bethlehem since 1948 and prior to that, was in Ramallah. I was a guest of the family for one week during August, 1980.

Responses: She does not use henna but she knows many women who use it on their hair. She had grey hair but did not care to cover it up with henna coloring. She remembered that it was used for hands and feet on special occasions, but it has not been used for those occasions for many years. 
Informant: 27

Country: Bethlehem, West Bank

Age: 23

Sex: $\quad$ Female

Background: This informant is the daughter of Informant 26 listed immediately above. She lives in Bethlehem and is married to a man whose family lives in various towns in the West Bank. When she was married, she did not use henna on her hands and feet. She was unfamiliar with any practices using henna except for dyeing the hair. She mentioned the Bedouin women have marks on their skin but thought that these were permanent (tattoos).

Informant: 28

Country: Bethiehem, lest Bank

Age: $\quad 29$

Sex: $\quad$ Female

Background: This informant teaches English at an all girl school in Bethlehem. She was married for one year and lived in Germany during that year. Her family is from Bethlehem.

Responses: We buy henna in the pharmacy to dye our hair. I do not think it is used for a medicine except that you can mix it with gasoline and put it on your hair if you have the very small bugs in your hair. We do not use it for any parties or occasions.

Informant: 29

Country: Bethlehem, West Bank

Age: 
Sex: $\quad$ Female

Background: This informant is a Lebanese Christian married to a

Palestinian Moslem. They have lived in Bethlehem for 31 years. I was a guest of the family for one week during September, 1980.

During my stay, she offered to show me how she puts the henna on her hair. She brought out four small plastic bags with henna in them. These were different grades of the powder. She mixed a few spoonfuls of three of the grades in a dish and mixed them with yogurt and water until she had a paste. The paste was applied to her streaks of white hair. (It was obvious that she had been doing this because the hair was white at the roots for about two inches but yellowish at the ends.) Then she placed a shower cap over her head. She slept this way and in the morning, she washed it out of her hair.

She commented several times that it had a beautiful smell. Her husband and son commented that the smell was terrible. (Their comments were in English and she was unable to understand.)

She said this was the only use for henna and that now the store had other products she could use, but she knew how to use henna and did not know how to use the other products.

Informant: 30

Country: Pakistan

Age: Approximateiy 60

Sex: Female

Background: This informant was in the United States visiting her daughter. Her English was limited to greetings and her daughter served as transiator. 
Responses: Henna is used by women to make themselves beautiful. I do not put it on my hands anymore. It takes a lot of time to make your hands and your feet beautiful. You must stop working for hours to put it on. We would do it when we had company and all the work was done. You can mix it with water or with some lemon juice added. This can be for the hair or for the hair or for the hands and feet. It has to be almost like water to put it on your hands.

Men do not use it. Some small children have it on them but it is hard for children to stand still.

It is not for Islam but it is a good thing because it is beautiful.

Informant: 31

Country: Pakistan

Age: $\quad$ Approximately 40

Sex: $\quad$ Female

Background: This informant is the daughter of informant 30 listed immediately above. She was raised in Pakistan but is attending school in Portland.

Responses: Women in my country stil! use henna for decorating but it does not have to be a party or a wedding. Some of the women cut circles or other decorations in gloves and then put the henna on. This is easier. It is not religious but it is an old custom. You can make it darker by adding fire ashes to the henna. It stays on for one month. We don't use it for any medicine. 
Informant: 32

Country: Pakistan

Age: Approximately 30

Sex: $\quad$ MaTe

Background: This informant has lived in the United States for approximately 8 years. He is from a large city in Pakistan.

Responses: The women in my country make beautiful decorations on their hands and feet with henna. They mix it with water and put it on with a stick which is very sharp on the end, or a needle. It sits on the hands and feet until the color is good. When there is a marriage, the families henna each other's hands and feet; it is a very old custom. It is not Islamic. (He offered to draw some pictures and they are Figures 8,9 , and 10 of Appendix C.)

Informant: 33

Country: Qatar

Age: $\quad 22$

Sex: Male

Background: This informant is from Doha. His family is there and in Bahrain.

Responses: The girls make pictures on their hands and their feet. older women don't have much time for it and very old women have lots of wrinkles on the hands $s$ iney don't put it on. My sisters do it in a group but the young ones don't leave it on for enough time.

They mix it with water and tea. They sit in the garden so it dries faster, maybe three or four hours. They make flowers and hearts 
on the hands and a lot of lines. The girls getting married do this a few days before the wedding.

It is not a medicine to eat but I have heard people use it on the head for headaches. It is also good for the eyes but I don't know how they make it good for the eyes.

It is not religious but it is a good thing; maybe it is in the Koran.

Informant: 34

Country: Qatar

Age : $\quad 24$

Sex: $\quad$ Male

Background: This informant said his family was not from a city.

Responses: I have no sisters but my mother and cousins and aunts use henna on their hair. They put oil on their head and mix it with henna. It is 1 ike washing your hair with it but you leave it on for the night. It gets all over the bed so they put plastic down on the bed. They have cloth around their heads but it sometimes comes off.

They use it for weddings. The bride and all the women in her family can have it on. The bride must have it on her hands and feet. Even the bottom where she walks.

It can be put on cuts or blisters. That is the only time men use it.

It is not religion; I don't know where it comes from but it is an old thing to do. 
Informant: 35

Country: Qatar

Age: $\quad 22$

Sex: $\quad$ Female

Background: This young woman was approached by myself during October, 1979. She was a student and recently married. When asked if I could interview her about henna, she asked why. After I explained, she said she did not want to answer any questions.

Informant: 36

Country: Bahrain

Age: $\quad$ Approximately 24

Sex: Female

Background: This informant was part of a group of girls who perform folk dances and sing. The interview was brief and consisted of questions concerning henna on her feet. She explained that the pattern was her own choice and her feet were hennaed because she was the bride in one part of the folk dance performance. Her hands were not done because they could not be covered from the public. The pattern on her feet can be seen in Appendix C, Figure 45.

Informant: 37

Country: Bahra in

Age: $\quad$ Approximately 22

Sex: MaTe

Background: This informant was from a city. His family is in Bahrain and Saudi Arabia. 
Responses: Henna is a beautiful thing. The color is a good color. I have a lot of respect for girls and women who use it on their hands and feet. A lot of women use it on their hair and old men do that, too. They put it on their beards like Mohammed did.

In my country, all the brides use it; I think in the Gulf area it is the way but not in places like Egypt.

I think they just mix it with water. They get it from Sudan or from India. It is the same from anywhere.

It is possible that it is good for your skin and the hair but not as a medicine.

Allah makes this a special tree that has a good smell. So the smelt on the head and the hands is good but it leaves fast. It is not reigious like praying but it is nice for good women.

\section{Informant: 38}

Country: Iraq

Age: $\quad 23$

Sex: Male

Background: This informant is from Baghdad.

Responses: Henna is used to make the hair red. Girls use it for that but old women in the hills probably still use it for other things.

It is not popular with girls 16 or 171 ike my sisters and my mother doesn't use it.

Maybe a long time ago they used it more. 
Informant: 39

Country: Iran

Age: $\quad$ Approximately 21

Sex: $\quad$ Female

Background: This informant is from just north of Tehran. Her famity is Jewish.

Responses: I think henna is used to color hair but that is done here too. We don't use it for anything. Maybe some people in other areas use it, especially people in the areas where there are small villages.

\section{Informant: $\div 0$}

Country: Iran

Age: $\quad$ Approximately 24

Sex: Male

Background: This informant is from just north of Tehran. His family is Jewish. He is the brother of the informant (39) Tisted immediately above.

Responses: I have not seen it used by anyone. It is a product for the hair; I think they use it to make it red in the sun.

Informant: 41

Country: Lebanon

Age: Approximately 30

Sex: Male

Background: This informant is a Lebanese Christian from a large city. Responses: Henna is used as a hair dye but also commercial products are used. I have not seen it used for dyeing the skin. I think 
Lebanon is more European than any other Arab country so this is not done.

Informant: 42

Country: Lebanon

Age: $\quad$ Approximately 26

Sex: $\quad$ Male

Background: This informant is from Beirut. His family is there and in various places in the United States.

Responses: I remember seeing some very old ladies with this coloring of yellow on their hands, maybe on the feet but that I don't remember. I have been to many weddings but I don't remember ever seeing this at a wedding. My sisters and my mother don't use it. Maybe it is in medicine but I never heard of that.

Informant: 43

Country: Lebanon

Age: $\quad$ Approximately 24

Sex: $\quad$ Female

Background: This informant has lived in Beirut and Morocco and the United States. She has family in Beirut and in the United States. Responses: I saw it used a lot in Morocco and a woman put it on me there. She did a beautiful design with a tiny stick. It took about three hours to dry. We had friends getting married so that's the reason. They spend hours doing this before a wedding. Every girl has it on. 
I think it was never popular in Lebanon. Some people there use it on their hair but now it is in the products you can buy.

Maybe it is religious in Morocco but I think it is not supposed to be.

I don't know what she mixed with it because it was in a bowl before I got there.

Informant: 44

Country: Saudi Arabia

Age: $\quad$ Approximately 45

Sex: $\quad$ Female

Background: This interview was conducted over the telephone with the informant's son as translator. The son, a personal friend, was informed of this research and mailed a sample of henna to me. The mother wanted me to know the directions of how it should be used. I was told the henna was from sudan. It should be mixed with tea and lemon, then left to settle for one day. It can then be used to apply as a paste to do hands or feet to make patterns.

A Sudanese woman had recently made a pattern of stars and flowers on the informant's hands. I was given the impression that the Sudanese, in general, are known for their patterns as well as the quality of their henna.

Informant: 45

Country: Egypt

Age: Approximately 30

Sex: $\quad$ Female 
Background: This informant is an American who has spent approximately five years in Egypt. The following is her summary.

Boys ages 5 and 6 are circumcised and henna is put on their hands for that. At birth, the women in the new mother's family put henna on their hands. It is used at the engagement party and one day before the wedding, the bride's hands and feet are hennaed. The Zar uses it on the woman who is having the exorcism. It is mixed with yogurt or water.

\section{Informant: 46}

Country: Afghanistan (and India)

Age: $\quad 25$

Sex: $\quad$ Female

Background: This informant is an American who traveled through India, Afghanistan and the Far East.

Responses: I saw a lot of women with orange hands and I did not know what it was. I was going to go to a wedding so the women I was staying with told me to hold a lump of clay in my hands for awhile. After a couple of hours, they let me open my hand and then I knew why everyone had orange hands. It stayed for about four weeks and people in Japan kept looking at me. My thumb was still yellow six weeks later when I got back to the United States.

Informant: 47

Country: Morocco

Age: $\quad$ Approximately 45

Sex: $\quad$ Female

Background: This informant is Elizabeth Fernea. She was at Portland 
State University on May 20, 1980. After I explained my research, she tole me she was not aware of any research concerning henna but recommended some references which proved useful (Westermarck, 1914 and Granquist, 1947).

She told me that henna is the first gift a man gives to the woman he wishes to marry. The "henna party" occurs the night before the wedding.

The hands and feet of the bride-to-be are covered with henna. Designs may be painted on the legs.

\section{Informant: 48}

Country: Syria

Age: $\quad$ Approximately 60

Sex: Mare

Background: This informant has Tived in the United States for many years but shared on several occasions, memories of his knowledge of the uses of henna.

Henna was used on his feet once when he was a boy because he had a skin irritation.

When a class of boys finishes reading the Koran for the first time, there is a celebration. Henna is put on the boys' hands and they are wrapped overnight. A stocking would be placed on the hand like a glove over the wrapping.

\section{Informant: 49}

Country: Israel

Age: 25 
Sex: Female

Background: This informant is from the United States but spent five years in Jerusalem and in the Gaza Strip.

Responses: I have seen women in Gaza with very orange hair. They cover up the grey with henna but it turns it an unnatural orange. Some of the older Bedouin women have the dark tattoos and then put henna on their fingernails. You don't see much of it in Jerusalem. I never saw a young girl with it on her nails.

Informant: 50

Country: Egypt

Age: $\quad$ Approximately 27

Sex: $\quad$ Female

This informant is an American who has done research concerning Ancient Egypt and heirogiyphics. She felt that ochre was used very eariy in Egypt for red coloring, but was replaced gradually by henna. It appears to her as if both colorants were used for similar reasons for several centuries. She felt that there was a possible economic class distinction between users of ochre and henna, the lower classes using henna. She could not state specific reasons for this opinion, but stated that it was the feeling she had received from literature. 


\section{APPENDIX B}

\section{METHODS OF APPLICATION}

\section{Hands and Feet}

A. Make a paste of henna powder and water. This should be thick enough to make into sticky balls. Place a ball in the center of the paim and make a fist around it. Bind the hand with a cloth and let it sit for twelve hours to one day, depending on the color you desire. The paste is smeared over the bottom of the foot and it is wrapped with cloth. The same instructions concerning time apply to the feet. At the end of the specified time, scrape off all the dried henna and rub the areas with oil and lemon. This procedure results in a solid color on the palms of the hands and the soles of the feet. A pattern can be created on the hand by cutting a design in a glove and wearing it during the procedure.

B. In separate bowls, mix one paste of water and flour and one of henna and water. The flour paste should be thick, the henna paste should be a little thinner. Apply the flour paste to the areas you wish to remain flesh colored. Apply the henna paste to the areas you wish to dye. Bind the hands and feet for approximately twelve hours. Rub the areas with oil and lemon after removing henna and flour.

This procedure allows a pattern to be created.

C. Make a paste of henna, tea and water ( 1 part tea to 2 parts water). Strain the mixture through a fine cloth and set the liquid 
aside up to 24 hours (Fig. 2). Discard the residue in the cloth. The liquid, which has now slightiy thickened, can be applied to the skin by using a thin twig, a pinhead, or an item such as an unbent hairpin (Fig. 3). Let the henna paste dry, applying a syrup of 1/4 cup water, 3 teaspoons sugar and two drops lemon to the henna when it appears dry (Figs. 4 and 5). Appiy to dry henna for six hours by soaking a cotton ball in the syrup, then apply oil to the area and rub henna off (Fig. 6).

This procedure allows a pattern to be drawn on the area (Fig. 7).

NOTE: The informant stated that there was a special cloth one could purchase for straining henna. There is also a special applicator which is a sharpened stick. When demonstrating this method, she used a nyton stocking for straining (Fig. 2) and thought it was superior to the special cloth. She commented that she was going to tell her sisters about this discovery. She used a hairpin to apply the liquid (Fig. 3). She used a vegetable oil to remove the henna but stated that she would use only eucalyptus oil if she were in the Middle East.

D. One informant was aware of a plastic pattern which could be placed upon the hand or foot and then henna paste could be smeared around it. She said that it is becoming popular with the women in Pakistan. This informant owns an import shop in Seattle. She has ordered some of these plastic patterns but, as of this writing, she has not received them.

II. Hair

A. The following methods are for dry hair.

1. Apply a paste of henna, yogurt and water to dry hair. Wrap the head with a cloth and allow the henna to dry for 6 to 24 hours. 
Figure

Page

2 Woman from the United Arab Emirates straining henna

3 Application of strained henna by using metal hairpin

4 Henna drying after pattern has been completed

5 Henna moistened by water, sugar and lemon mixture

84

6 Scraping off henna with the aid of vegetable oil

85

$70 i 1$ coated paims after the removal of henna 


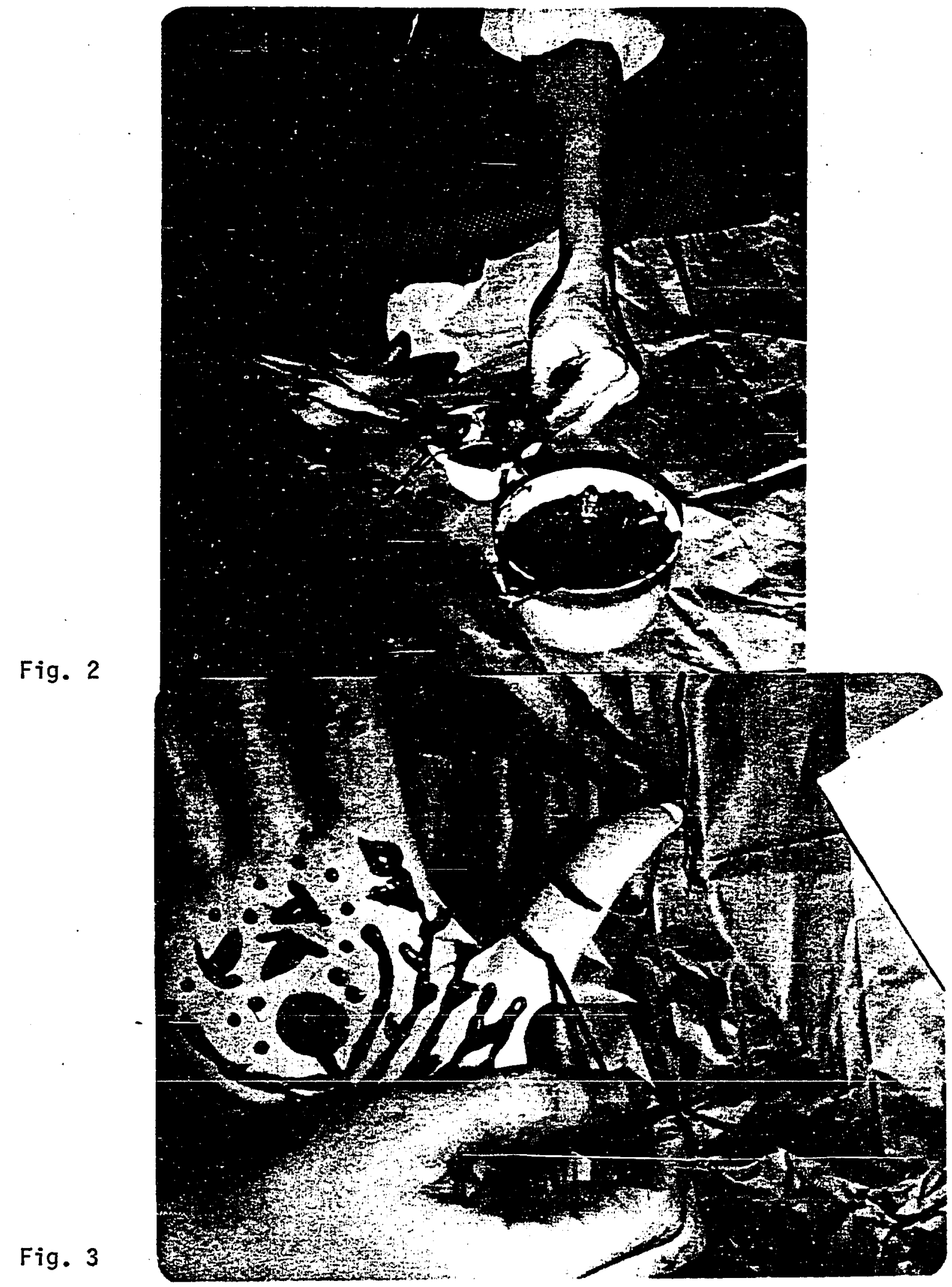


Fig. 4
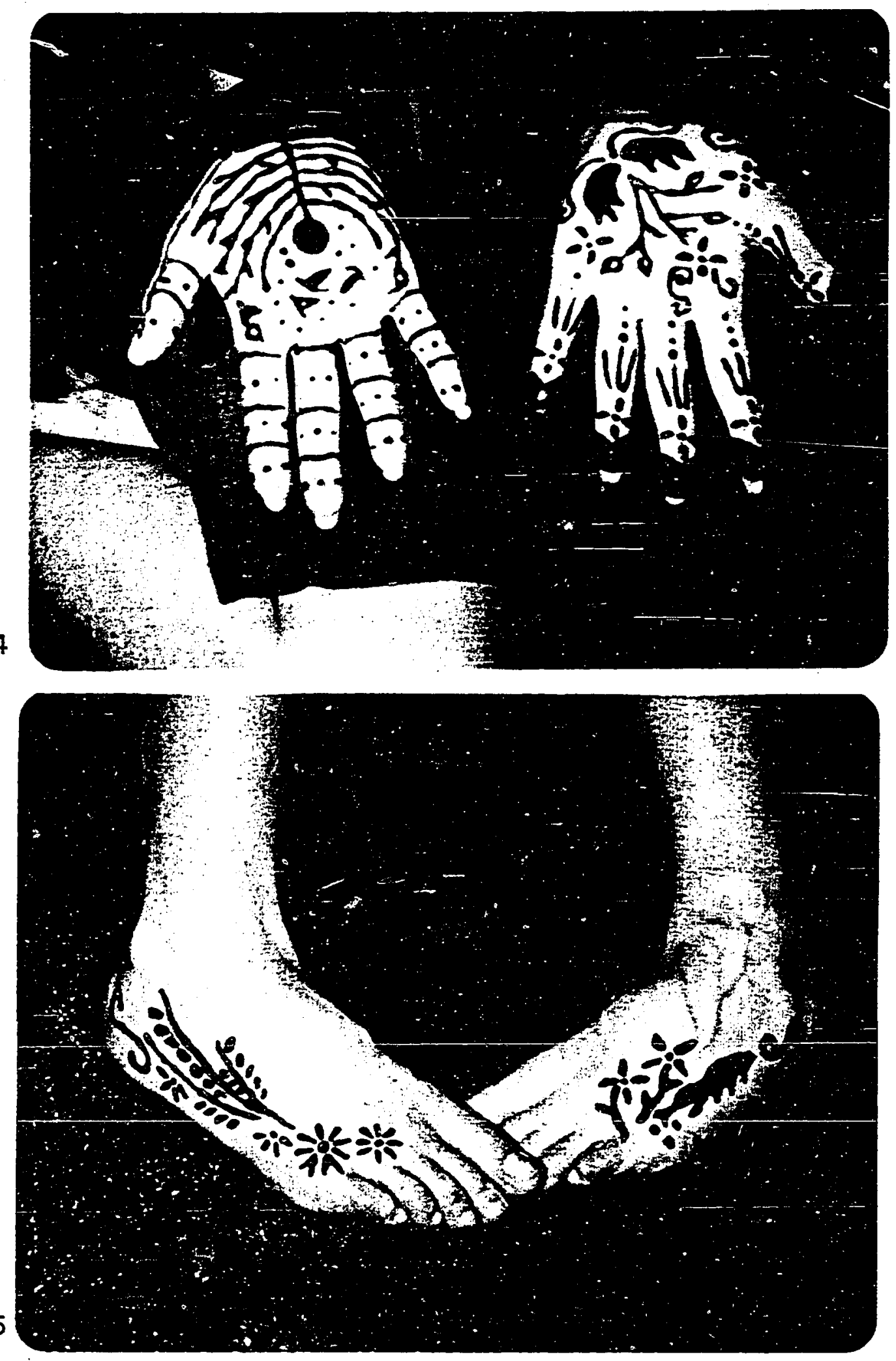

Fig. 5 


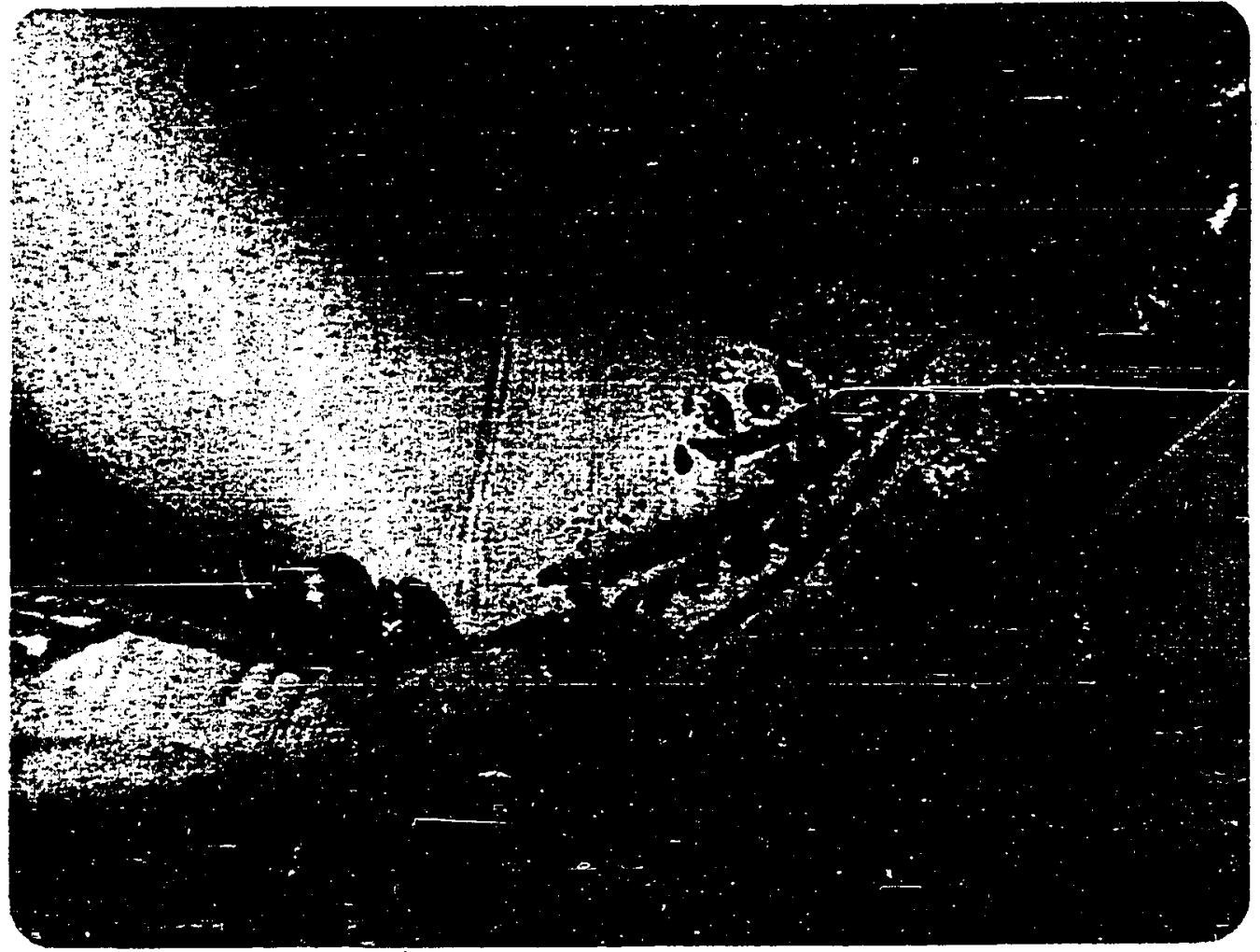

Fig. 6

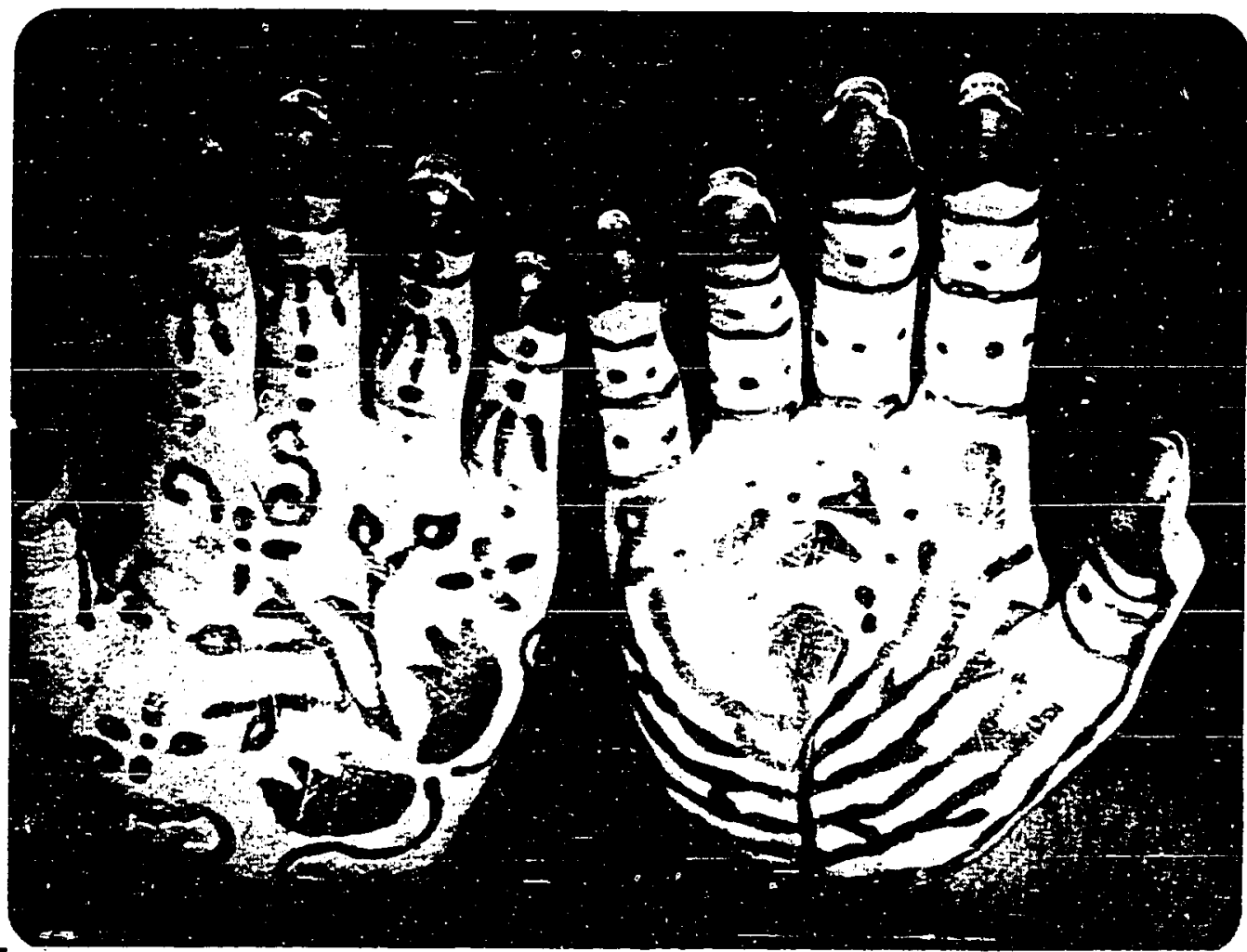

Fig. 7 
2. Comb ol ive oil through the hair. Apply dry henna powder to the hair and rub it in. Wrap the head in cloth and allow it to stay on the hair for 24 to 48 hours. The hair may be braided into six braids before wrapping.

B. The following method is used for oily hair.

1. Apply a mixture of henna, water and vinegar or lemon juice to dry hair. Wrap head with cloth and allow it to dry for 6 to 24 hours.

C. Variations

1. Normal hair can be colored with a paste of henna and water. Honey may be added.

2. Liquid tea can be added to the henna to help set the color.

3. Liquid coffee can be added to the henna to alter the color.

4. Ash can be added to the henna to alter the color.

5. Gasoline can be added to the henna. The reason may be due to its ability to rid the hair and scalp of insects.

6. The process may be shortened with the assistance of an electric hair dryer. 


\section{APPENDIX $C$}

\section{FIGURES}

The following figures are examples of patterns used by women when staining their hands and feet with henna.

Figures 8,9 and 10 were drawn by a Pakistani male. He stated that these were patterns he remembers from weddings. Figures 11 through 42 were taken from a notebook kept by a Saudi Arabian woman. These are patterns she has used. The patterns shown in Figures 43 and 44 were drawn by another Saudi Arabian woman. These were her wedding patterns. Figure 45 is a Bahraini pattern worn by a folkdancer for a role she played as a bride in a presentation. The Kuwaiti pattern shown in Figure 46 is shown in Dickson (1949:159). Figures 47 and 48 are packagings from Sudan and Egypt. 

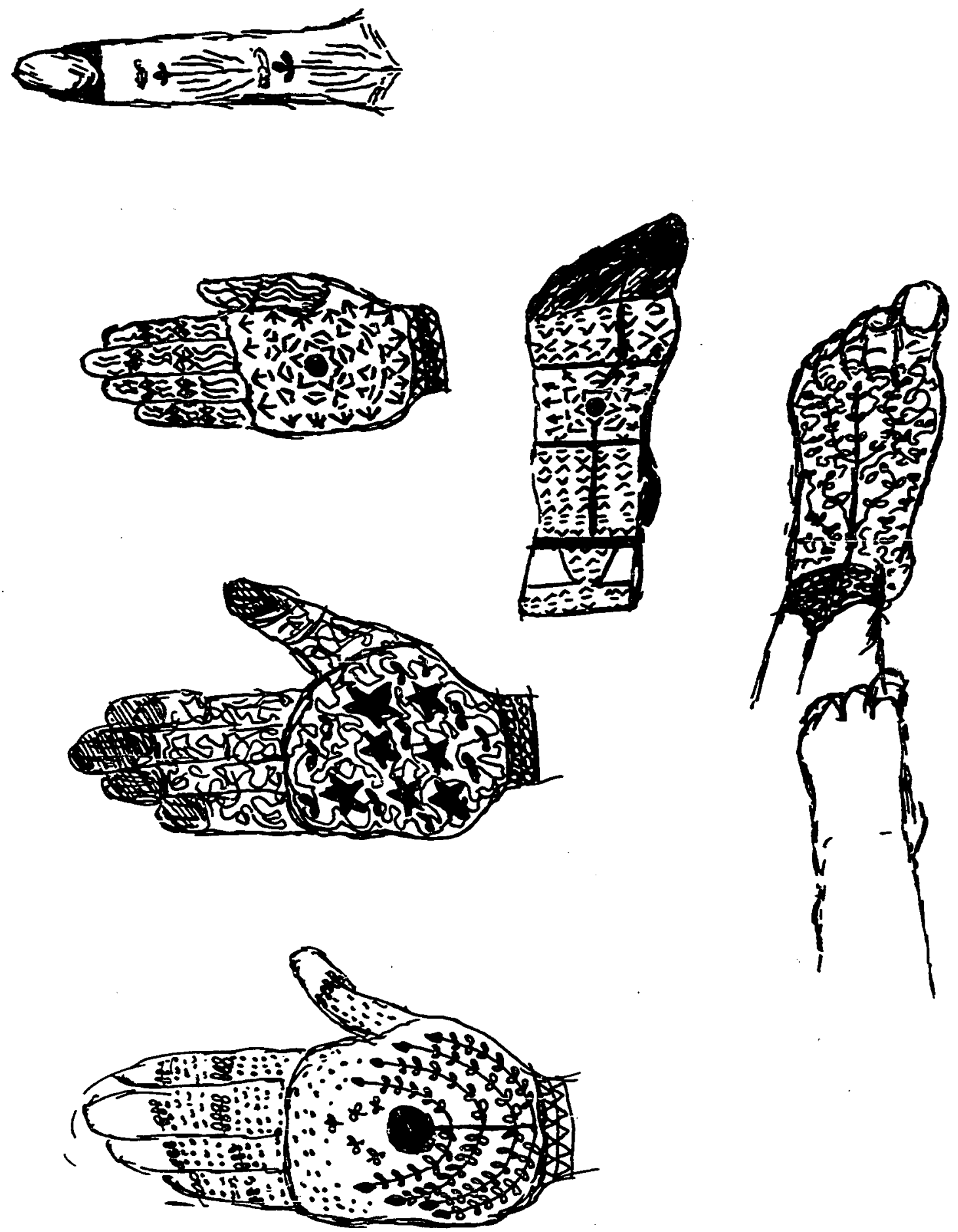

Figure 8. Drawings by Pakistani male. 


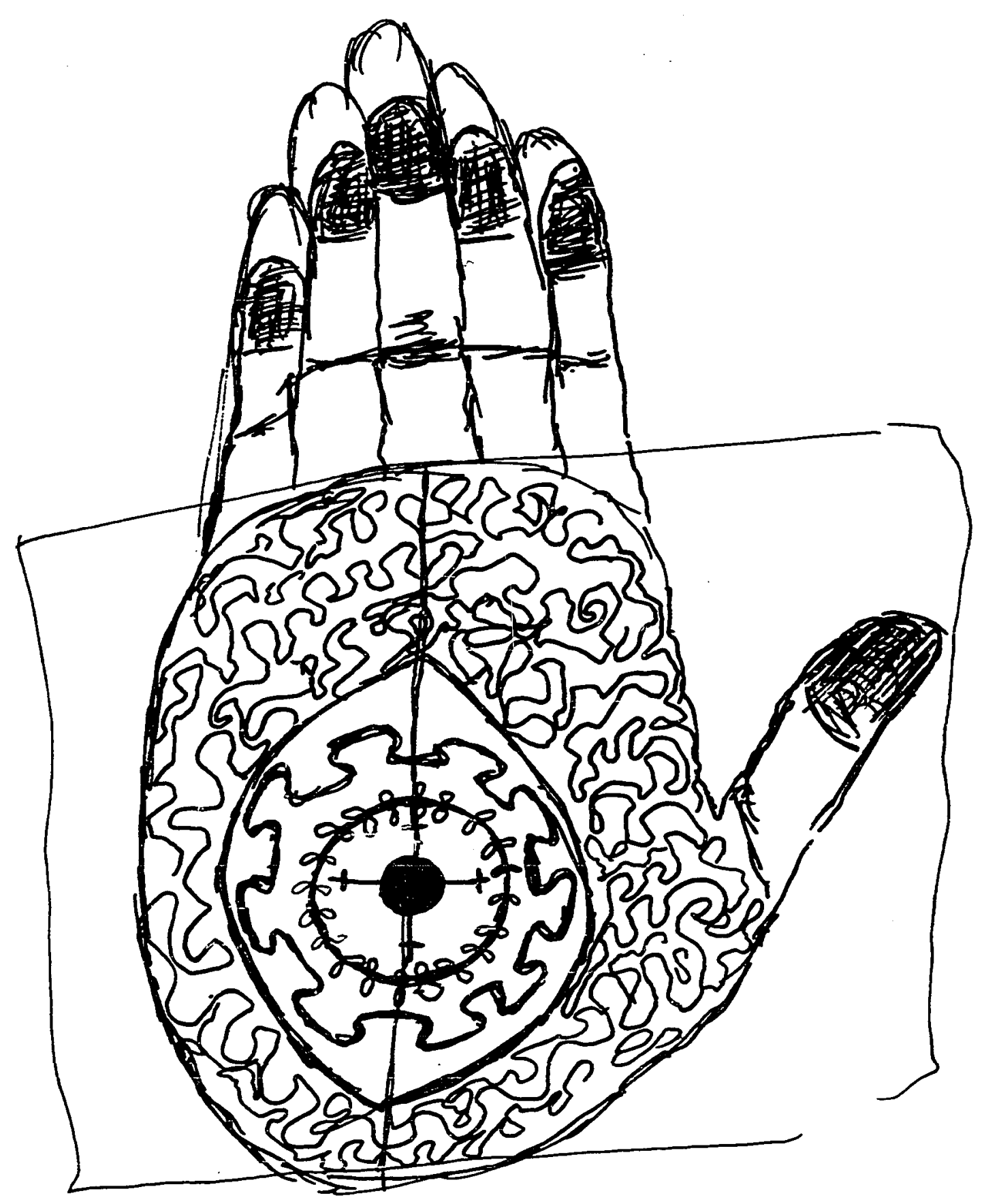

Figure 9. Drawing by Pakistani male. 


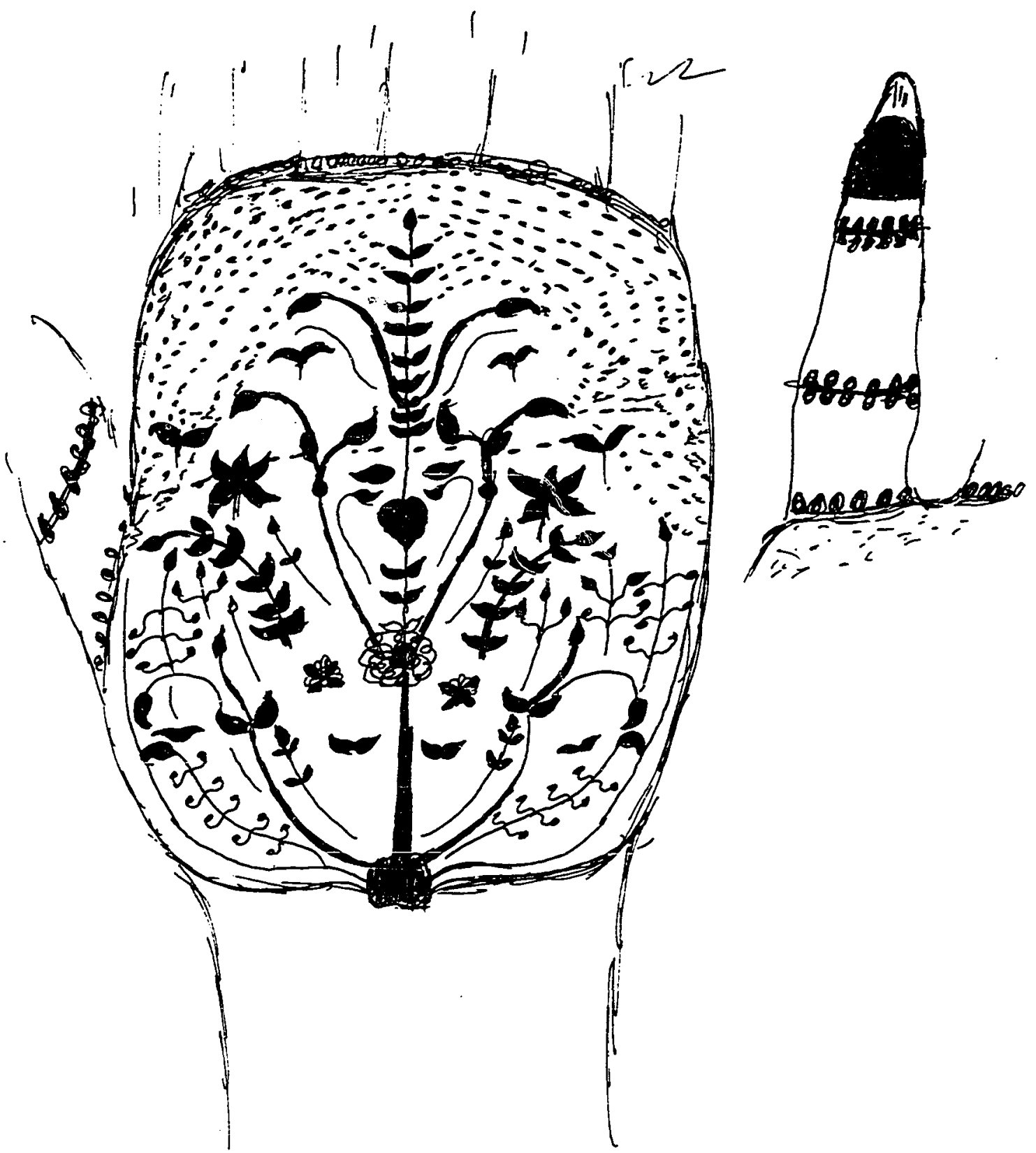

Figure 10. Drawing by Pakistani male. 


$$
\begin{array}{r}
. \\
+\quad 91
\end{array}
$$
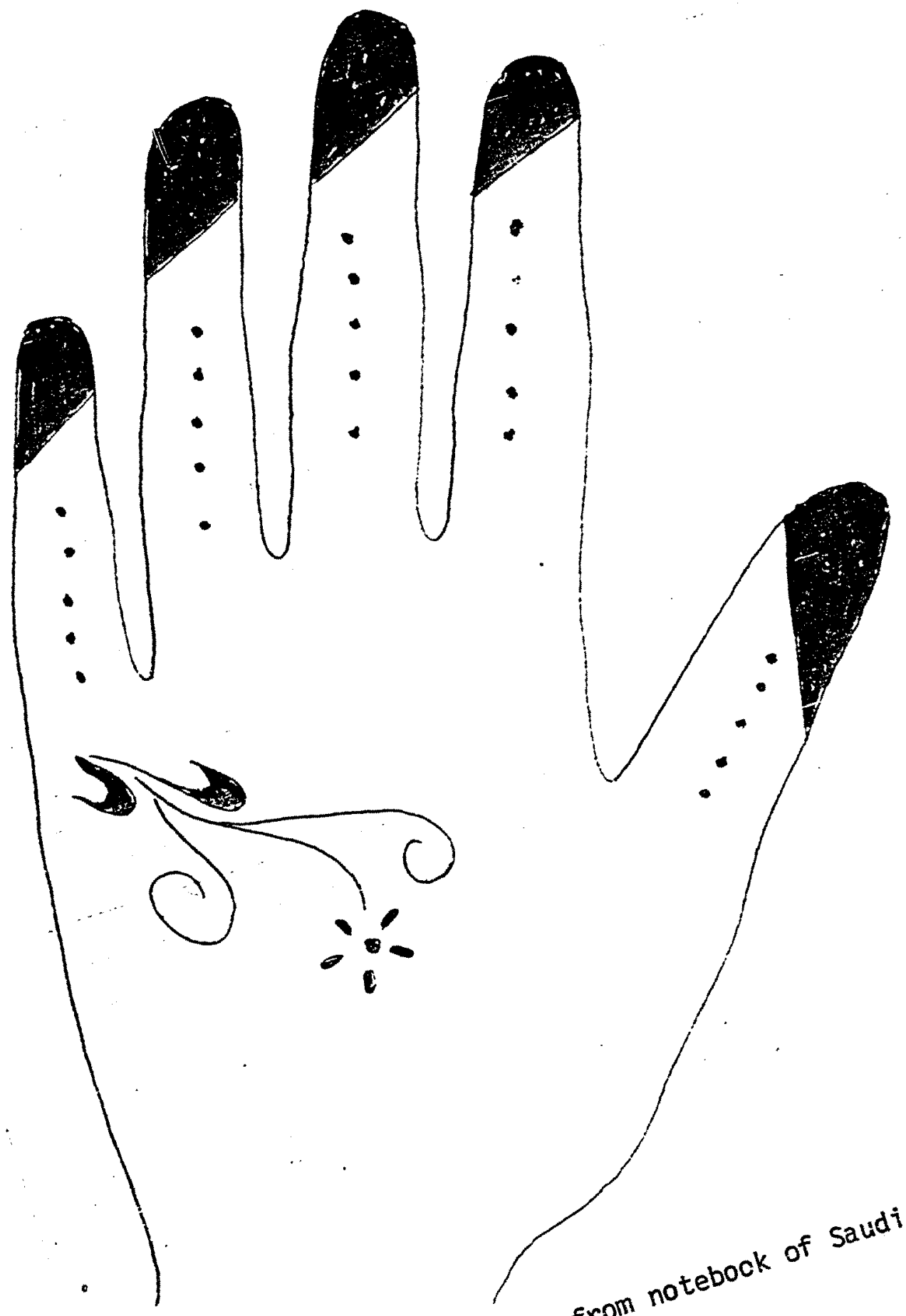

Figure 11.

Reproduced with permission of the copyright owner. Further reproduction prohibited without permission. 
$r$

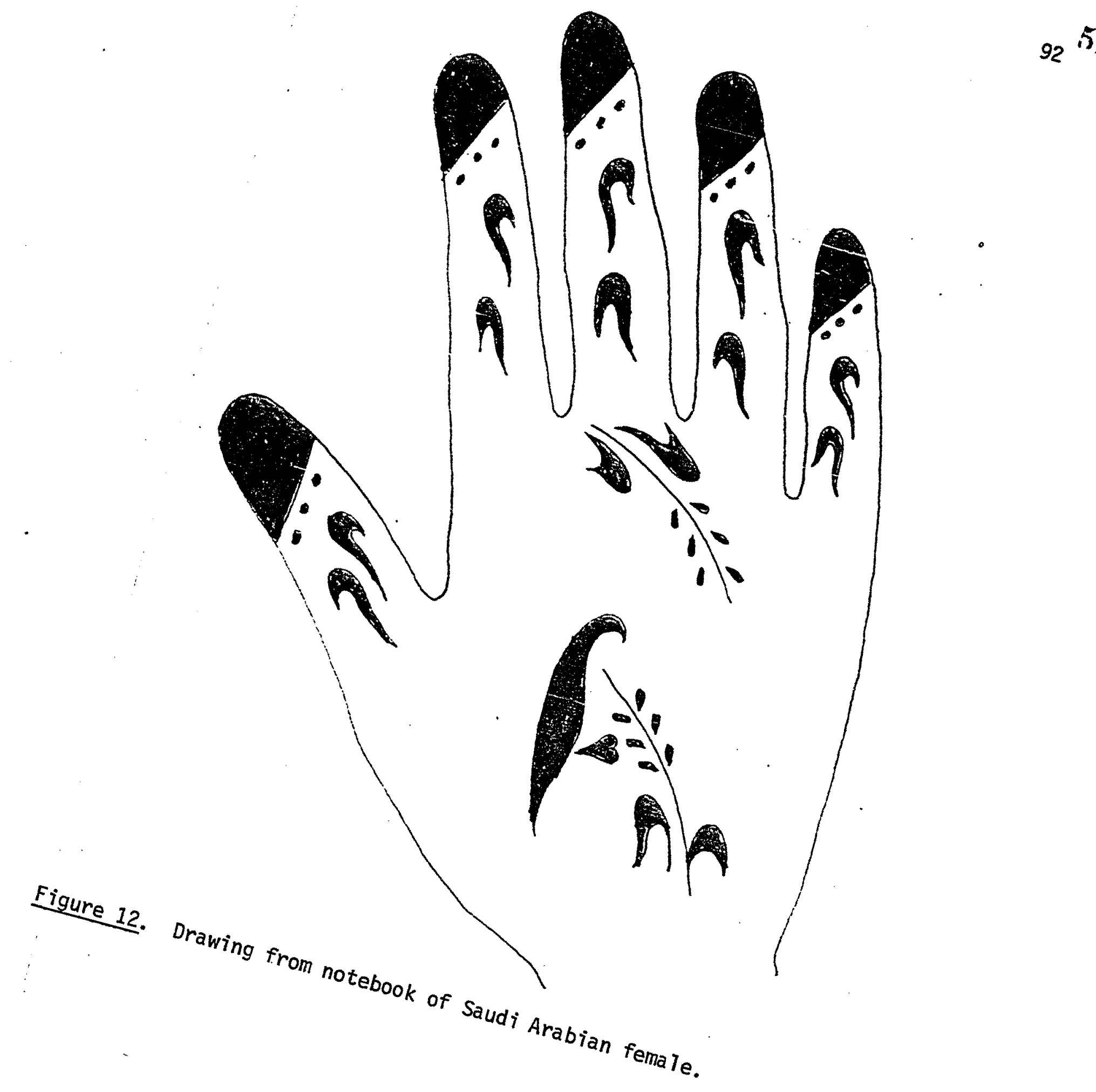


93

6

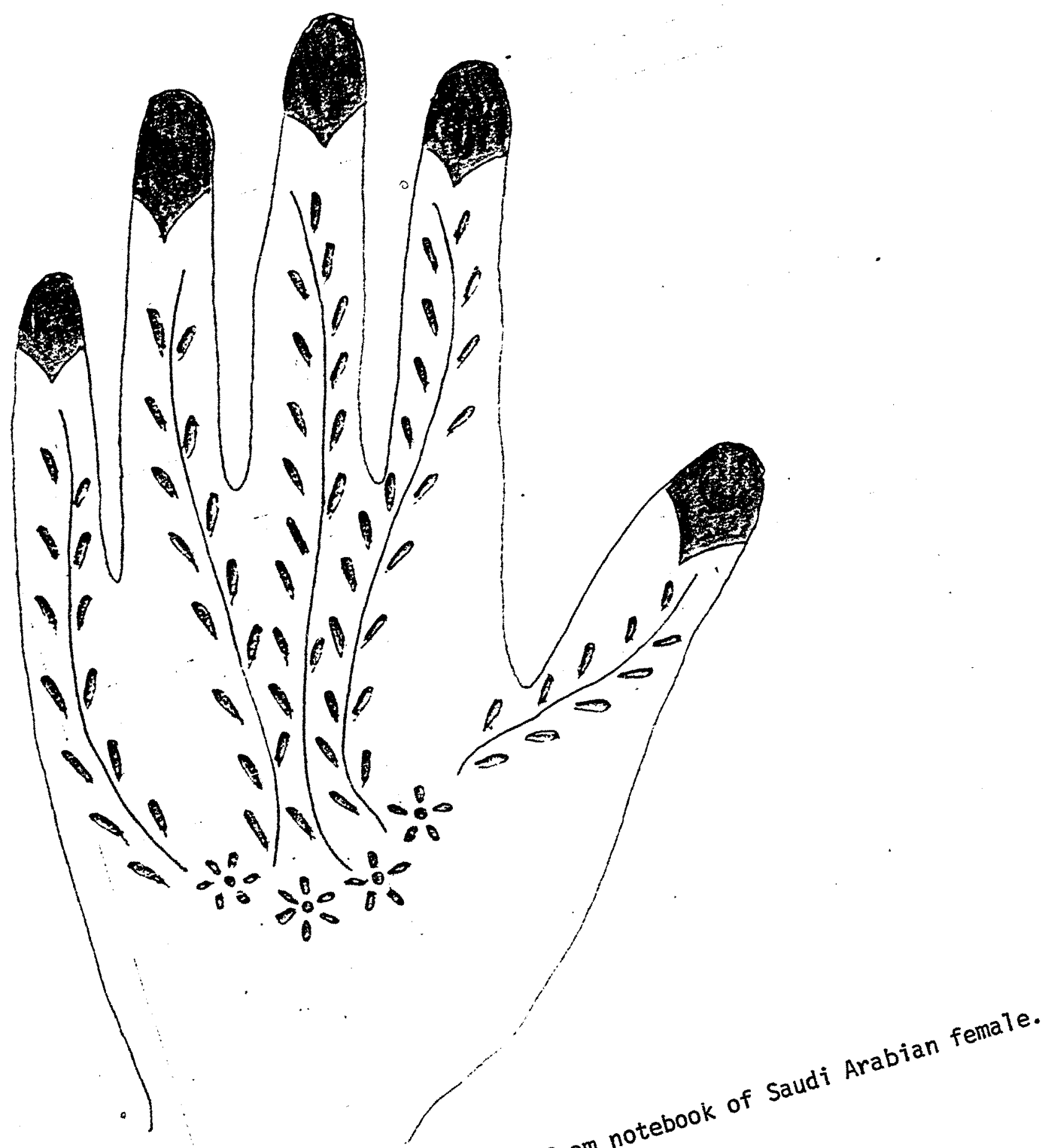

Figure 13. Drawing from notebook 


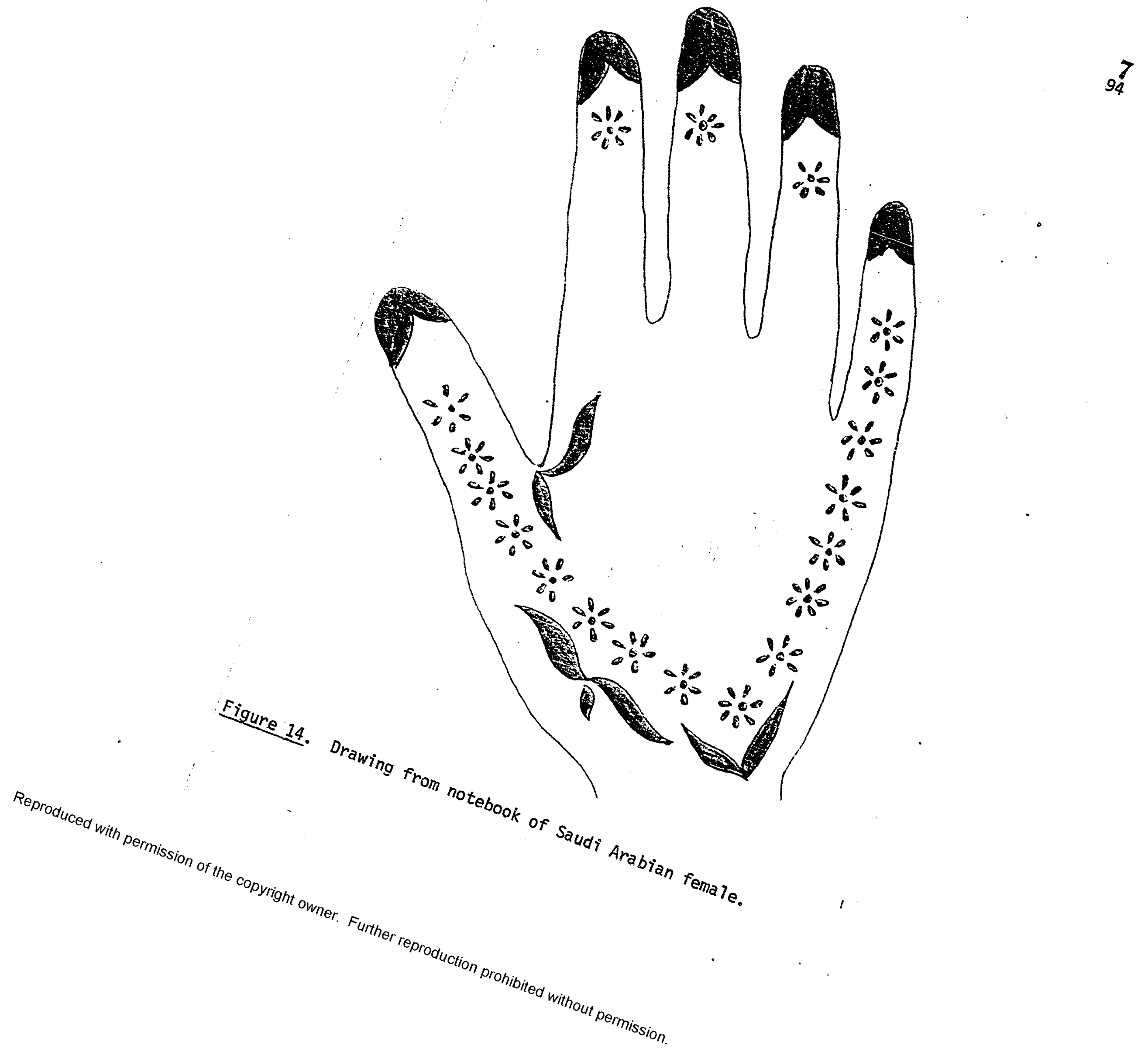




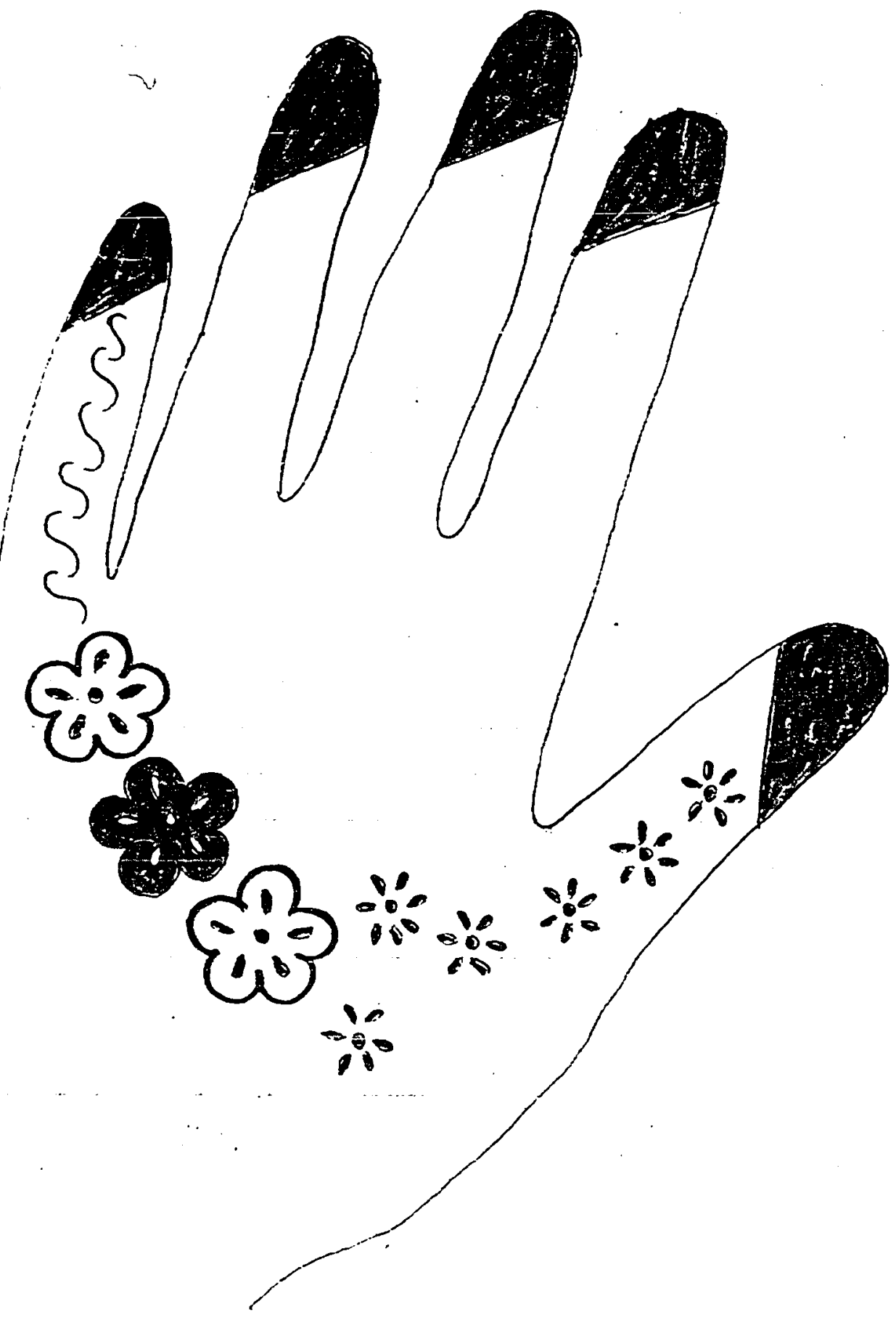

Figure 15. Drawing from notebook of Saudi Arabian female. 


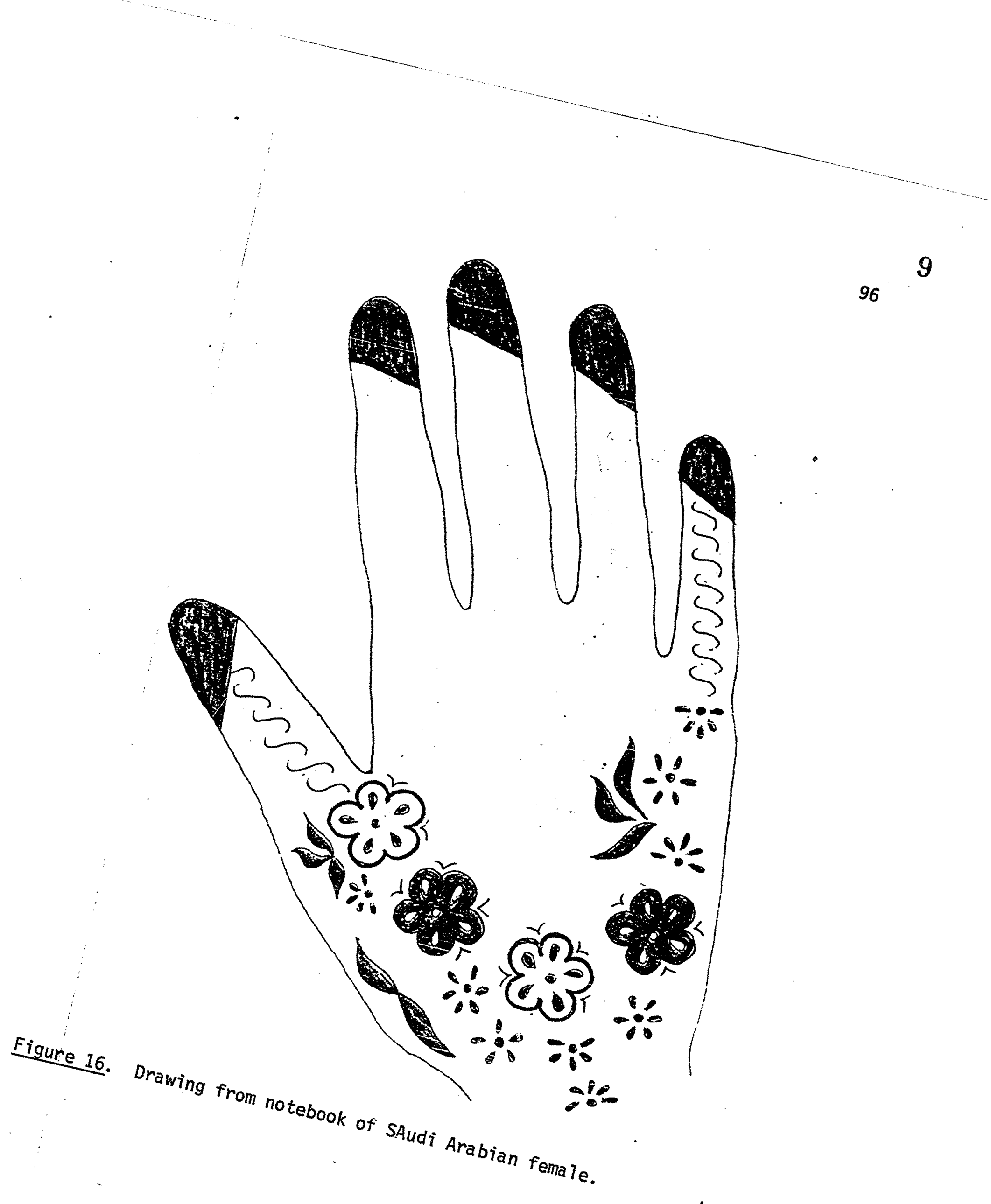


97

13

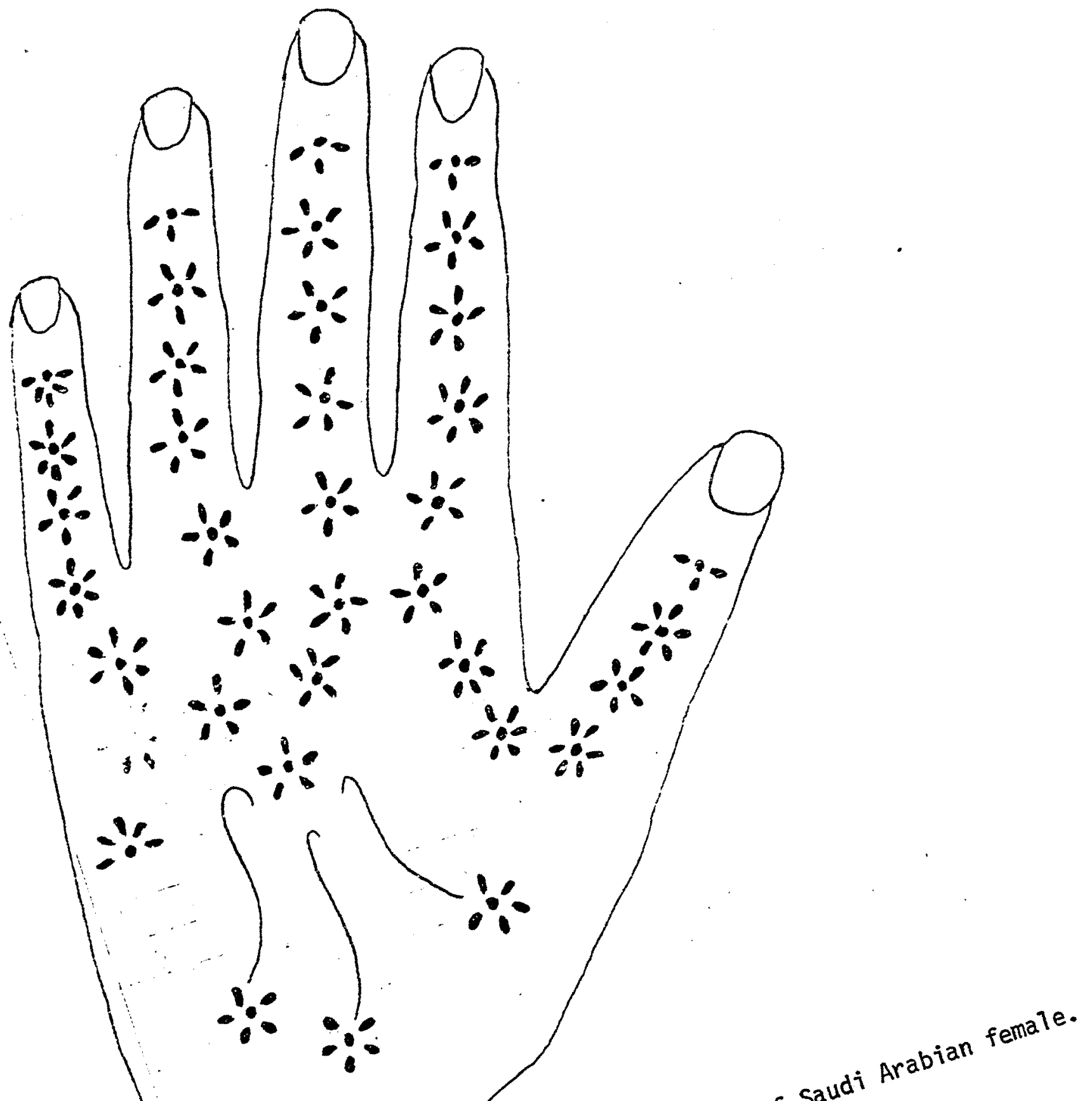




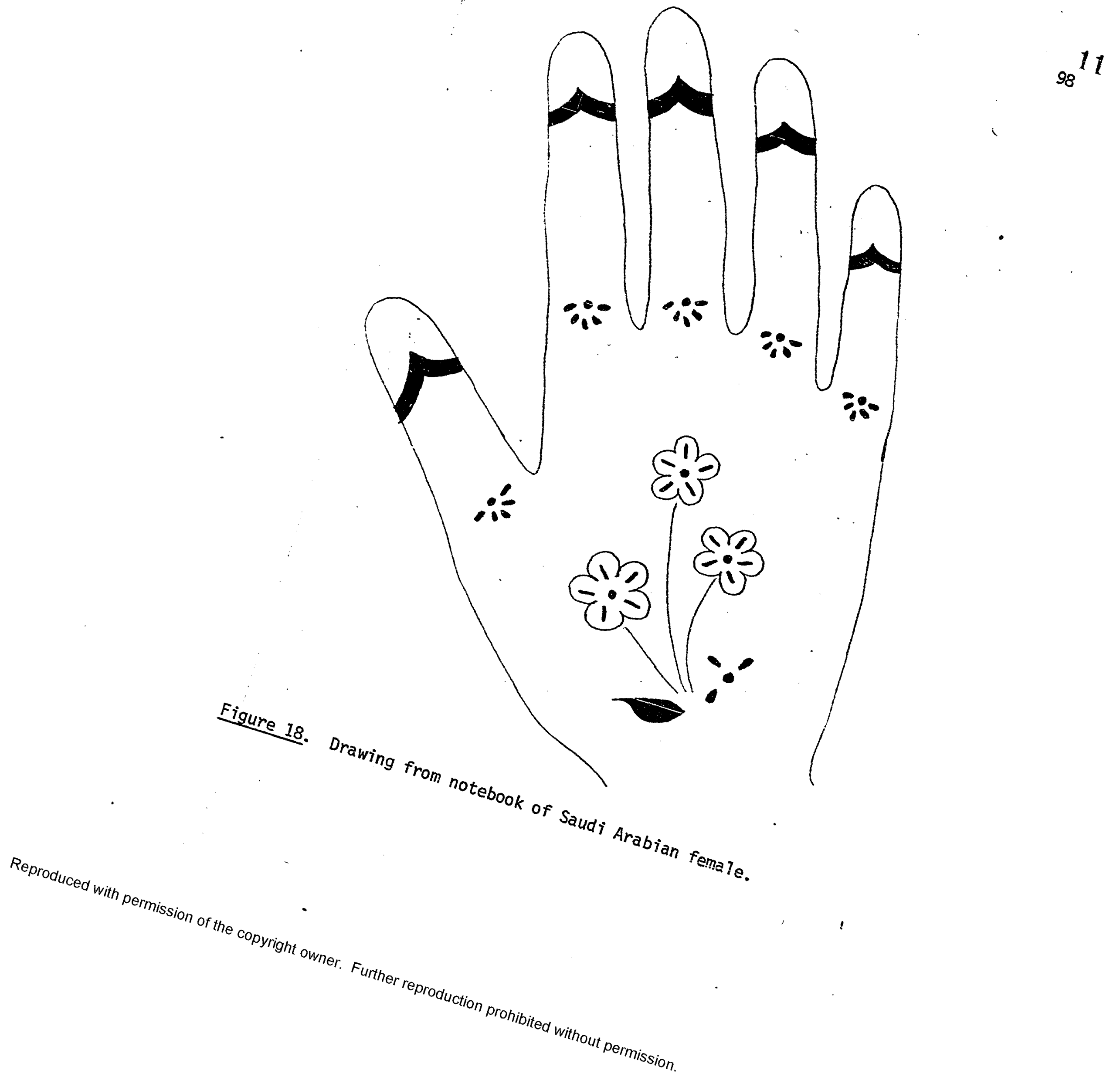




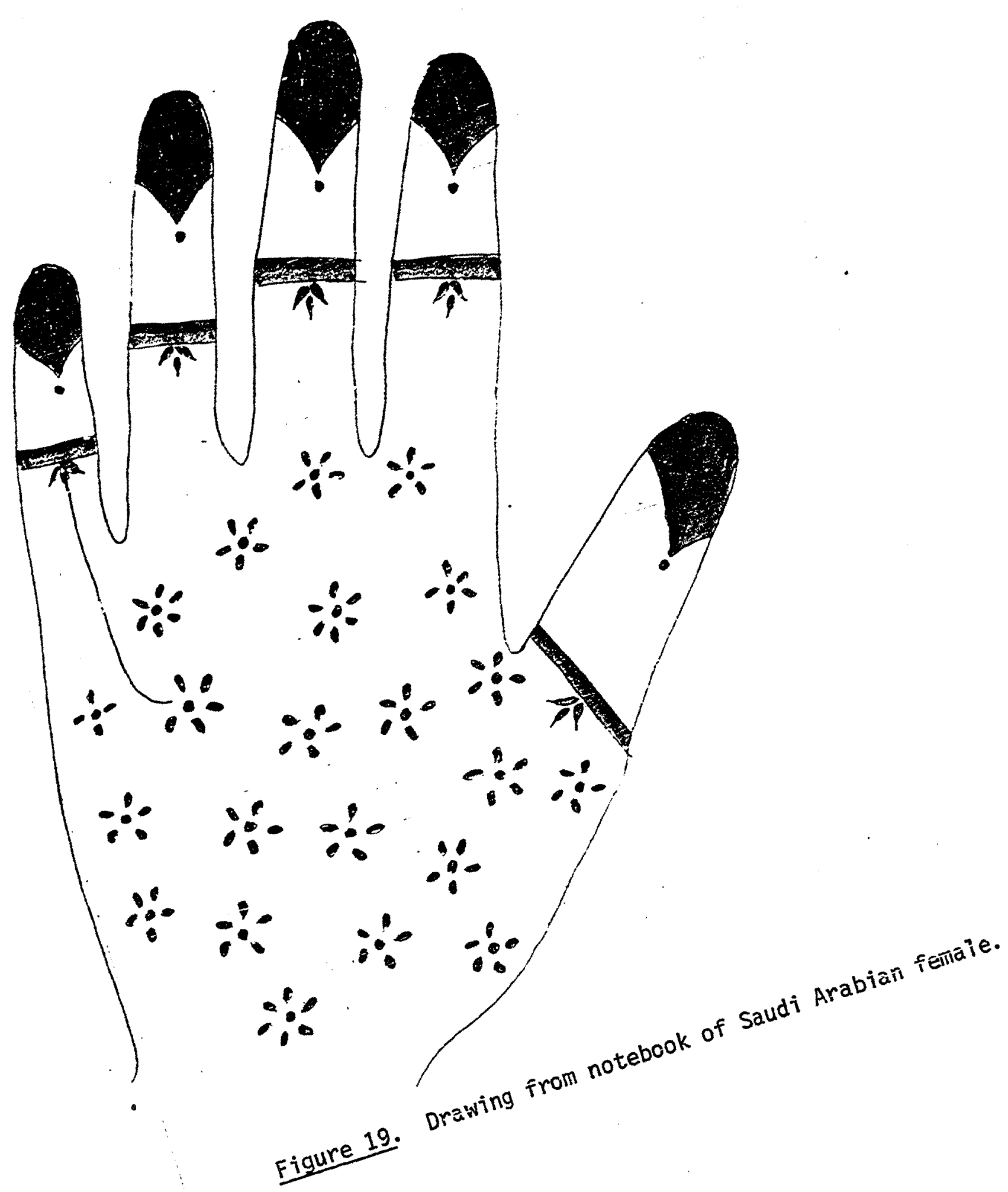

12

rermission. 

101
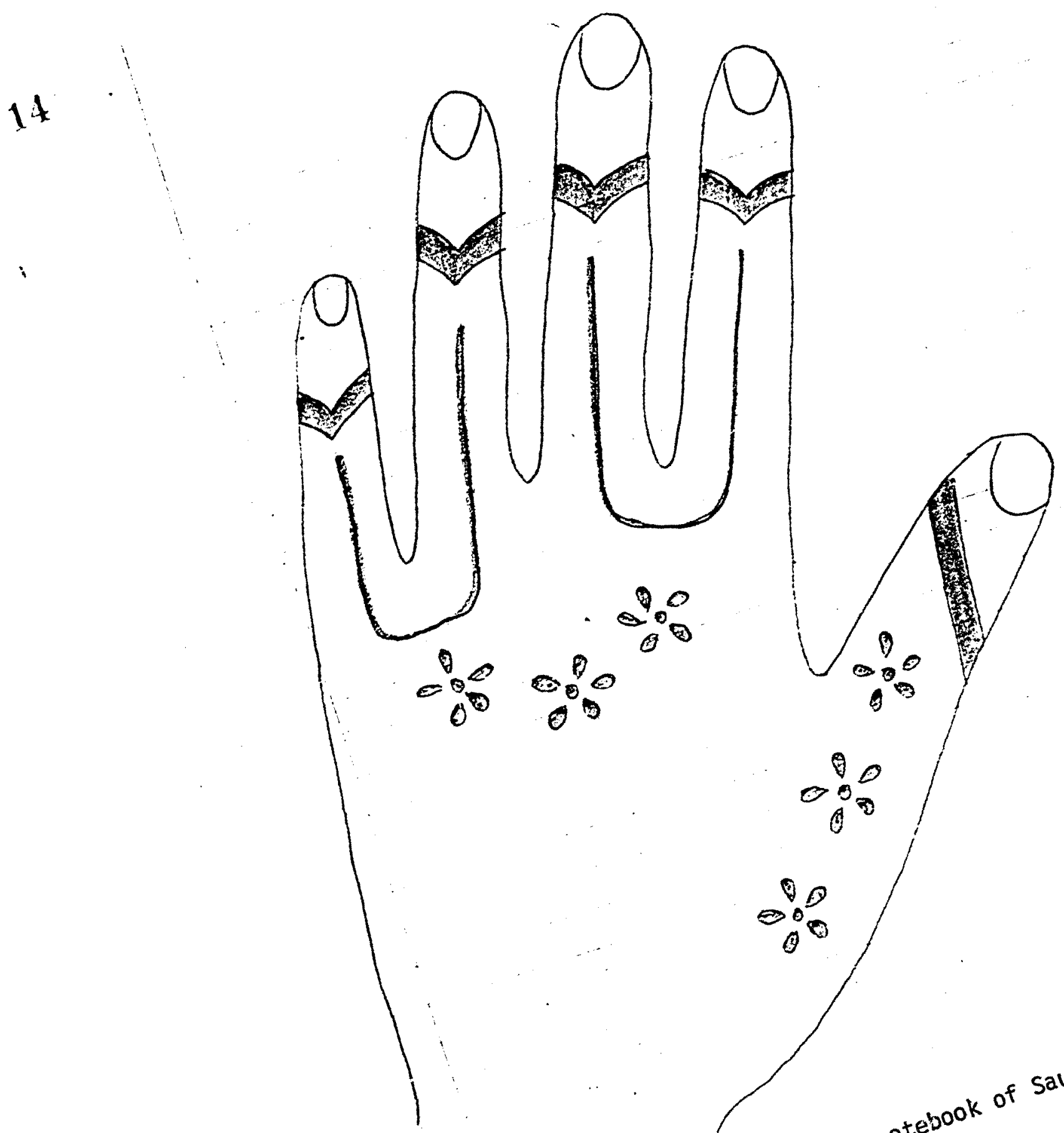

Reproduced with permission of the copyright owner. Further reproduction prohibited without permission. 


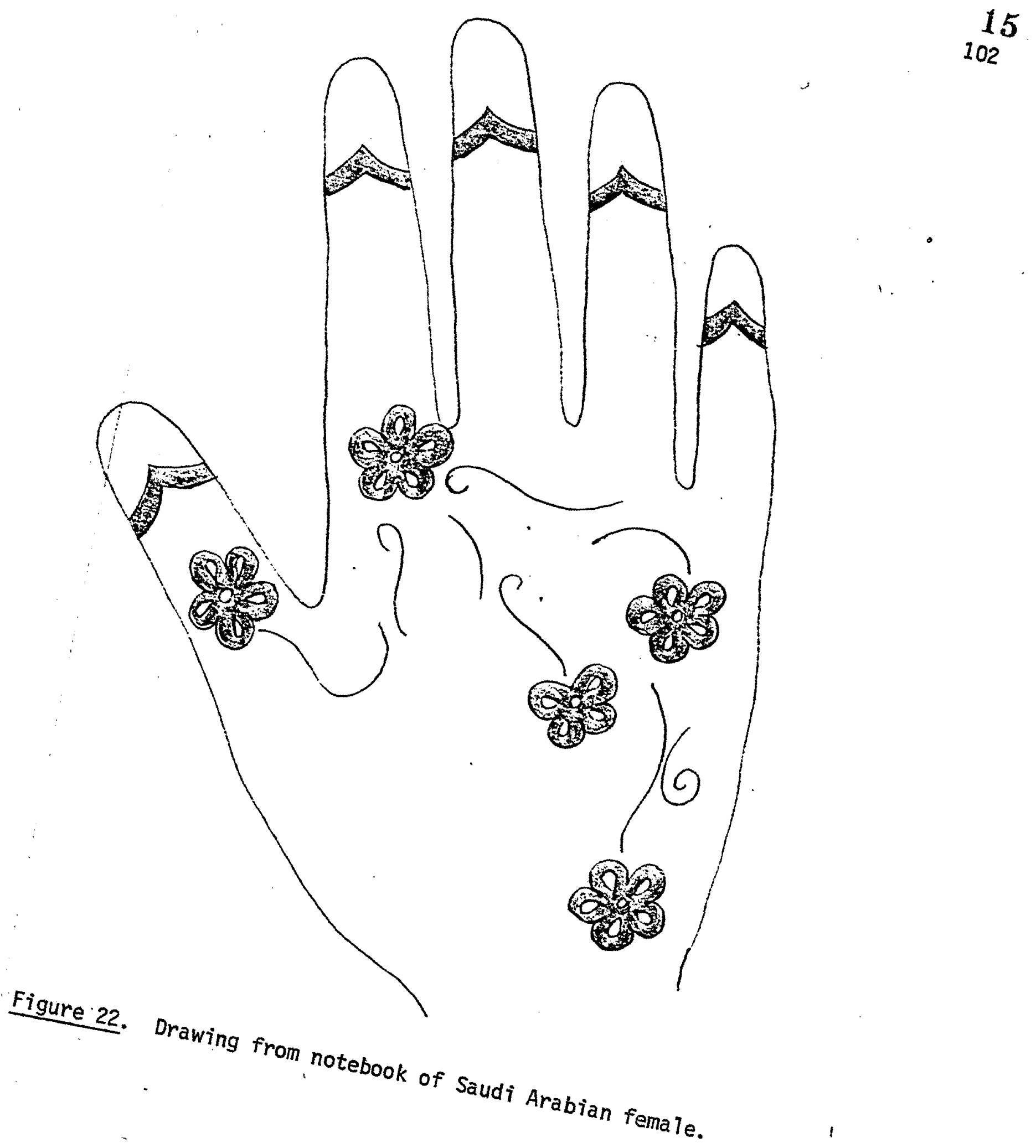

Reproduced with permission of the copyright owner. Further reproduction prohibited without permission. 
10

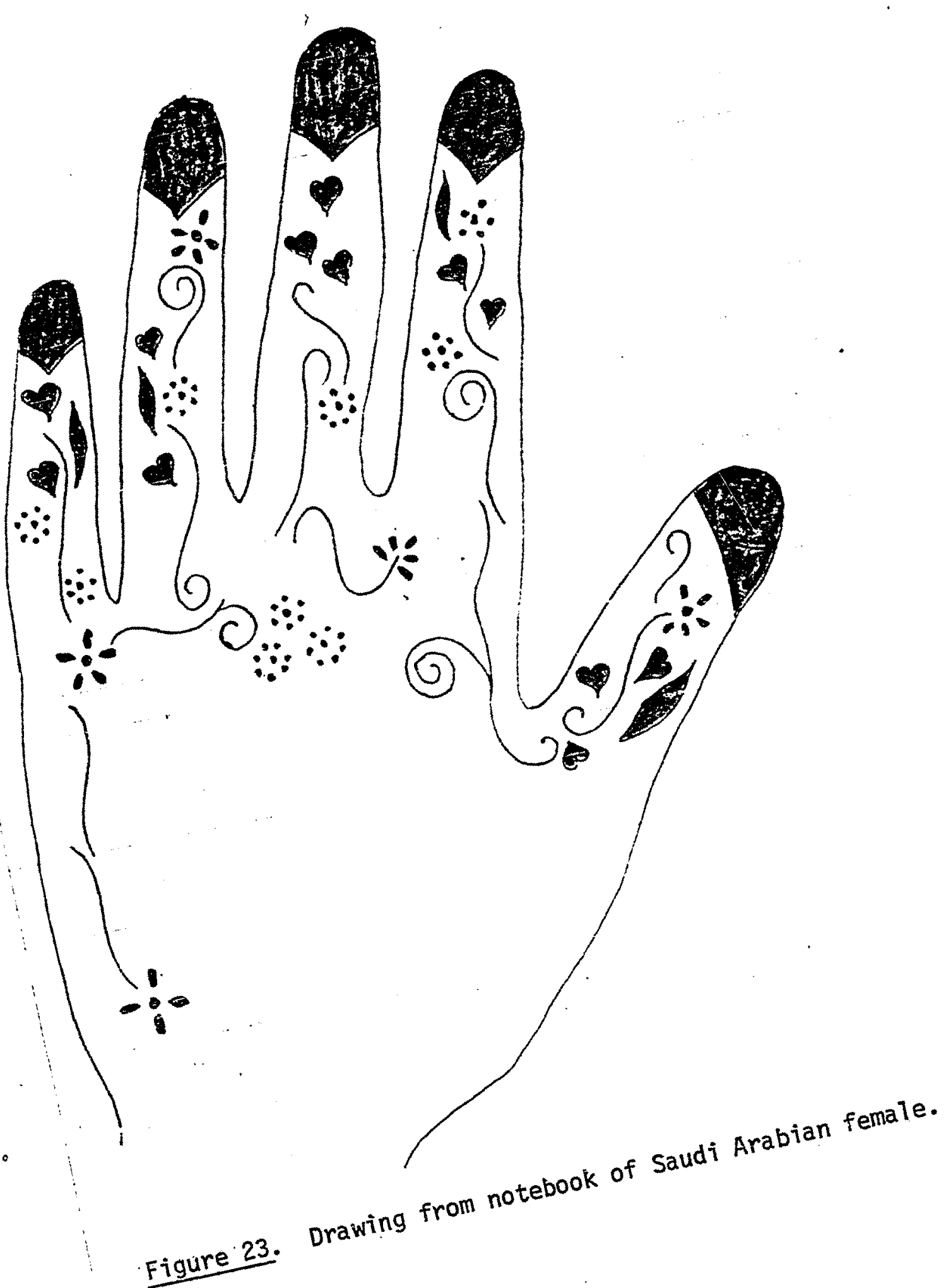




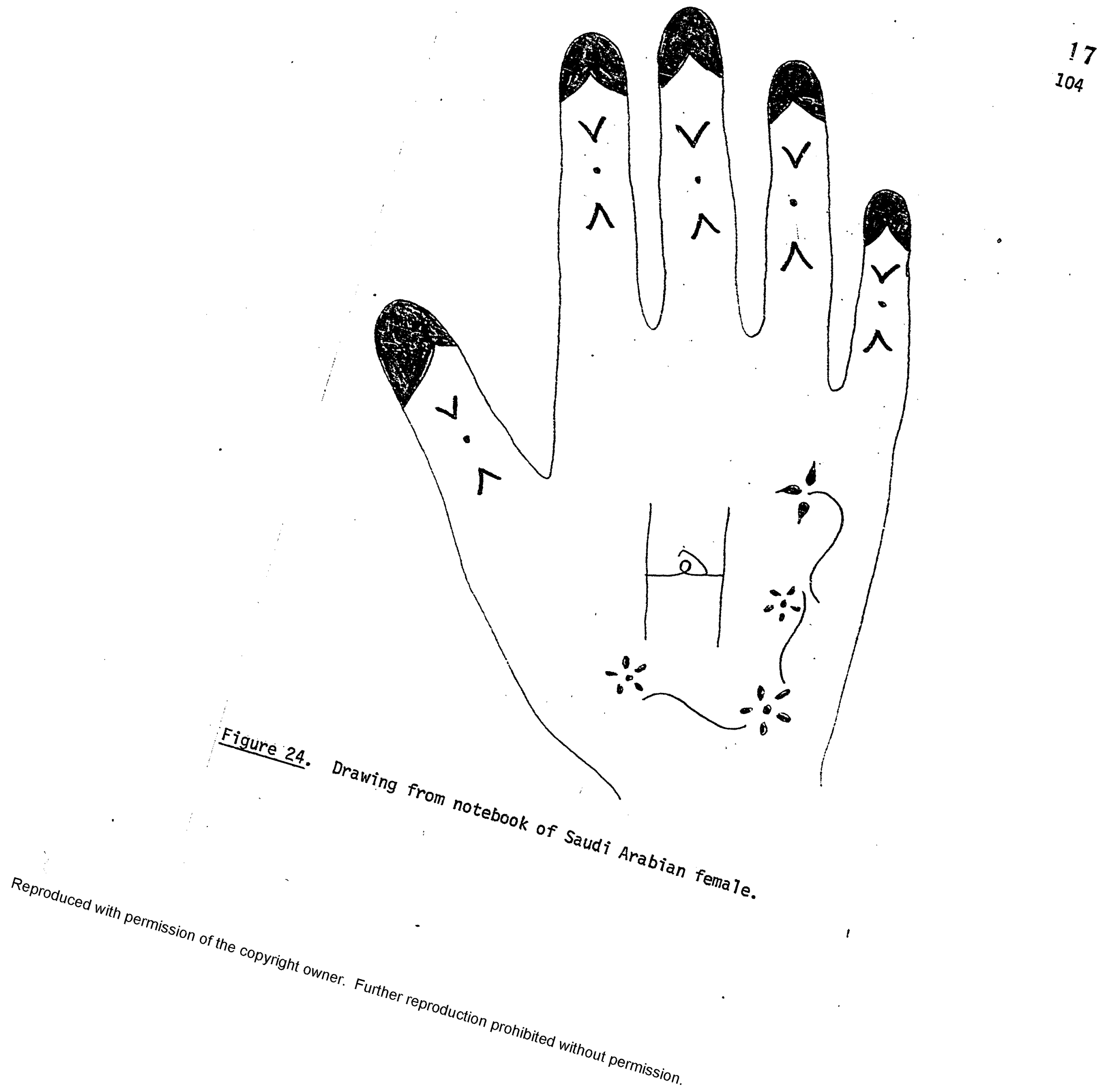


105

is

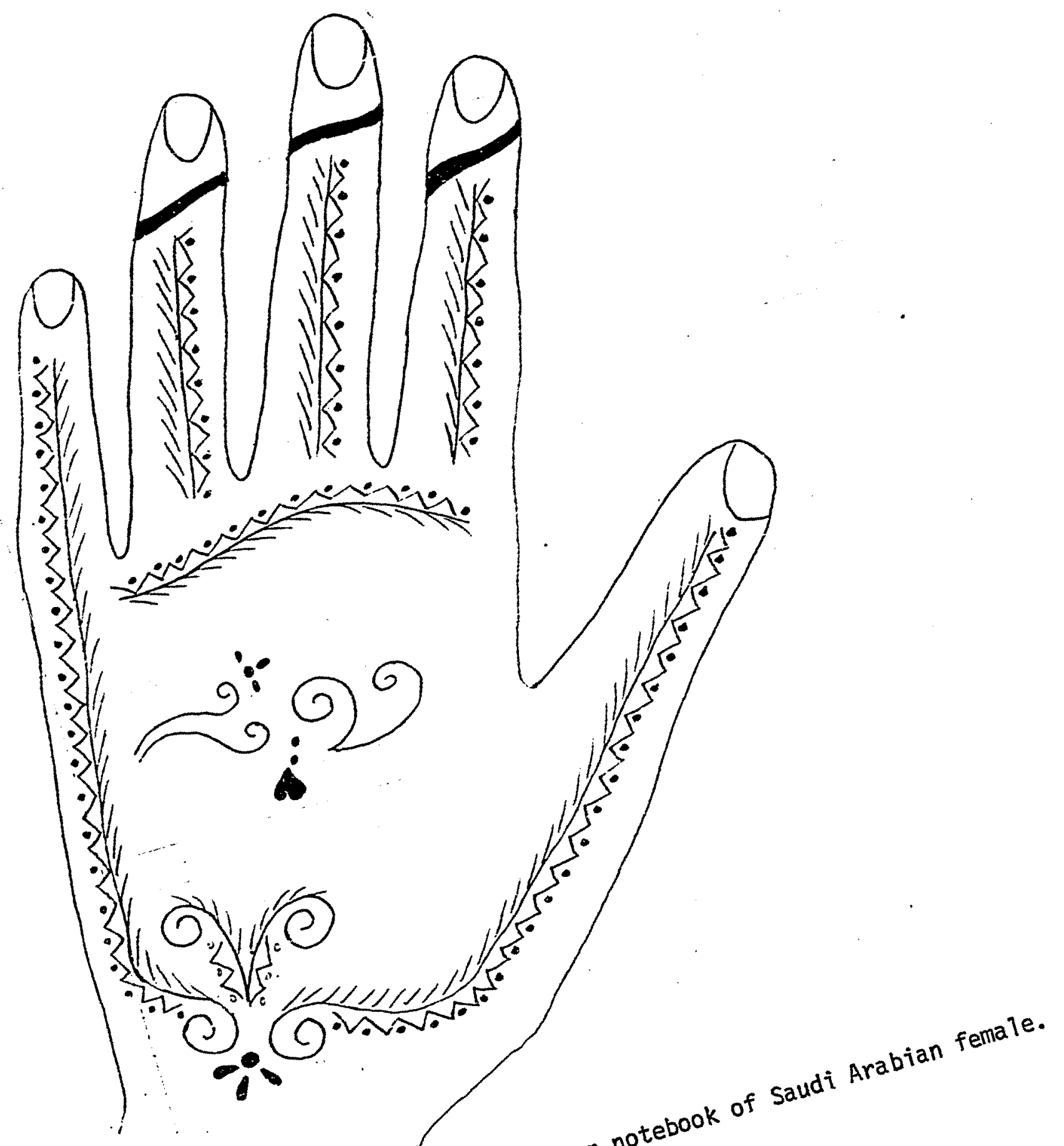

Figure 25 . Dra 


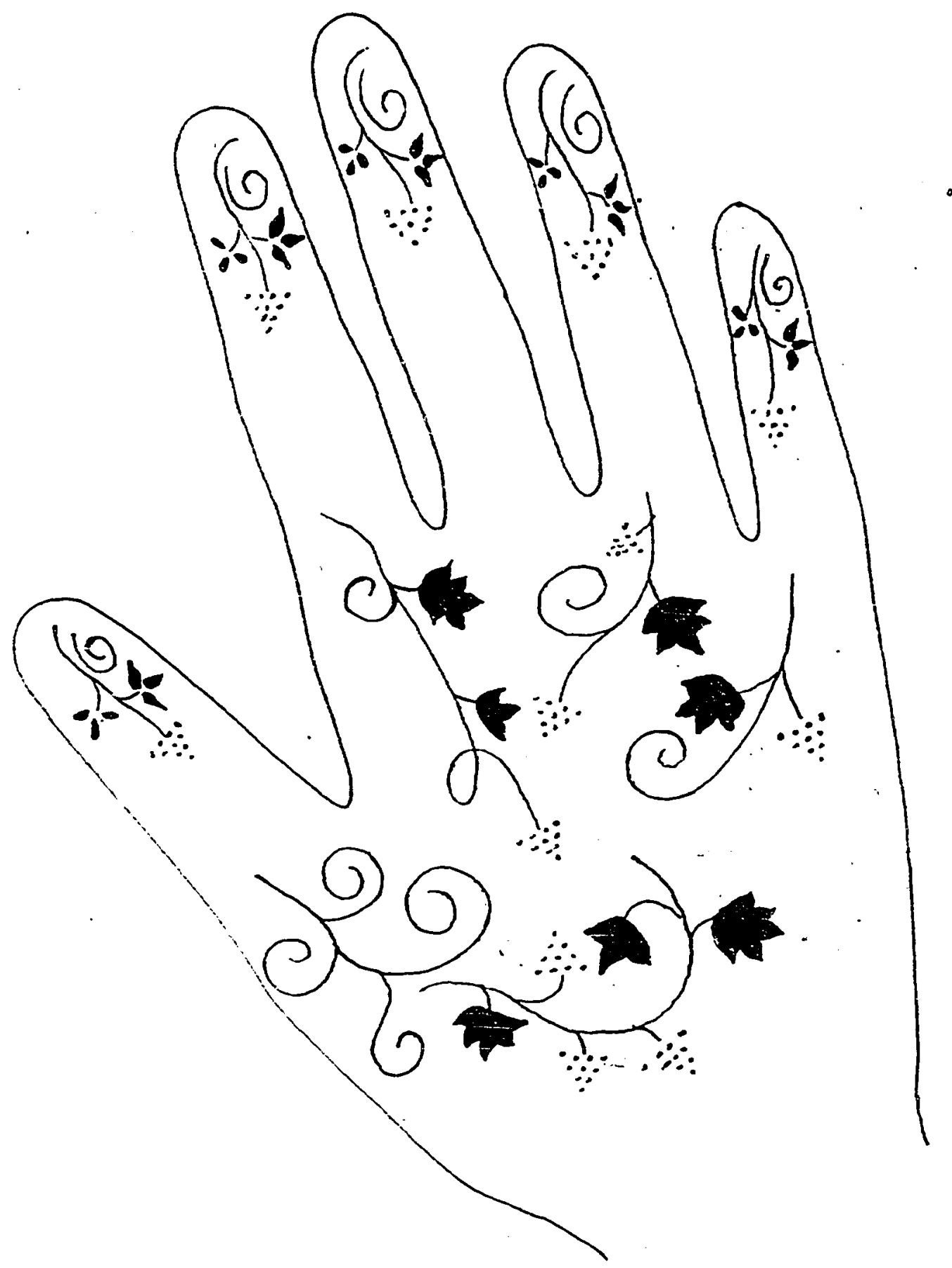

Figure 26, Drawing from notebook of Saudi Arabian female. 



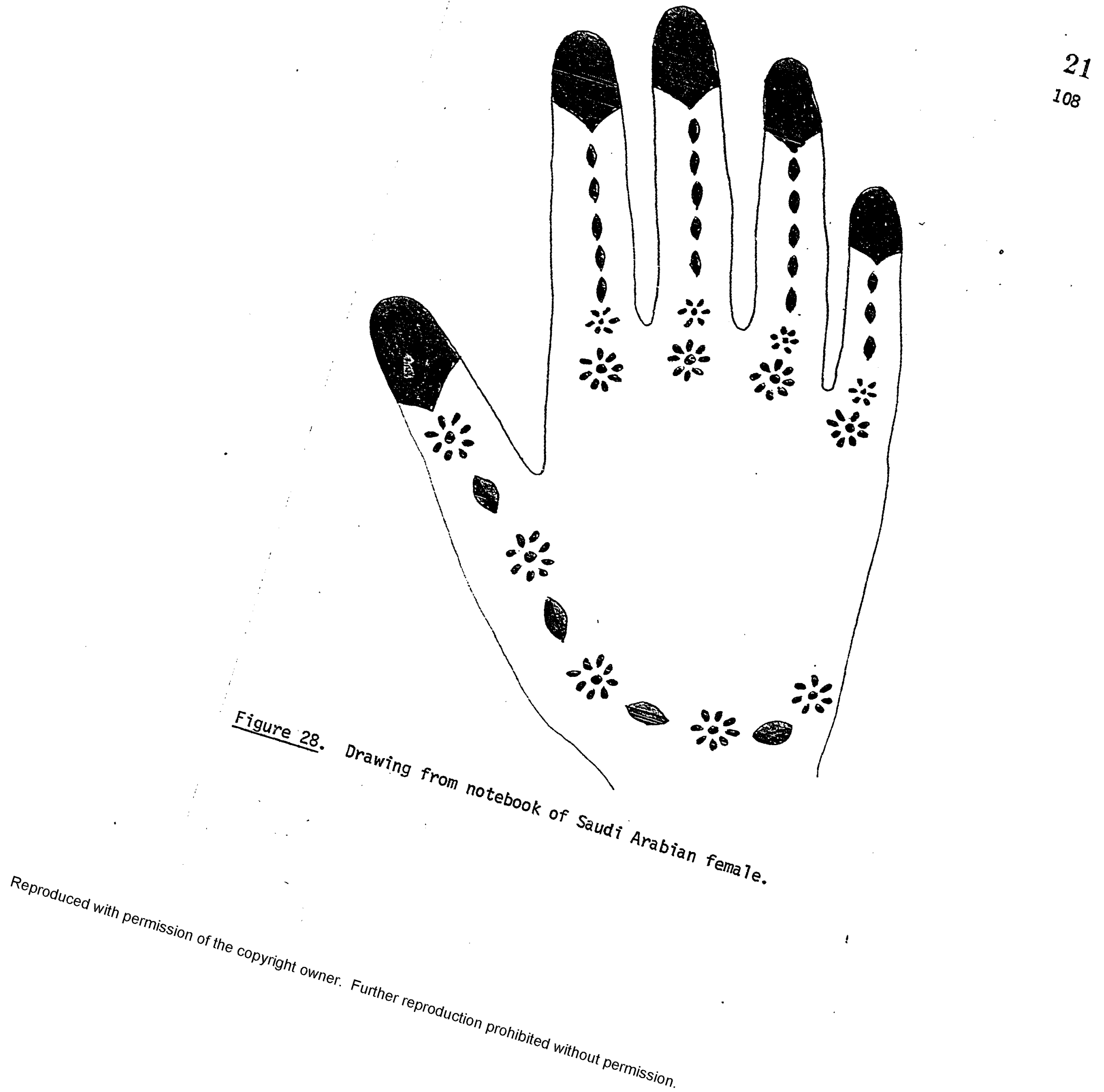





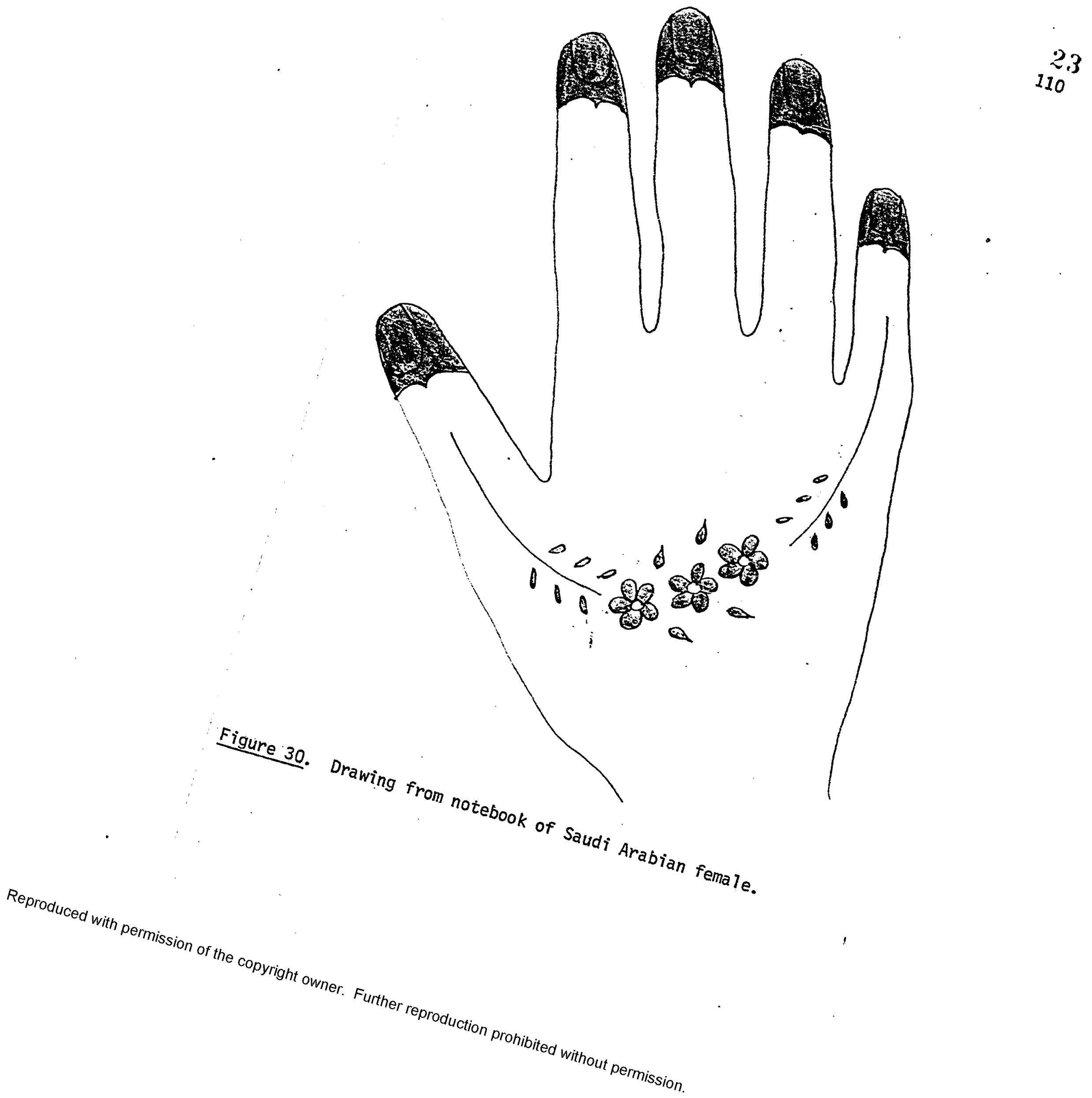


24

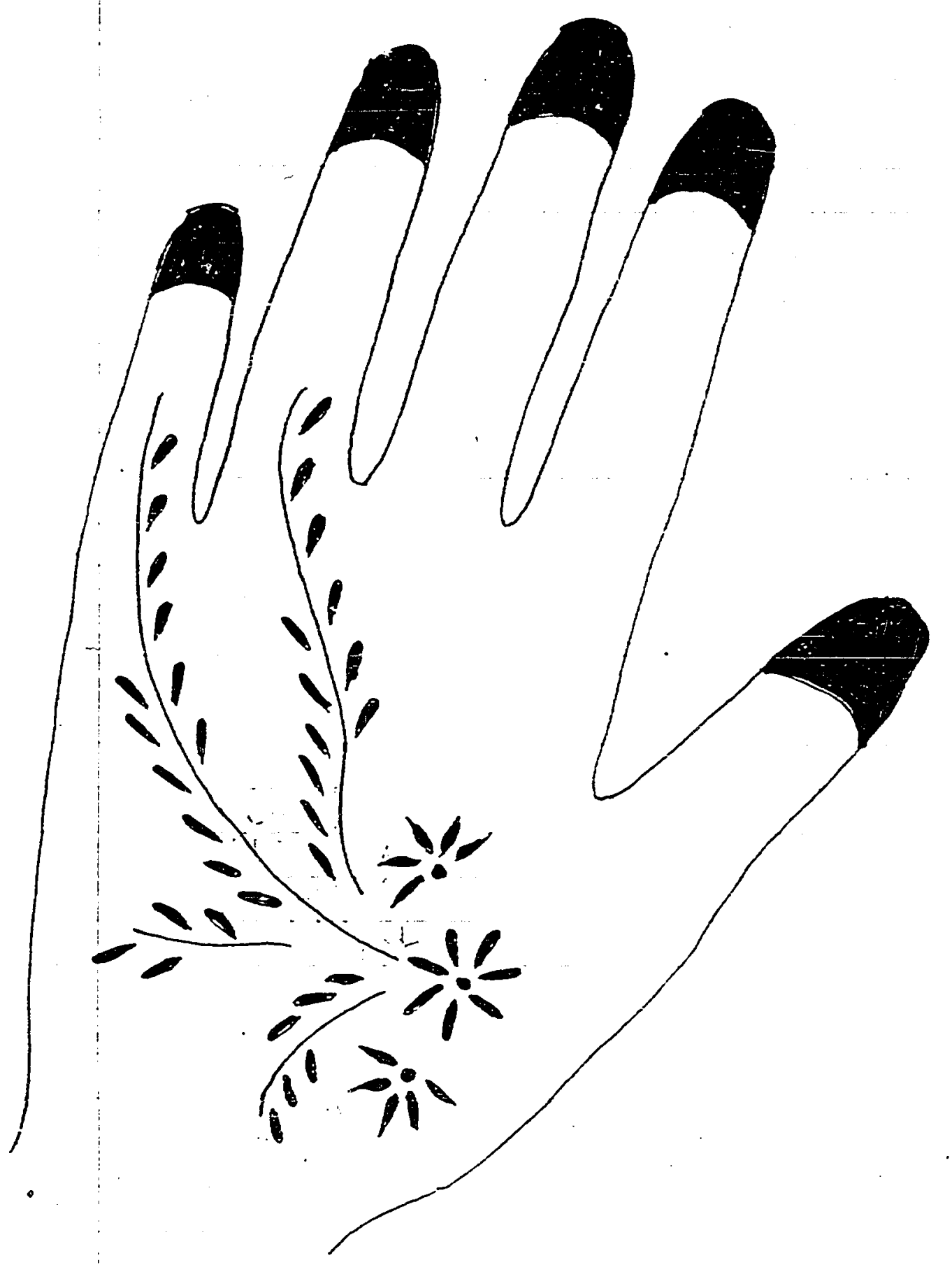

Figure 31. Drawing from notebook of Saudi Arabian female. 

113
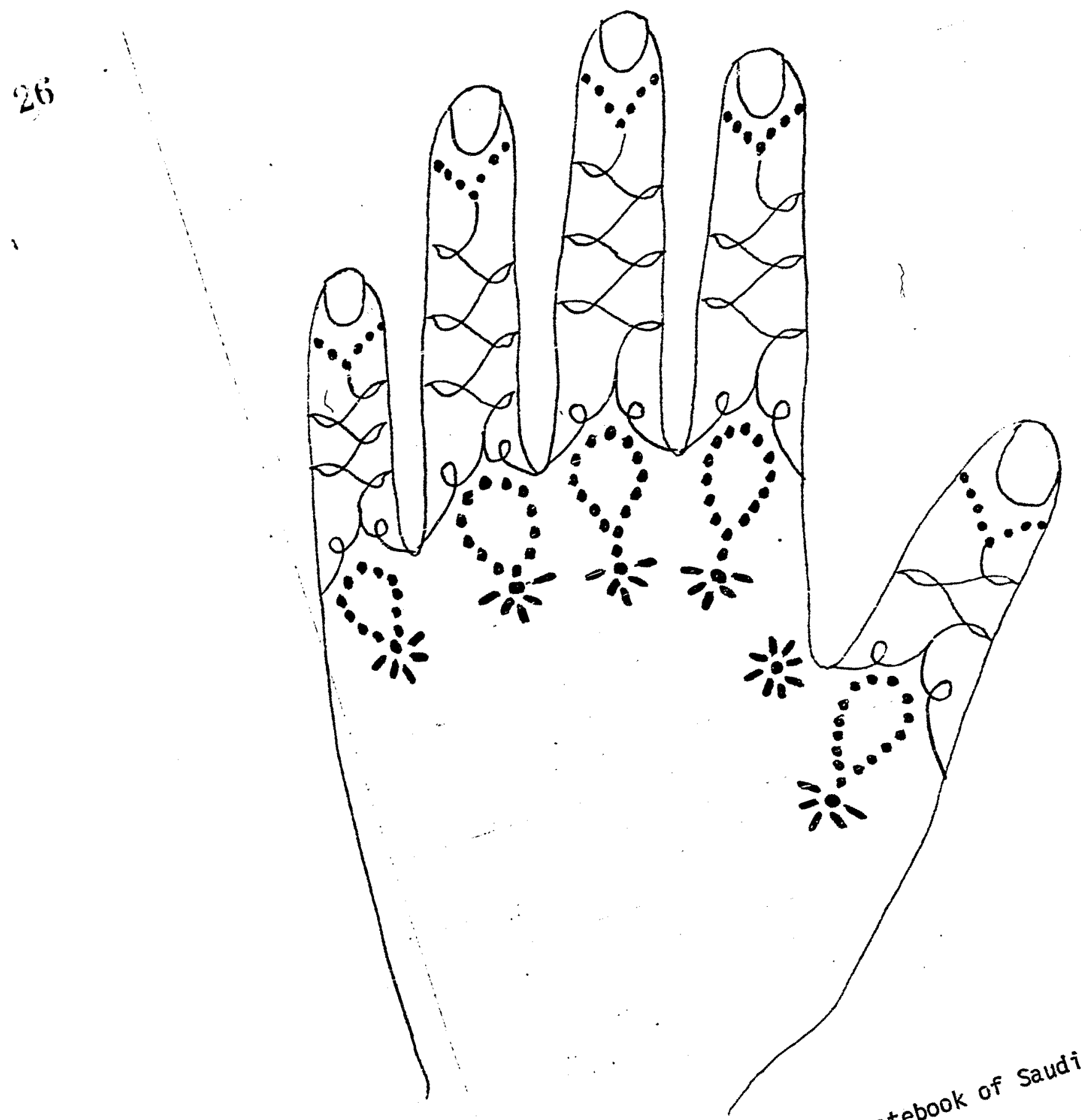

Figure 33.

Reproduced with 


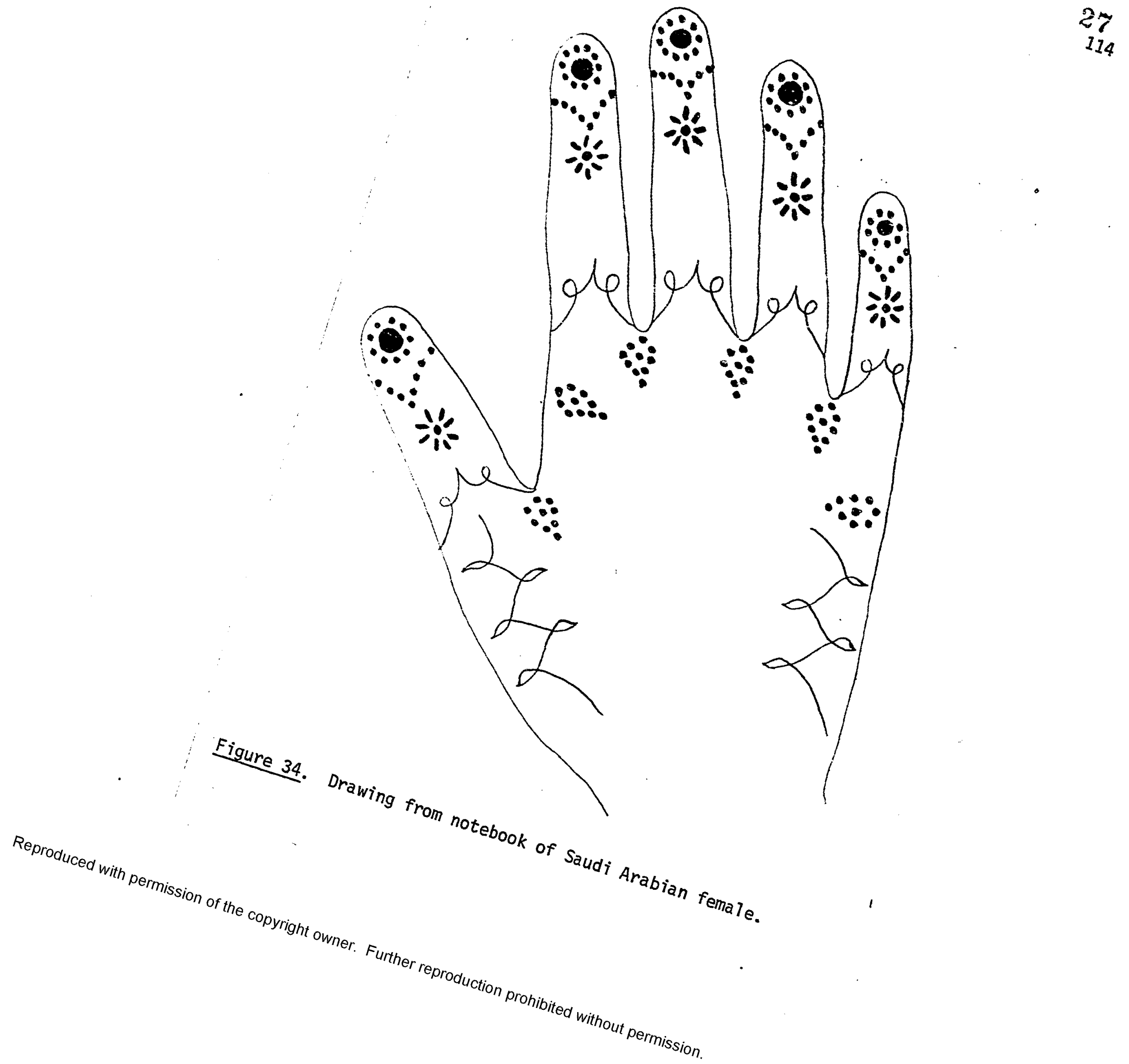




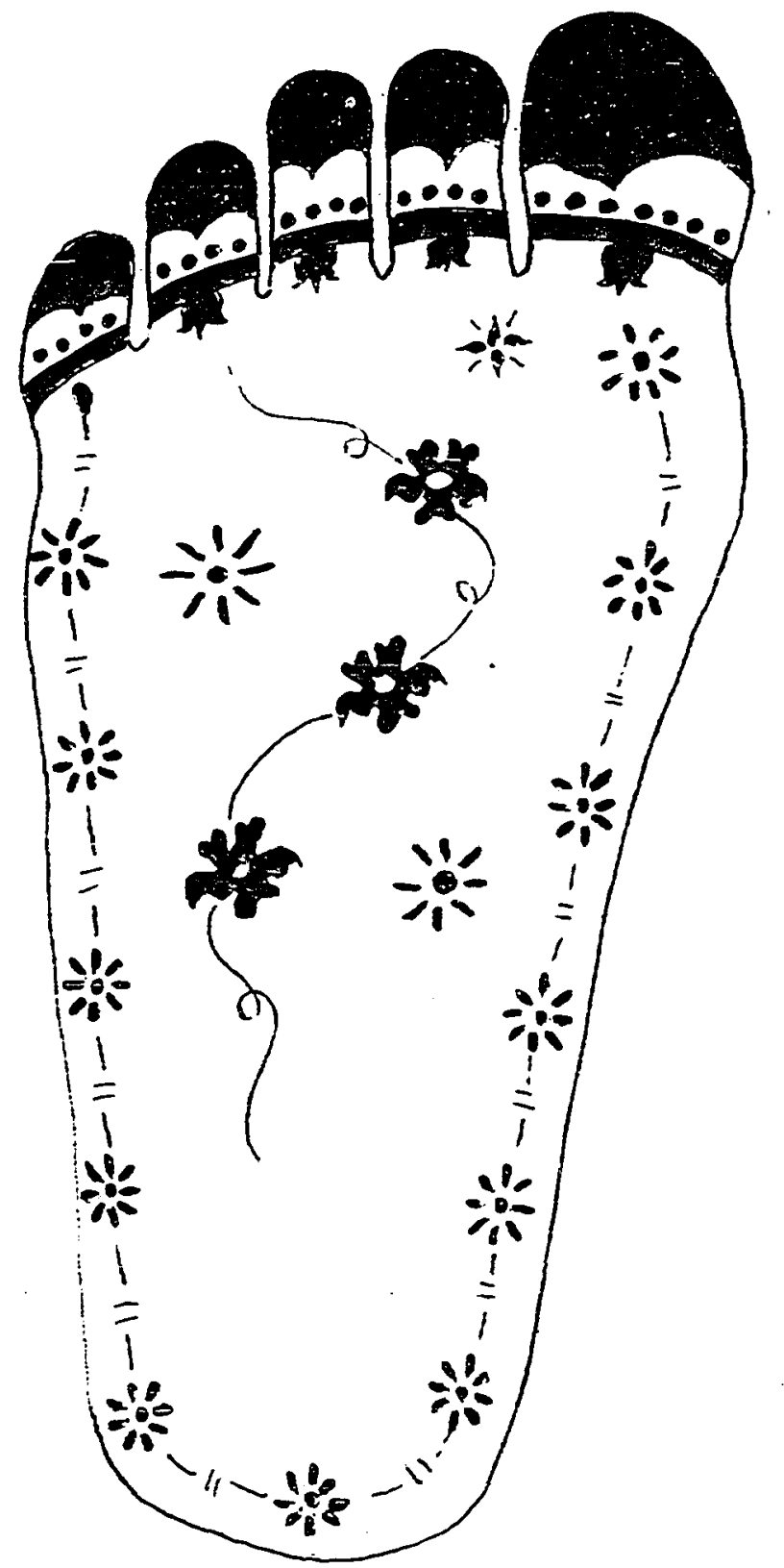

Figure 35. Drawing from notebook of Saudi Arabian female. 


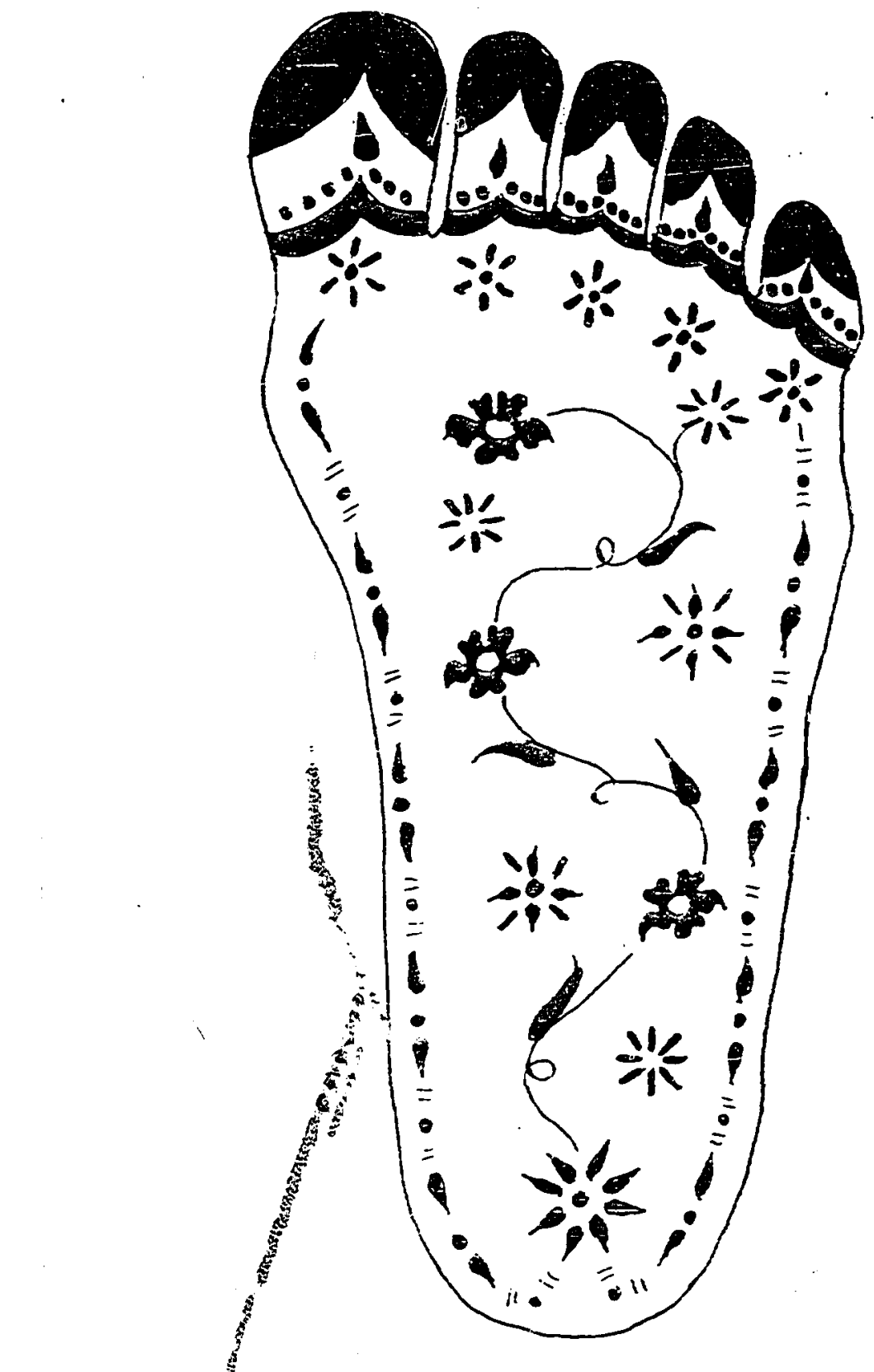

Figure 36. Drawing from notebook of Saudi Arabian female. 


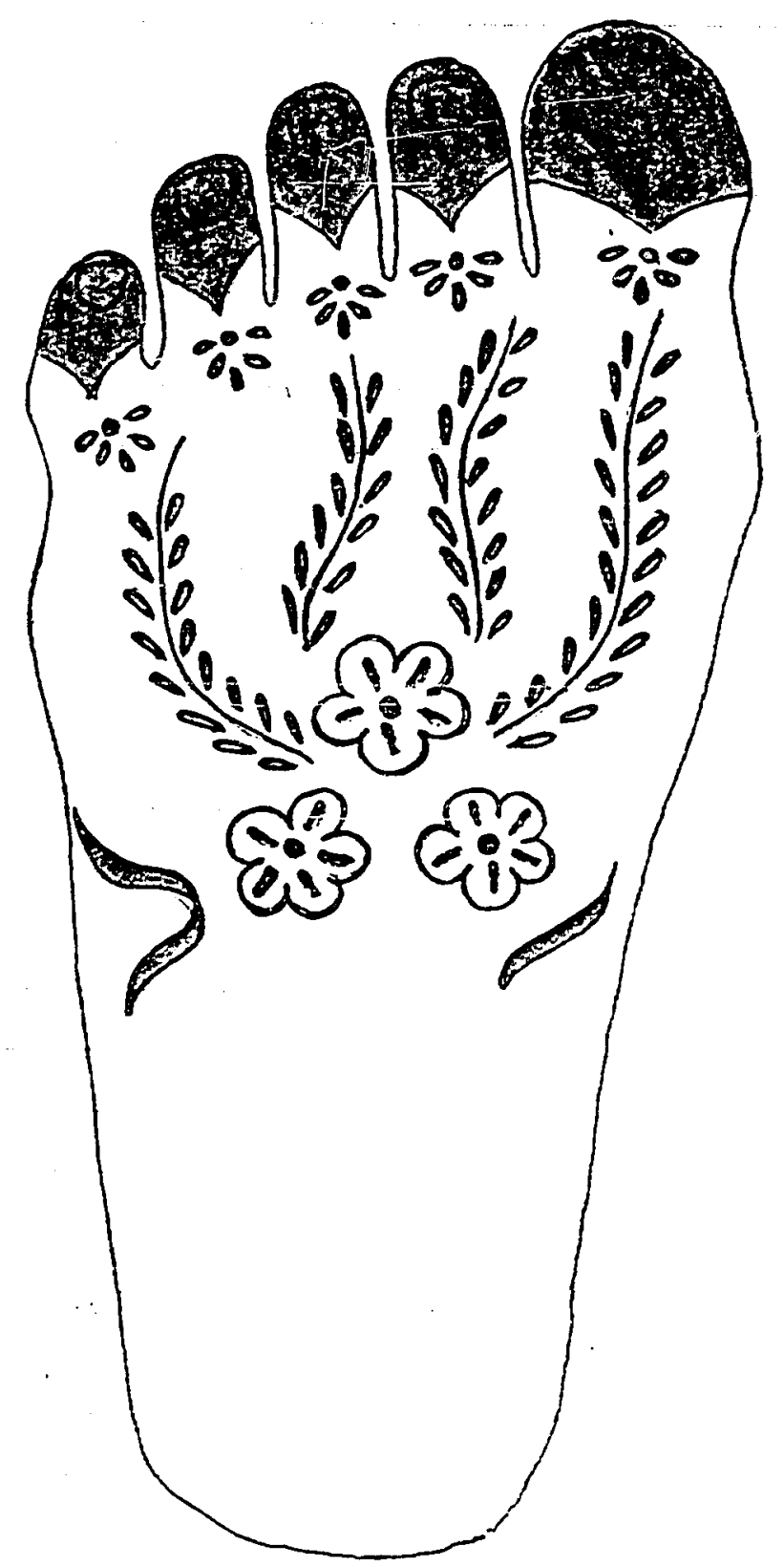

Figure 37. Drawing from notebook of Saudi Arabian female. 


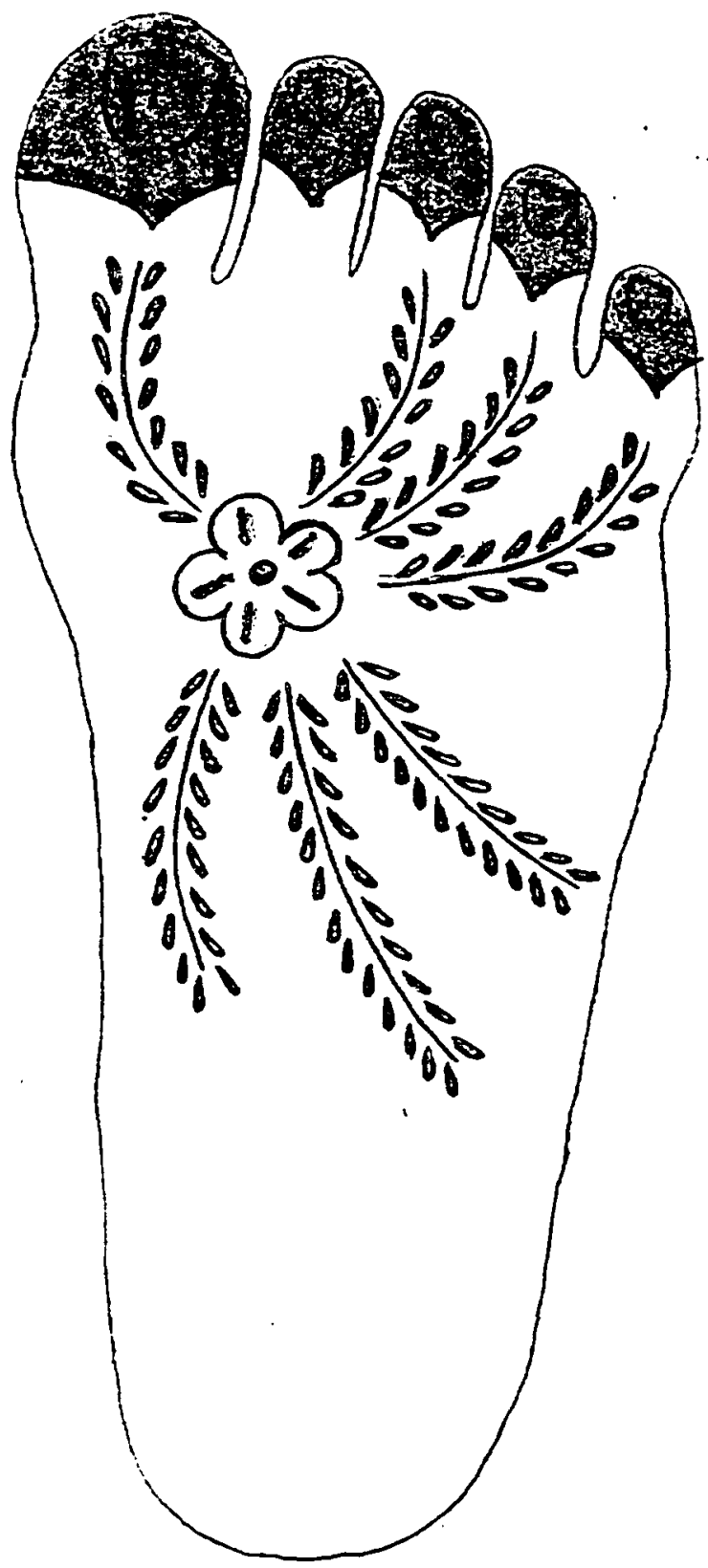

Figure 38. Drawing from notebook of Saudi Arabian female. 


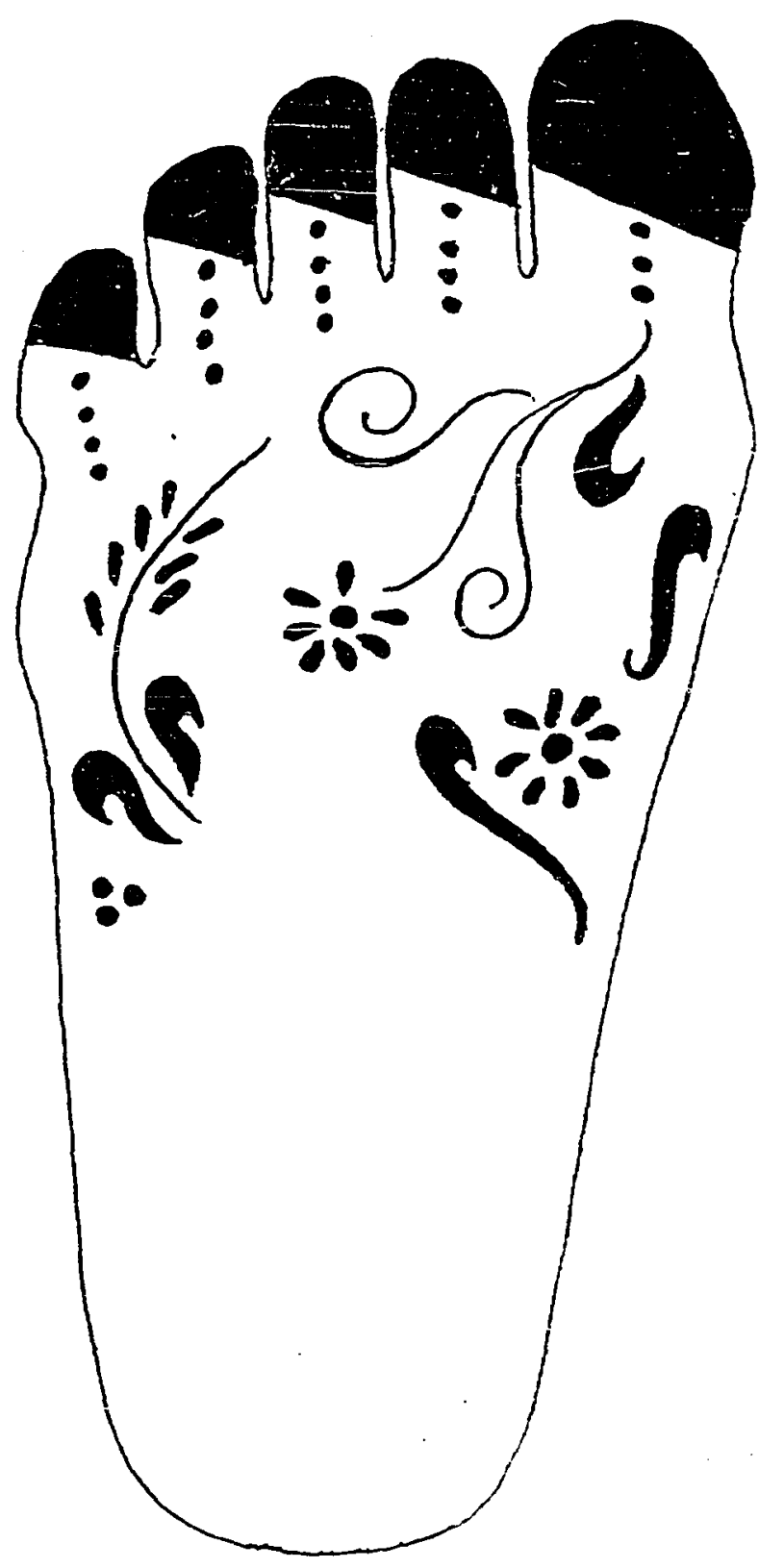

Figure 39. Drawing from notebook of Saudi Arabian female. 


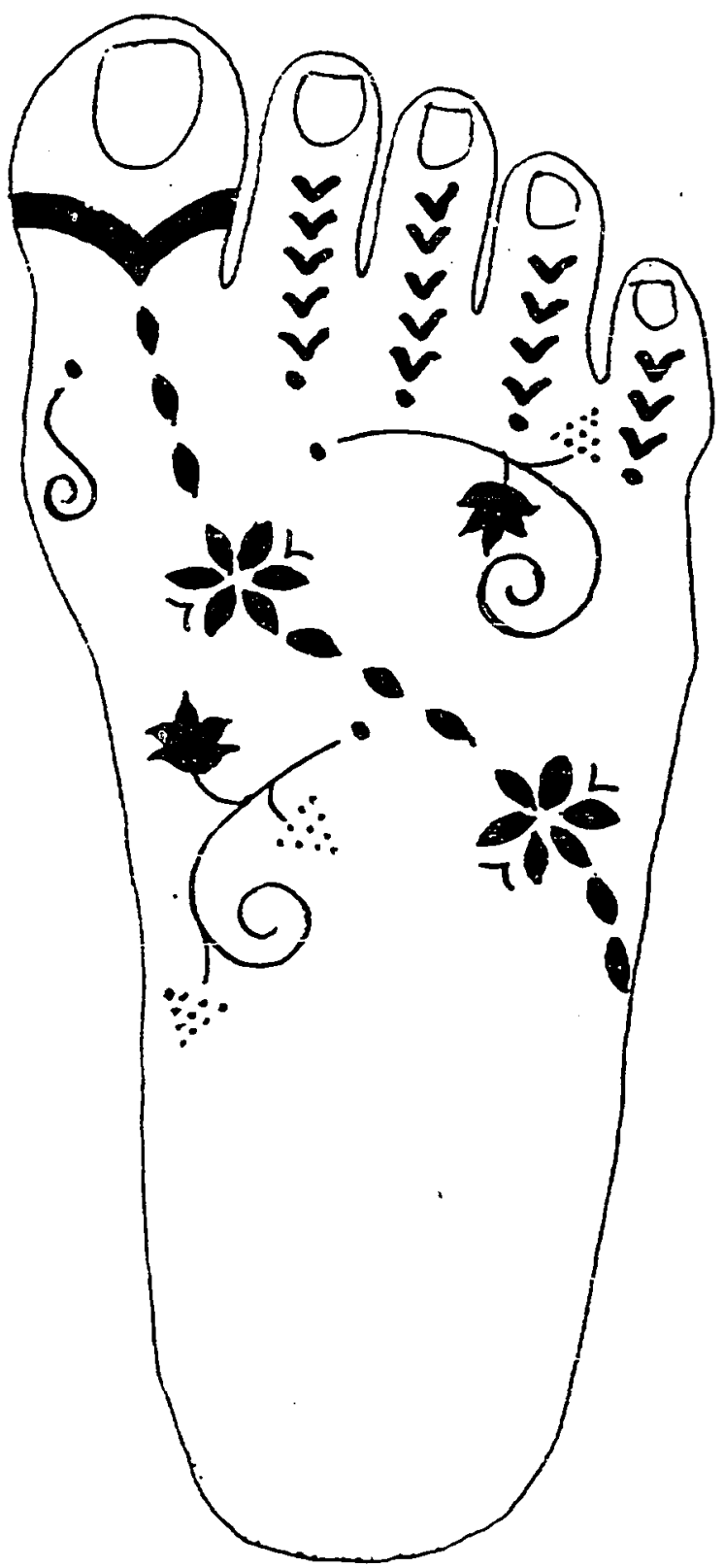

Figure 40. Drawing from notebook of Saudi Arabian female. 


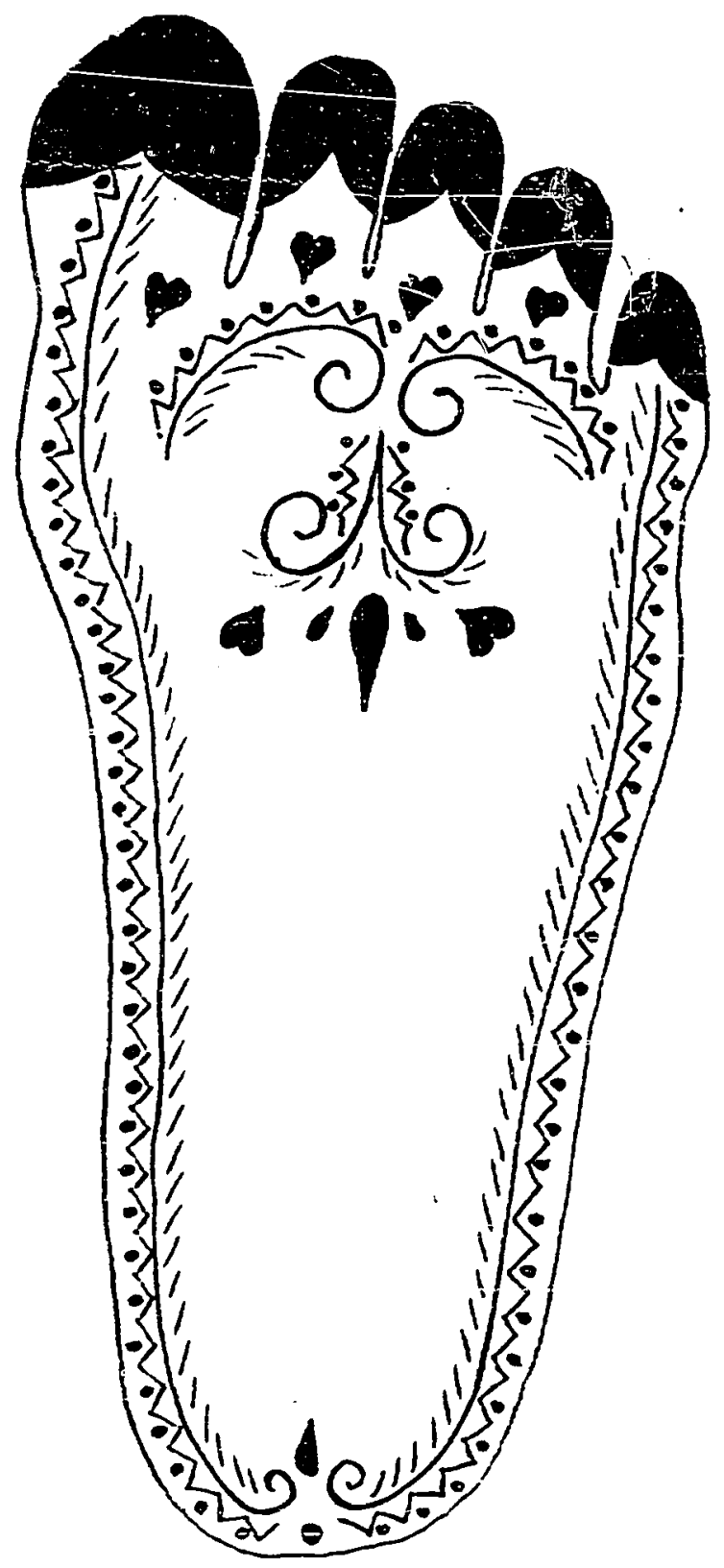

Figure 41. Drawing from notebook of Saudi Arabian femaie. 


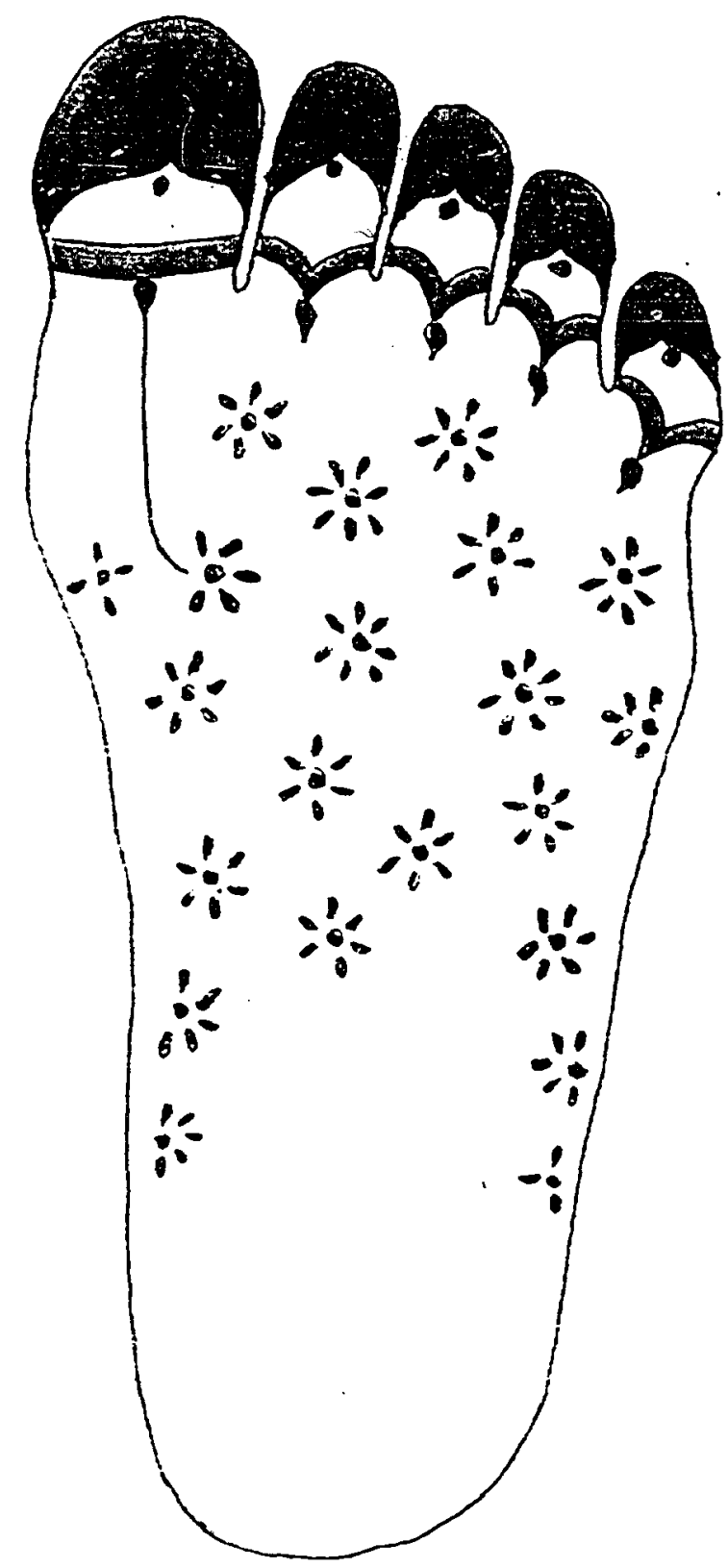

Figure 42. Drawing from notebook of Saudi Arabian female. 


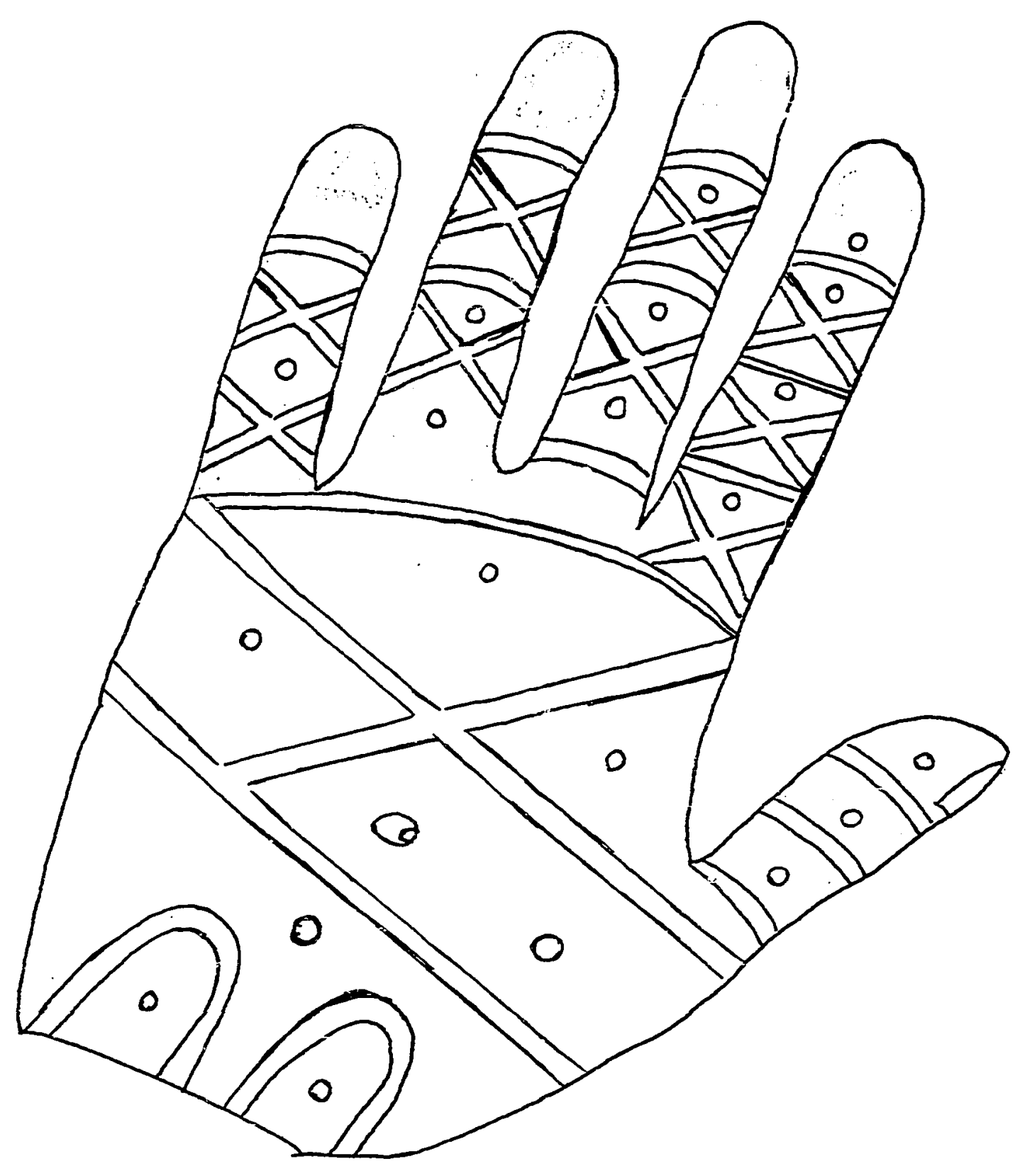

Figure 43. Wedding pattern drawn by Saudi Arabian female. 


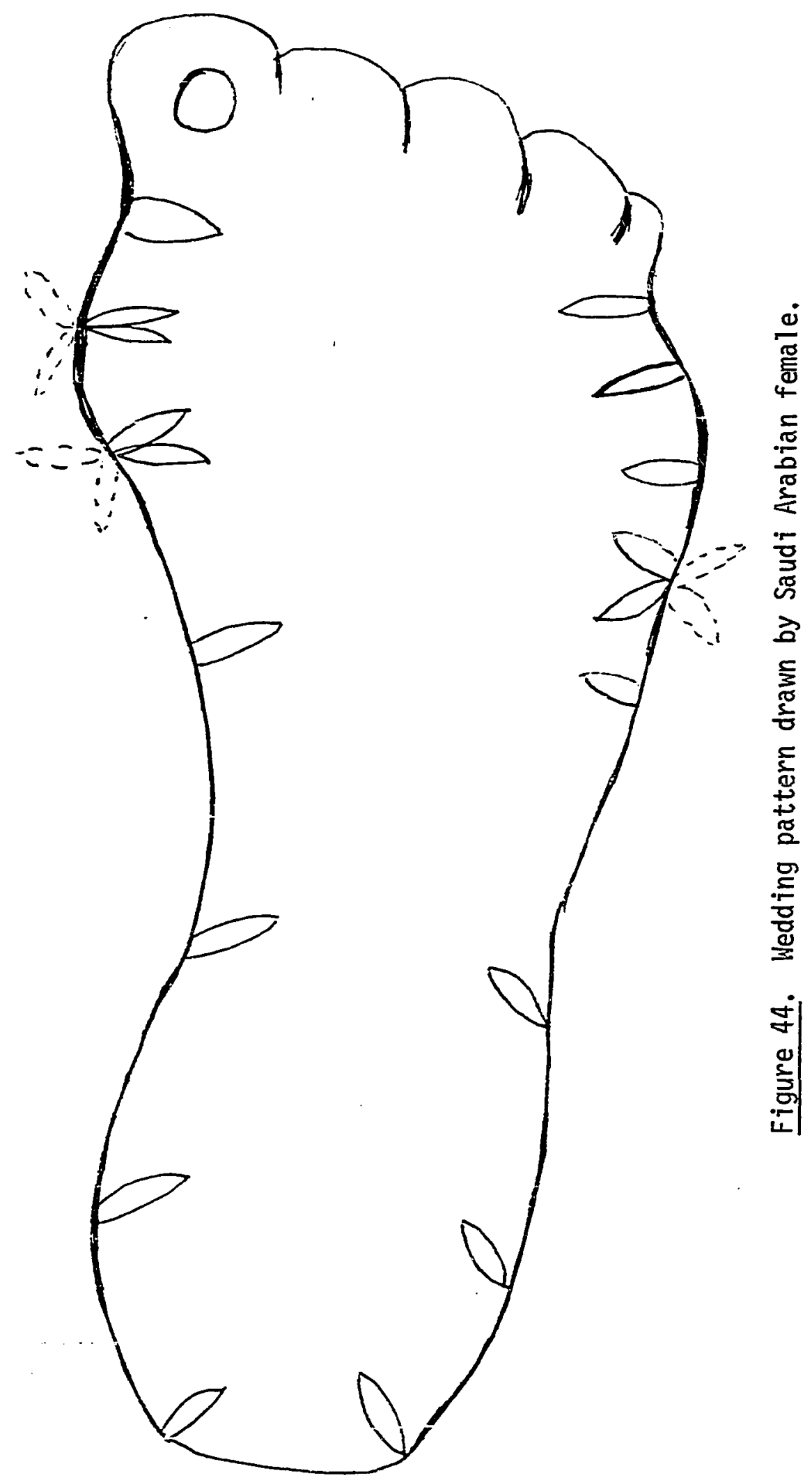




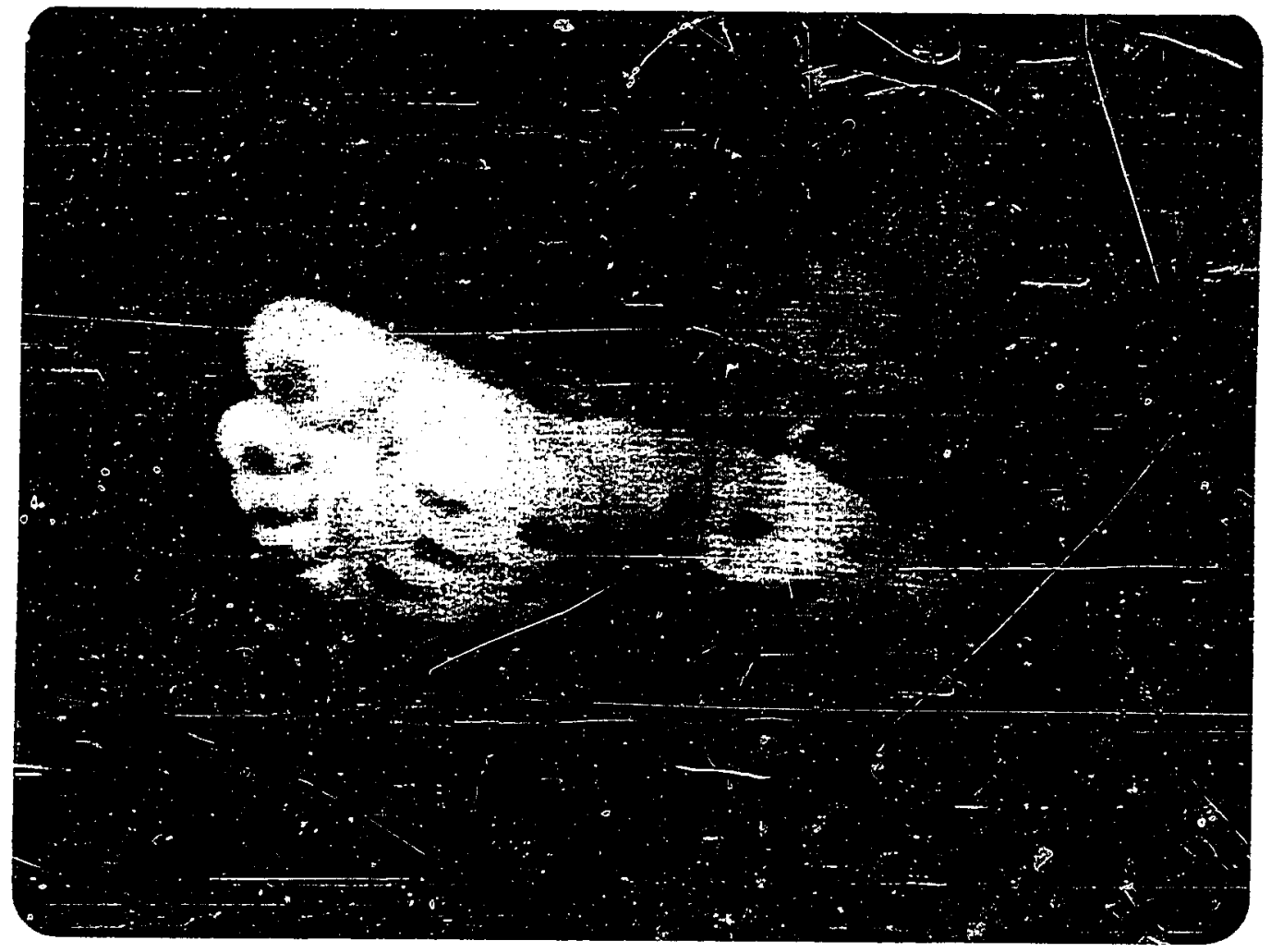

Figure 45. Bahraini folk dancer's foot.
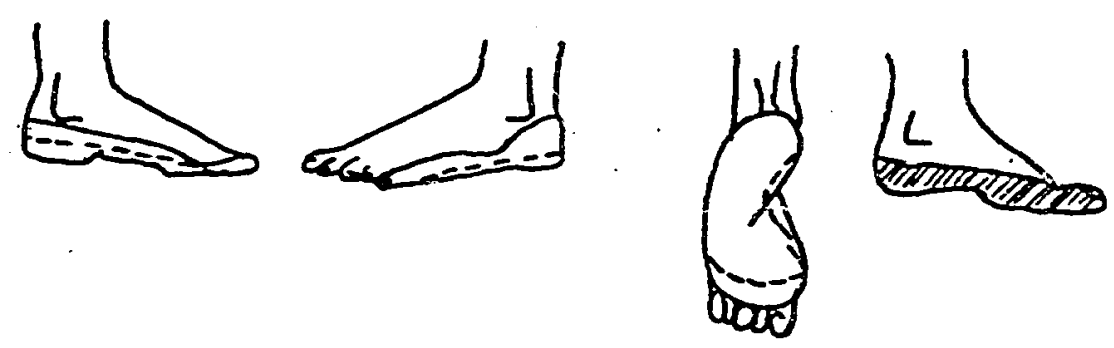

Figure 46. Kuwaiti foot pattern (Dickson 1949:159). 


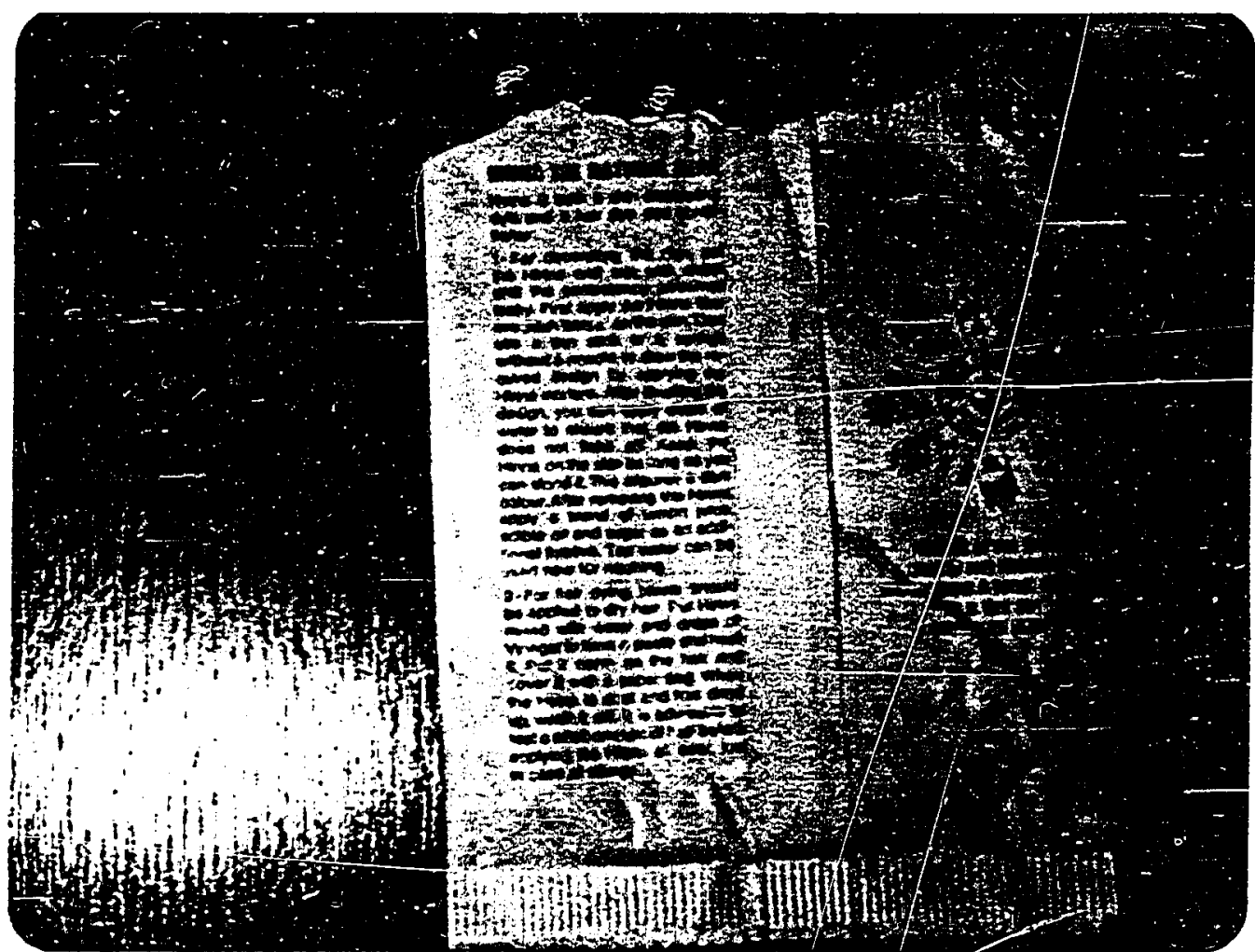

\section{Figure 47. Packaging from Sudan.}

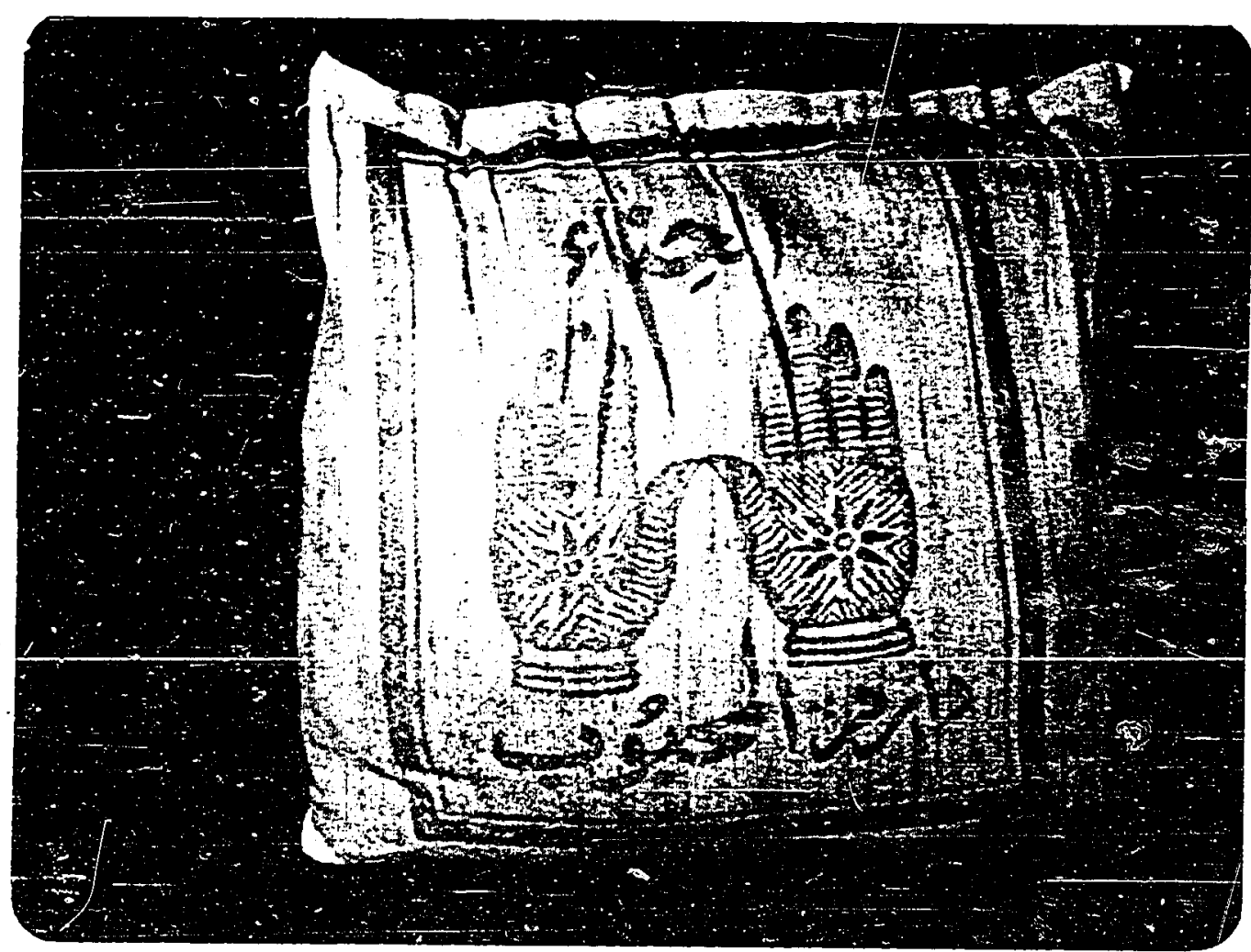

Figure 48. Packaging from Egypt. 


\title{
APPENDIX D
}

\section{LINGUISTIC DATA}

The following is a list of terms for the henna plant:

\author{
Sanskrit mendhika and sakachera \\ Hindi mehndi \\ Farsi hina \\ Greek kinna \\ Turkish kina \\ Arabic henna \\ Hebrew kofer \\ Some efforts to locate the origin of the henna plant have tried \\ using linguistic information. The evidence has been inconclusive.
}

